\title{
How humans economize: energy restriction and end energy expenditure
}

Citation for published version (APA):

Camps, S. G. J. A. (2015). How humans economize: energy restriction and end energy expenditure. [Doctoral Thesis, Maastricht University]. Uitgeverij BOXPress. https://doi.org/10.26481/dis.20150416sc

Document status and date:

Published: 01/01/2015

DOI:

10.26481/dis.20150416sc

Document Version:

Publisher's PDF, also known as Version of record

\section{Please check the document version of this publication:}

- A submitted manuscript is the version of the article upon submission and before peer-review. There can be important differences between the submitted version and the official published version of record. People interested in the research are advised to contact the author for the final version of the publication, or visit the DOI to the publisher's website.

- The final author version and the galley proof are versions of the publication after peer review.

- The final published version features the final layout of the paper including the volume, issue and page numbers.

Link to publication

\footnotetext{
General rights rights.

- You may freely distribute the URL identifying the publication in the public portal. please follow below link for the End User Agreement:

www.umlib.nl/taverne-license

Take down policy

If you believe that this document breaches copyright please contact us at:

repository@maastrichtuniversity.nl

providing details and we will investigate your claim.
}

Copyright and moral rights for the publications made accessible in the public portal are retained by the authors and/or other copyright owners and it is a condition of accessing publications that users recognise and abide by the legal requirements associated with these

- Users may download and print one copy of any publication from the public portal for the purpose of private study or research.

- You may not further distribute the material or use it for any profit-making activity or commercial gain

If the publication is distributed under the terms of Article $25 \mathrm{fa}$ of the Dutch Copyright Act, indicated by the "Taverne" license above, 


\section{How humans economize}

Energy restriction and end energy expenditure 

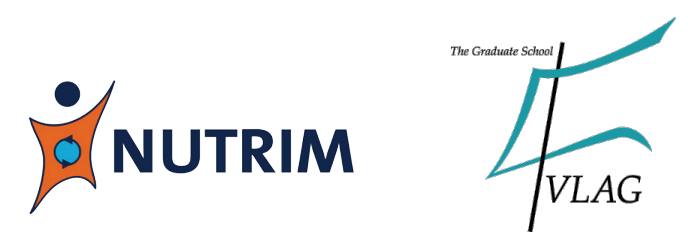

The studies presented in this thesis were performed within NUTRIM School of Nutrition and Translational Research in Metabolism, which participates in the graduate School VLAG (Food Technology, Agrobiotechnology, Nutrition and Health Sciences), accredited by the Royal Netherlands Academy of Arts and Sciences.

(c) Stefan Camps, Maastricht 2015

Cover design: $\quad$ Proefschriftmaken.nl || Uitgeverij BOXpress

Layout: $\quad$ Proefschriftmaken.nl \| Uitgeverij BOXpress

Printed by: $\quad$ Proefschriftmaken.nl || Uitgeverij BOXpress 


\title{
How humans economize
}

\section{Energy restriction and end energy expenditure}

\author{
PROEFSCHRIFT
}

Ter verkrijging van de graad van doctor aan de Universiteit Maastricht, op gezag van de Rector Magnificus, Prof. dr. L.L.G. Soete

volgens het besluit van het college van Decanen, in het openbaar te verdedigen op donderdag 16 april 2015 om 10:00 uur.

door

Stefan Gerardus Joseph Anna Camps geboren te Heerlen op 19 november 1985 


\section{Promotoren}

Prof. dr. K.R. Westerterp

Prof. dr. E.C.M. Mariman

\section{Beoordelingscommissie}

Prof. dr. L.P.A.J. Schrauwen, voorzitter

Dr. A. Bonomi (Philips Research Laboratories, Eindhoven)

Prof. dr. ir. A.H. Kersten (Wageningen University)

Prof. dr. M.S. Westerterp-Plantenga

Prof. dr. M.P.A. Zeegers 


\section{Table of contents}

$\begin{array}{lll}\text { Chapter } 1 & \text { General introduction } & 7\end{array}$

Chapter 2 Weight loss, weight maintenance, and adaptive thermogenesis

Chapter 3 Weight loss-induced reductions in physical activity recover during weight maintenance

Chapter 4 Physical activity and weight loss are independent predictors of improved insulin sensitivity following energy restriction

Chapter 5 Weight loss-induced changes in fatty acid and glucose metabolism relate to adaptations in body composition and energy expenditure

Chapter 6 Leptin and energy restriction induced adaptation in energy expenditure

Chapter 7 Genetic predisposition and energy restriction induced adaptations in resting energy expenditure and physical activity

Chapter 8 General discussion 109

Summary

Samenvatting

Valorization

Dankwoord

List of publications

Curriculum vitae 145 



7
$\frac{5}{ \pm}$
$\frac{0}{0}$
$\frac{0}{U}$

$$
\text { Chapter } 1
$$

General introduction 
The increasing prevalence of obesity and its association with an impaired insulin homeostasis are major health problems in our modern world (1, 2); both are linked to the development of non-communicable diseases as type 2 diabetes and cardiovascular diseases $(3,4)$. Weight gain and obesity occur when energy intake exceeds energy expenditure; this positive energy balance will result in the storage of excessive energy as fat. The prevalence of obesity coincided with technological developments like computers, cars, washing machines and television, contributing to sedentary lifestyles, suggesting a causal link (5, 6). However, analysis of measurements with doubly labeled water, showed that physical activity induced energy expenditure did not decrease between 1983 and 2005 while obesity rates at least doubled over the same period (7). The latter implies that an increased intake is responsible for the energy imbalance resulting in the obesity epidemic. It is supported by the fact that during the same period dietary habits changed, with increased portion sizes, changed meal composition and eating out, plus the fact that palatable, energy-dense foods became readily available in our Western society $(8,9)$. The change of our environment to an obesogenic risk factor cannot fully explain the development of obesity at an individual level, since there are still many individuals who manage to remain lean. In fact, the susceptibility to become obese also depends on behavioral, social, cultural, economic, metabolic, physiological and genetic factors $(10,11)$.

There is a simple remedy to obesity, i.e. losing weight by creating a negative energy balance for a longer period of time. This can be realized by a dietary intervention, increased physical activity, or pharmacological and/or surgical treatment. Although weight loss strategies target the intake as well as the expenditure side of the energy balance, the success of long-term weight loss maintenance is low $(12,13)$. Weight loss and weight loss maintenance is counteracted by physiological adaptations in response to energy restriction, characterized by changes that promote a positive energy balance and cause the susceptibility for weight regain. Hunger feelings are increased and appetite is elevated until the lost weight is regained (14-17). On the other side, a decrease in total energy expenditure is often described. Resting energy expenditure (REE) decreases during and shortly after weight loss, to values below predictions based on weight loss and body composition changes (18-23). The decrease in REE beyond what can be predicted by the loss of fat-free mass (FFM) and fat mass (FM) is defined as adaptive thermogenesis. Additionally, there is a decrease in physical activity and activity induced energy expenditure (AEE) as a result of weight loss (24-28) as well as an increase in movement economy and skeletal muscle work efficiency $(18,29)$. In origin, these adaptations were a meaningful survival mechanism to conserve energy in the face of starvation and dangerously low energy supplies (30, 31), nowadays these adaptations increase the susceptibility for weight regain after intentional weight loss.

Adipose tissue is important for energy storage and release and as such, adipocytes respond quickly to variations in the demand. During energy restriction, the limiting glucose availability is compensated by an increased mitochondrial fatty acid oxidation to preserve blood glucose levels and supply glucose-dependent tissues with sufficient energy, such as 
the brain or red blood cells (32). The first part of this thesis encompasses the quantification of adaptations in energy expenditure during weight loss and weight maintenance. The second part focuses on unraveling underlying pathways of these changes in energy expenditure with an emphasis on adipose tissue.

\section{Quantification of adaptations in energy expenditure}

To quantify adaptations in energy expenditure it is important to know the different components of the average daily metabolic rate (ADMR) and subsequently how these components can be determined.

\section{Components}

Daily energy expenditure or total energy expenditure (TEE) consists of four components: sleeping metabolic rate (SMR), the energy cost of arousal, the energy cost of food processing or diet induced energy expenditure (DEE), and the energy cost of physical activity or activity induced energy expenditure (AEE). Sleeping metabolic rate, the lowest energy expenditure at night, and the energy cost for arousal together are known as resting energy expenditure (REE) or basal metabolic rate (BMR) (33-35).

Resting energy expenditure is the energy required for maintenance, necessary to sustain and maintain the integrity of vital functions and is mainly determined by the amount of lean tissue, which represents the metabolic active mass of the body (36). It is usually the largest component and accounts on average for $60-80 \%$ of ADMR.

Diet induced energy expenditure consists of the energy that is required during the postprandial period for the processing of food, i.e. digestion, intestinal absorption, transportation, utilization as fuel or building material, and storage (37). It is defined as the increase in energy expenditure above REE after a meal. In theory, DEE is different for each nutrient based on the amount of ATP required for the initial steps of metabolism and storage. Reported DEE values for separate nutrients are 0-3\% for fat, 5-10\% for carbohydrate, 20-30\% for protein, and 10-30\% for alcohol (38). Consequently, DEE is dependent on the amount and on the composition of the food ingested. In healthy people, who eat a mixed diet according to what they need, DEE represents about 10\% of ADMR (39).

Activity induced energy expenditure reflects the energy cost associated with physical activity and is the most variable component of ADMR. It is a direct function of the energy required for skeletal muscle contraction during physical activity and is characterized by the intensity, duration and type of physical activity but also the mass of the body moved during the activities. 


\section{Assessment}

Energy expenditure (EE) can be assessed with both direct and indirect calorimetry. Direct calorimetry measures the heat production resulting from substrate oxidation while indirect calorimetry is based on the measurement of gas exchange (oxygen $\left(\mathrm{O}_{2}\right)$ consumption and carbon dioxide $\left(\mathrm{CO}_{2}\right)$ production) for substrate utilization. Additionally, urine nitrogen can be measured to assess the contribution of the individual macronutrients on $E E(36,40,41)$.

Resting energy expenditure is usually measured using the ventilated hood. It requires the subjects to be at rest, while being awake, in the fasted state and under thermoneutral conditions while they lie in a supine position on a bed with a transparent ventilated canopy placed over the head. Additionally, they are instructed to avoid physical activity in the hours preceding the procedure. Subjects are usually measured for 15-30 minutes after at least 15-30 minutes of bed rest and habituation to the testing procedure, i.e. the measurement lasts 3060 minutes (36). Airflow through the hood and the oxygen and carbon dioxide concentrations of the air going in and out are determined and used to calculate REE (41).

Diet induced energy expenditure can also be measured using the ventilated hood. Therefore, EE has to be measured before and for at least 6 hours after a meal; the postprandial increase is DEE (42). Since subjects have to be in a supine position for at least 6 hours, restlessness of the subject becomes a problem.

Sleeping metabolic rate is usually measured using a respiration chamber or wholeroom calorimeter. The respiration chamber can be seen as a large version of a ventilated hood with the subject being completely enclosed instead of the head only. It is a fully equipped room that measures $14 \mathrm{~m}^{3}$ with a bed, washing bowl, toilet, table, chair, computer and other entertainment equipment (40). Due to the larger size, a measurement interval in the respiration chamber is much longer compared to the ventilated hood. Overnight, the sleeping metabolic rate can be measured; it is the lowest average EE over a 3-hour interval, usually from 3.00 to $6.00 \mathrm{~h}$.

Total energy expenditure or average daily metabolic rate, and activity induced energy expenditure are preferably measured in free living daily life conditions. Hence, the optimal method is the doubly labeled water technique, which is considered as the gold standard to measure TEE and AEE (43). Subjects are given a dose of water labeled with the stable isotopes ${ }^{18} \mathrm{O}$ and ${ }^{2} \mathrm{H}$ based on body size. While ${ }^{2} \mathrm{H}$ will be eliminated from the body as ${ }^{2} \mathrm{H}_{2} \mathrm{O},{ }^{18} \mathrm{O}$ will be eliminated $\mathrm{as}_{2}{ }^{18} \mathrm{O}$ and $\mathrm{C}^{18} \mathrm{O}_{2}$. Concentrations of both isotopes can be measured in urine, saliva or blood samples and the difference between both elimination rates is a measure of the $\mathrm{CO}_{2}$-production, from which $\mathrm{O}_{2}$-uptake and energy expenditure can be calculated (44). The method allows measurement of TEE over intervals of 2.5 days in extremely active subjects to 30 days in sedentary elderly, depending on the size of the isotope dose and energy turnover of the subjects (45). Despite the use of high precision Isotope Ratio Mass Spectrometry that allow smaller doses of isotopes, the cost of the doubly labeled water technique remains expensive and thus limits the number of subjects included in a study. Total energy expenditure and activity induced energy expenditure can be measured with 
subjects in a respiration chamber as well, although the limited space should be considered when translating results to TEE and AEE in free living daily life conditions.

\section{Physical activity}

Physical activity is defined as body movement produced by skeletal muscles and resulting in energy expenditure. It is multi-dimensional, characterized by several aspects such as type, intensity, duration and frequency. This complex nature of physical activity makes it difficult to accurately measure all its aspects and to assess the impact on energy expenditure. Measuring techniques available can be grouped into five categories: behavioral observation, self-report (questionnaires and activity diaries), physiological markers (heart rate, body temperature, ventilation), calorimetry and motion sensors. Here physical activity was measured with a combination of calorimetry and motion sensors.

Activity induced energy expenditure can be calculated as [(0.9*TEE)-REE]. Thus, measurement includes the assessment of TEE in daily life with doubly labeled water, in combination with a measurement of REE with a ventilated hood and the assumption of DEE to be $10 \%$ of TEE. There is no consensus yet on how to correct AEE for differences in body size and body composition to compare between individual subjects and over time $(46,47)$. Often, AEE is adjusted for body size by expressing AEE per kg body mass, assuming that energy expenditure associated with physical activity is weight dependent. Physical activity can also be expressed as physical activity level (PAL), which can be calculated as TEE divided by SMR or REE (48). It assumes that the variation in TEE depends on body size and physical activity. The effect of body size on TEE is corrected for by expressing TEE as a multiple of SMR or REE. PAL ranges from 1.2 for a very sedentary subject up to 2.5 for a subject who spends $50 \%$ of its energy on activity. Though, AEE does not provide information on type, intensity, duration, and frequency.

Motion sensors for the measurement of physical activity have evolved from step counter to accelerometer. Over the past decades, quick advances in technology have resulted in the development of wearable and minimally obtrusive accelerometers, more specifically triaxial accelerometers, which can accurately measure body movement expressed in activity counts $(49,50)$. For the measurement of energy expenditure per activity count, body size and composition as well as type of activity should be considered. Hence, the complementary characteristics of motions sensors and calorimetry provide a useful combination for the assessment of physical activity.

\section{Adaptations in energy expenditure}

A negative energy balance as a result of energy restriction leads to weight loss, however in response, changes in energy expenditure decrease the energy gap and increase susceptibility for less weight loss or weight regain. In origin, the metabolic adaptation is a biologically meaningful survival mechanism that conserves energy in the face of starvation and 
dangerously low energy supplies (30,31). Adaptive thermogenesis is described as a decrease in resting energy expenditure beyond what can be predicted by the loss of fat-free mass (FFM) and fat mass (FM). In lean and obese subjects, adaptive thermogenesis was shown during and shortly after weight loss $(18-22,26,51,52)$. In addition, there is evidence that adaptive thermogenesis is sustained, even up to 6 years after severe weight loss $(53,54)$.

Adaptive thermogenesis can be calculated as measured resting energy expenditure (REE) (with a ventilated hood) divided by predicted REE based on body composition. A value above 1 indicates measured REE is higher than what is expected based on body composition, a value lower than 1 indicates measured REE is lower than what is expected based on body composition. Predicted REE is calculated with the equation: REE $(\mathrm{MJ} / \mathrm{d})=$ $0.024 \times$ fat mass $(\mathrm{kg})+0.102 \times$ fat free mass $\times(\mathrm{kg})+0.85$ (55). Since FM and FFM are used it can be used independently for gender. The influence of energy restriction on physical activity is not unambiguously determined (25-28, 56-58).

\section{Unraveling underlying pathways of adaptations in energy expenditure}

In addition to the quantification of the adaptations in energy expenditure it is important to gain insight in the underlying pathways of these changes. As an energy storing and releasing tissue and as an endocrine organ, adipose tissue could play an important role in functionally responding to disturbances in energy balance.

\section{Adipose tissue}

Under normal conditions, the body constantly cycles energy between storage and mobilization with the balance favoring one or the other, depending on the instantaneous energy requirement. On a daily basis, lipogenesis and lipolysis of triacylglycerol/fatty acids are closely matched within adipocytes and the net fatty acid flux across the adipocyte membrane is neutral (59). However, since energy acquisition by the body is intermittent, whereas energy expenditure is continuous, the fatty acid influx and efflux are dissociated in time. After a meal there will be a net influx of fatty acid into the adipocyte and postabsorptive there will be a net efflux of fatty acids out of the adipocyte (60). Over a longer period, adipose tissue also needs to respond to variations in supply and demand of energy. During a positive energy balance, adipocytes will actively take up and store fatty acids and will grow (hypertrophy). During energy restriction, adipocytes will mobilize stored fatty acids and will decrease in size (61). Metabolic disturbances associated with obesity, like insulin resistance, are typically associated with adipocyte hypertrophy (62). Additionally, metabolic processes in adipocytes of obese subjects are dysregulated emphasizing the important role of adipose tissue in obesity. After weight loss adipocytes either normalize to a preobese status or change in favor of weight regain (63-67). Simultaneously, weight loss causes 
adaptations in energy expenditure on a whole body level. Therefore, adipocyte glucose and fatty acid metabolism could be related to changes in energy expenditure during weight loss.

\section{Leptin}

The adipocyte-derived hormone leptin is a critical mediator of energy balance that interacts with specific receptors in the brain (68). The hormone functions as the "satiety" hormone in a negative feedback loop regulating energy intake (69). Serum leptin concentration is highly correlated with BMI and body fat and during weight loss leptin levels drop as fat mass reduces. Leptin levels decrease even much more than fat mass $(70,71)$. It is suggested that this drop of leptin leads to leptin deficiency in the brain, creating a high risk for increased energy intake during weight loss maintenance (72). This also resembles the hypothesis that that the hyperphagic, hypometabolic phenotype of weight-reduced humans is similar to that of leptin-deficient or-unresponsive rodents (73).

Energy restriction and maintenance of reduced body weight is accompanied by declines in circulating leptin concentrations (74). This reduction in leptin is seen with different protocols for weight loss, indicating a consistent effect $(71,75)$. Experiments in mice revealed that part of the physiological response to weight loss can be prevented by leptin injections (76). Subsequent research in humans has indicated that administration of leptin that restores circulating leptin to levels present before weight loss reversed the increased energy intake (77) and decreased resting and activity induced energy expenditure (78) as well as changes in sympathetic nervous system tone, thyroid function and movement economy (72). It is now believed that leptin or similar drug treatment may decrease or diminish the negative physiological consequence of energy restriction and could lead to more successful weight maintenance.

\section{Genetic predisposition}

Individuals respond differently to environmental changes and weight gain risk factors and this inter-individual variation in the susceptibility to develop obesity is partly explained by genetics. Based on family and twin studies the genetic contribution is estimated at 40-70\% $(11,79)$. Since the start of the genome-wide association studies (GWAS) and candidate gene analysis, 56 loci have been identified to be unequivocally associated with obesity-relatedtraits $(80,81)$. However, the separate effects of these loci on obesity-susceptibility are small and explain only a small fraction of the total variation with a poor predictive ability (80-83).

Individual differences in weight loss and weight regain could also be partly explained by genetic predisposition to resist weight loss and/or promoting weight regain (84). Indeed, twin studies indeed have shown a larger variability between pairs compared to within pairs in response to energy restriction (85). This could mean that individual differences in weight loss induced adaptations in energy expenditure may also be explained in part by genetic predisposition (84). Analysis of candidate genes and GWAS identified loci already lead 
to associations of many genetic variants or single nucleotide polymorphisms (SNPS) with obesity, like polymorphisms in the fat mass and obesity associated (FTO) gene (86-91) and the melanocortin 4 receptor (MC4R) gene (92-94). SNPs already associated with obesity could therefore be investigated for a relation to energy restriction induced adaptations in energy expenditure.

\section{Outline of the thesis}

Understanding the adaptations in energy expenditure caused by energy restriction can be beneficial for weight loss and weight maintenance strategies and can lead to pharmacological targets in the battle against obesity. In this thesis, a series of studies on the quantification and possibly underlying pathways of adaptations in energy expenditure is presented.

Chapter $\mathbf{2}$ focuses on adaptive thermogenesis after energy restriction and additionally the question if adaptive thermogenesis is still present after one-year weight maintenance was addressed. Therefore, measured resting energy expenditure was compared to resting energy expenditure based on measured body composition. In chapter $\mathbf{3}$ a similar study is presented, here the change in physical activity after energy restriction was assessed and if it was attenuated after one year of follow up. Physical activity measures were physical activity level, activity induced energy expenditure divided by body weight and activity counts measured by tri-axial accelerometry. Chapter $\mathbf{4}$ describes the role of physical activity on insulin sensitivity during energy restriction and weight maintenance.

The studies presented in Chapters 5, 6 and $\mathbf{7}$ aimed to gain insight in the underlying pathways of the metabolic adaptations as a result of energy restriction. In chapter $\mathbf{5}$, markers for glucose and fatty acid metabolism in adipose tissue were determined for changes induced by weight loss and were assessed for correlations with the metabolic adaptations. Chapter $\mathbf{6}$ describes whether there is a relation between weight loss induced decrease in circulating leptin concentration and adaptive thermogenesis, changes in physical activity and increased movement economy. Chapter $\mathbf{7}$ describes a study in which it was examined if the metabolic adaptations were affected by the individual effects of six genetic variants, which had shown associations with obesity-related traits from different angles like physical activity, fat distribution, regulation of energy expenditure and energy intake were tested.

Finally, the results of the above-described studies are summarized and discussed in

\section{chapter 8.}




\section{References}

1. Catenacci VA, Hill JO, Wyatt HR. The obesity epidemic. Clin Chest Med 2009;30:415-44, vii.

2. Shaw JE, Sicree RA, Zimmet PZ. Global estimates of the prevalence of diabetes for 2010 and 2030. Diabetes Res Clin Pract 2009;87:4-14.

3. Lorenzo C, Wagenknecht LE, D’Agostino RB, Jr., Rewers MJ, Karter AJ, Haffner SM. Insulin resistance, beta-cell dysfunction, and conversion to type 2 diabetes in a multiethnic population: the Insulin Resistance Atherosclerosis Study. Diabetes Care 2010;33:67-72.

4. Smith JD, Borel AL, Nazare JA, Haffner SM, Balkau B, Ross R, Massien C, Almeras N, Despres JP. Visceral adipose tissue indicates the severity of cardiometabolic risk in patients with and without type 2 diabetes: results from the INSPIRE ME IAA study. J Clin Endocrinol Metab 2012;97:1517-25.

5. Ng SW, Popkin BM. Time use and physical activity: a shift away from movement across the globe. Obes Rev 2012;13:659-80.

6. Manson JE, Skerrett PJ, Greenland P, Vanltallie TB. The escalating pandemics of obesity and sedentary lifestyle. A call to action for clinicians. Arch Intern Med 2004;164:249-58.

7. Westerterp KR, Speakman JR. Physical activity energy expenditure has not declined since the 1980s and matches energy expenditures of wild mammals. Int J Obes (Lond) 2008;32:1256-63.

8. Sallis JF, Glanz K. Physical activity and food environments: solutions to the obesity epidemic. Milbank Q 2009;87:123-54.

9. Jeffery RW, Utter J. The changing environment and population obesity in the United States. Obes Res 2003;11 Suppl:12S-22S.

10. Pi-Sunyer FX, Laferrere B, Aronne LJ, Bray GA. Therapeutic controversy: Obesity--a modern-day epidemic. J Clin Endocrinol Metab 1999;84:3-12.

11. Maes HH, Neale MC, Eaves LJ. Genetic and environmental factors in relative body weight and human adiposity. Behav Genet 1997;27:325-51.

12. Kraschnewski JL, Boan J, Esposito J, Sherwood NE, Lehman EB, Kephart DK, Sciamanna CN. Longterm weight loss maintenance in the United States. Int J Obes (Lond) 2010;34:1644-54.

13. Wing RR, Phelan S. Long-term weight loss maintenance. Am J Clin Nutr 2005;82:222S-225S.

14. Anton SD, Han H, York E, Martin CK, Ravussin E, Williamson DA. Effect of calorie restriction on subjective ratings of appetite. J Hum Nutr Diet 2009;22:141-7.

15. Doucet E, Imbeault P, St-Pierre S, Almeras N, Mauriege P, Richard D, Tremblay A. Appetite after weight loss by energy restriction and a low-fat diet-exercise follow-up. Int J Obes Relat Metab Disord 2000;24:906-14.

16. Dulloo AG, Calokatisa R. Adaptation to low calorie intake in obese mice: contribution of a metabolic component to diminished energy expenditures during and after weight loss. Int J Obes 1991;15:716.

17. Levin BE, Dunn-Meynell AA. Defense of body weight against chronic caloric restriction in obesityprone and -resistant rats. Am J Physiol Regul Integr Comp Physiol 2000;278:R231-7.

18. Leibel RL, Rosenbaum M, Hirsch J. Changes in energy expenditure resulting from altered body weight. N Engl J Med 1995;332:621-8.

19. Dulloo AG, Jacquet J. Adaptive reduction in basal metabolic rate in response to food deprivation in humans: a role for feedback signals from fat stores. Am J Clin Nutr 1998;68:599-606.

20. Schwartz A, Doucet E. Relative changes in resting energy expenditure during weight loss: a systematic review. Obes Rev 2010;11:531-47. 
21. Tremblay A, Chaput JP. Adaptive reduction in thermogenesis and resistance to lose fat in obese men. Br J Nutr 2009;102:488-92.

22. Weyer C, Walford RL, Harper IT, Milner M, MacCallum T, Tataranni PA, Ravussin E. Energy metabolism after 2 y of energy restriction: the biosphere 2 experiment. Am J Clin Nutr 2000;72:946-53.

23. Camps SG, Verhoef SP, Westerterp KR. Weight loss, weight maintenance, and adaptive thermogenesis. Am J Clin Nutr 2013;97:990-4.

24. Camps SV, SPM; Westerterp KR. Weight loss induced reduction in physical activity recovers during weight maintenance. Am J Clin Nutr 2013.

25. de Groot LC, van Es AJ, van Raaij JM, Vogt JE, Hautvast JG. Adaptation of energy metabolism of overweight women to alternating and continuous low energy intake. Am J Clin Nutr 1989;50:131423.

26. Martin CK, Heilbronn LK, de Jonge L, DeLany JP, Volaufova J, Anton SD, Redman LM, Smith SR, Ravussin E. Effect of calorie restriction on resting metabolic rate and spontaneous physical activity. Obesity (Silver Spring) 2007;15:2964-73.

27. Redman LM, Heilbronn LK, Martin CK, de Jonge L, Williamson DA, Delany JP, Ravussin E. Metabolic and behavioral compensations in response to caloric restriction: implications for the maintenance of weight loss. PLoS One 2009;4:e4377.

28. Bonomi AG, Soenen S, Goris AH, Westerterp KR. Weight-Loss Induced Changes in Physical Activity and Activity Energy Expenditure in Overweight and Obese Subjects before and after Energy Restriction. PLoS One 2013;8:e59641.

29. Rosenbaum M, Vandenborne K, Goldsmith R, Simoneau JA, Heymsfield S, Joanisse DR, Hirsch J, Murphy E, Matthews D, Segal KR, et al. Effects of experimental weight perturbation on skeletal muscle work efficiency in human subjects. Am J Physiol Regul Integr Comp Physiol 2003;285:R18392.

30. Keys A. The residues of malnutrition and starvation. Science 1950;112:371-3.

31. Taylor HL, Keys A. Adaptation to caloric restriction. Science 1950;112:215-8.

32. Cahill GF, Jr., Herrera MG, Morgan AP, Soeldner JS, Steinke J, Levy PL, Reichard GA, Jr., Kipnis DM. Hormone-fuel interrelationships during fasting. J Clin Invest 1966;45:1751-69.

33. Westerterp KR. Impacts of vigorous and non-vigorous activity on daily energy expenditure. Proc Nutr Soc 2003;62:645-50.

34. van Mil EA, Westerterp KR, Gerver WJ, Curfs LM, Schrander-Stumpel CT, Kester AD, Saris WH. Energy expenditure at rest and during sleep in children with Prader-Willi syndrome is explained by body composition. Am J Clin Nutr 2000;71:752-6.

35. Black AE, Coward WA, Cole TJ, Prentice AM. Human energy expenditure in affluent societies: an analysis of 574 doubly-labelled water measurements. Eur J Clin Nutr 1996;50:72-92.

36. Adriaens MP, Schoffelen PF, Westerterp KR. Intra-individual variation of basal metabolic rate and the influence of daily habitual physical activity before testing. Br J Nutr 2003;90:419-23.

37. Westerterp KR. Diet induced thermogenesis. Nutr Metab (Lond) 2004;1:5.

38. Tappy L. Thermic effect of food and sympathetic nervous system activity in humans. Reprod Nutr Dev 1996;36:391-7.

39. Westerterp KR, Wilson SA, Rolland V. Diet induced thermogenesis measured over $24 \mathrm{~h}$ in a respiration chamber: effect of diet composition. Int J Obes Relat Metab Disord 1999;23:287-92.

40. Schoffelen PF, Westerterp KR, Saris WH, Ten Hoor F. A dual-respiration chamber system with automated calibration. J Appl Physiol 1997;83:2064-72. 
41. Brouwer E. On simple formulae for calculating the heat expenditure and the quantities of carbohydrate and fat oxidized in metabolism of men and animals, from gaseous exchange (Oxygen intake and carbonic acid output) and urine-N. Acta Physiol Pharmacol Neerl 1957;6:795-802.

42. Segal KR, Edano A, Tomas MB. Thermic effect of a meal over 3 and 6 hours in lean and obese men. Metabolism 1990;39:985-92.

43. Schoeller DA, Hnilicka JM. Reliability of the doubly labeled water method for the measurement of total daily energy expenditure in free-living subjects. J Nutr 1996;126:348S-354S.

44. Speakman JR. The history and theory of the doubly labeled water technique. Am J Clin Nutr 1998;68:932S-938S.

45. Westerterp KR, Wouters L, van Marken LichtenbeltWD. The Maastricht protocol for the measurement of body composition and energy expenditure with labeled water. Obes Res 1995;3 Suppl 1:49-57.

46. Schoeller DA, Jefford G. Determinants of the energy costs of light activities: inferences for interpreting doubly labeled water data. Int J Obes Relat Metab Disord 2002;26:97-101.

47. Prentice AM, Goldberg GR, Murgatroyd PR, Cole TJ. Physical activity and obesity: problems in correcting expenditure for body size. Int J Obes Relat Metab Disord 1996;20:688-91.

48. Westerterp KR. Alterations in energy balance with exercise. Am J Clin Nutr 1998;68:970S-974S.

49. Bonomi AG, Plasqui G, Goris AH, Westerterp KR. Estimation of free-living energy expenditure using a novel activity monitor designed to minimize obtrusiveness. Obesity (Silver Spring) 2010;18:184551.

50. Bonomi AG, Plasqui G, Goris AH, Westerterp KR. Improving assessment of daily energy expenditure by identifying types of physical activity with a single accelerometer. J Appl Physiol (1985) 2009;107:655-61.

51. Doucet E, St-Pierre S, Almeras N, Despres JP, Bouchard C, Tremblay A. Evidence for the existence of adaptive thermogenesis during weight loss. Br J Nutr 2001;85:715-23.

52. Johannsen DL, Knuth ND, Huizenga R, Rood JC, Ravussin E, Hall KD. Metabolic Slowing with Massive Weight Loss despite Preservation of Fat-Free Mass. J Clin Endocrinol Metab 2012;97.

53. van Gemert WG, Westerterp KR, Greve JW, Soeters PB. Reduction of sleeping metabolic rate after vertical banded gastroplasty. Int J Obes Relat Metab Disord 1998;22:343-8.

54. Rosenbaum M, Hirsch J, Gallagher DA, Leibel RL. Long-term persistence of adaptive thermogenesis in subjects who have maintained a reduced body weight. Am J Clin Nutr 2008;88:906-12.

55. Westerterp KR, Donkers JH, Fredrix EW, Boekhoudt P. Energy intake, physical activity and body weight: a simulation model. Br J Nutr 1995;73:337-47.

56. Ravussin E, Burnand B, Schutz Y, Jequier E. Energy expenditure before and during energy restriction in obese patients. Am J Clin Nutr 1985;41:753-9.

57. Levine JA, Lanningham-Foster LM, McCrady SK, Krizan AC, Olson LR, Kane PH, Jensen MD, Clark MM. Interindividual variation in posture allocation: possible role in human obesity. Science 2005;307:584-6.

58. Velthuis-te Wierik E, Westerterp K, van den Berg H. Impact of a moderately energy-restricted diet on energy metabolism and body composition in non-obese men. International journal of obesity and related metabolic disorders : journal of the International Association for the Study of Obesity 1995;19:318-324.

59. Smith J, Al-Amri M, Dorairaj P, Sniderman A. The adipocyte life cycle hypothesis. Clin Sci (Lond) 2006;110:1-9. 
60. Frayn KN, Shadid S, Hamlani R, Humphreys SM, Clark ML, Fielding BA, Boland O, Coppack SW. Regulation of fatty acid movement in human adipose tissue in the postabsorptive-to-postprandial transition. Am J Physiol 1994;266:E308-17.

61. Verhoef SP, Camps SG, Bouwman FG, Mariman EC, Westerterp KR. Physiological response of adipocytes to weight loss and maintenance. PLoS One 2013;8:e58011.

62. Farnier C, Krief S, Blache M, Diot-Dupuy F, Mory G, Ferre P, Bazin R. Adipocyte functions are modulated by cell size change: potential involvement of an integrin/ERK signalling pathway. Int J Obes Relat Metab Disord 2003;27:1178-86.

63. Capel F, Viguerie N, Vega N, Dejean S, Arner P, Klimcakova E, Martinez JA, Saris WH, Holst C, Taylor $\mathrm{M}$, et al. Contribution of energy restriction and macronutrient composition to changes in adipose tissue gene expression during dietary weight-loss programs in obese women. J Clin Endocrinol Metab 2008;93:4315-22.

64. Aubin D, Gagnon A, Grunder L, Dent R, Allen M, Sorisky A. Adipogenic and antiapoptotic protein levels in human adipose stromal cells after weight loss. Obes Res 2004;12:1231-4.

65. Bennetzen MF, Wellner N, Ahmed SS, Ahmed SM, Diep TA, Hansen HS, Richelsen B, Pedersen SB. Investigations of the human endocannabinoid system in two subcutaneous adipose tissue depots in lean subjects and in obese subjects before and after weight loss. Int J Obes (Lond) 2005;35:137784.

66. Langin D, Dicker A, Tavernier G, Hoffstedt J, Mairal A, Ryden M, Arner E, Sicard A, Jenkins CM, Viguerie N, et al. Adipocyte lipases and defect of lipolysis in human obesity. Diabetes 2005;54:31907.

67. Walewski JL, Ge F, Gagner M, Inabnet WB, Pomp A, Branch AD, Berk PD. Adipocyte accumulation of long-chain fatty acids in obesity is multifactorial, resulting from increased fatty acid uptake and decreased activity of genes involved in fat utilization. Obes Surg 2010;20:93-107.

68. Wisse BE. The inflammatory syndrome: the role of adipose tissue cytokines in metabolic disorders linked to obesity. J Am Soc Nephrol 2004;15:2792-800.

69. Friedman JM. The function of leptin in nutrition, weight, and physiology. Nutr Rev 2002;60:S1-14; discussion S68-84, 85-7.

70. Bouwman FG, Claessens M, van Baak MA, Noben JP, Wang P, Saris WH, Mariman EC. The physiologic effects of caloric restriction are reflected in the in vivo adipocyte-enriched proteome of overweight/ obese subjects. J Proteome Res 2009;8:5532-40.

71. Sumithran P, Prendergast LA, Delbridge E, Purcell K, Shulkes A, Kriketos A, Proietto J. Long-term persistence of hormonal adaptations to weight loss. N Engl J Med 2011;365:1597-604.

72. Rosenbaum M, Goldsmith R, Bloomfield D, Magnano A, Weimer L, Heymsfield S, Gallagher D, Mayer L, Murphy E, Leibel RL. Low-dose leptin reverses skeletal muscle, autonomic, and neuroendocrine adaptations to maintenance of reduced weight. J Clin Invest 2005;115:3579-86.

73. Leibel RL. The role of leptin in the control of body weight. Nutr Rev 2002;60:S15-9; discussion S6884, 85-7.

74. Rosenbaum M, Nicolson M, Hirsch J, Murphy E, Chu F, Leibel RL. Effects of weight change on plasma leptin concentrations and energy expenditure. J Clin Endocrinol Metab 1997;82:3647-54.

75. Ozcelik O, Dogan H, Celik H, Ayar A, Serhatlioglu S, Kelestimur H. Effects of different weight loss protocols on serum leptin levels in obese females. Physiol Res 2005;54:271-7.

76. Ahima RS, Prabakaran D, Mantzoros C, Qu D, Lowell B, Maratos-Flier E, Flier JS. Role of leptin in the neuroendocrine response to fasting. Nature 1996;382:250-2. 
77. Rosenbaum M, Sy M, Pavlovich K, Leibel RL, Hirsch J. Leptin reverses weight loss-induced changes in regional neural activity responses to visual food stimuli. J Clin Invest 2008;118:2583-91.

78. Rosenbaum M, Murphy EM, Heymsfield SB, Matthews DE, Leibel RL. Low dose leptin administration reverses effects of sustained weight-reduction on energy expenditure and circulating concentrations of thyroid hormones. J Clin Endocrinol Metab 2002;87:2391-4.

79. Loos RJ, Bouchard C. Obesity--is it a genetic disorder? J Intern Med 2003;254:401-25.

80. Loos RJ. Genetic determinants of common obesity and their value in prediction. Best Pract Res Clin Endocrinol Metab 2012;26:211-26.

81. Wheeler E, Huang N, Bochukova EG, Keogh JM, Lindsay S, Garg S, Henning E, Blackburn H, Loos RJ, Wareham NJ, et al. Genome-wide SNP and CNV analysis identifies common and low-frequency variants associated with severe early-onset obesity. Nat Genet 2013;45:513-7.

82. Li S, Zhao JH, Luan J, Luben RN, Rodwell SA, Khaw KT, Ong KK, Wareham NJ, Loos RJ. Cumulative effects and predictive value of common obesity-susceptibility variants identified by genome-wide association studies. Am J Clin Nutr 2010;91:184-90.

83. Speliotes EK, Willer CJ, Berndt SI, Monda KL, Thorleifsson G, Jackson AU, Lango Allen H, Lindgren CM, Luan J, Magi R, et al. Association analyses of 249,796 individuals reveal 18 new loci associated with body mass index. Nat Genet 2010;42:937-48.

84. Mariman EC. Human biology of weight maintenance after weight loss. J Nutrigenet Nutrigenomics 2012;5:13-25.

85. Hainer V, Stunkard AJ, Kunesova M, Parizkova J, Stich V, Allison DB. Intrapair resemblance in very low calorie diet-induced weight loss in female obese identical twins. Int J Obes Relat Metab Disord 2000;24:1051-7.

86. Andreasen CH, Stender-Petersen KL, Mogensen MS, Torekov SS, Wegner L, Andersen G, Nielsen AL, Albrechtsen A, Borch-Johnsen K, Rasmussen SS, et al. Low physical activity accentuates the effect of the FTO rs9939609 polymorphism on body fat accumulation. Diabetes 2008;57:95-101.

87. Cornes BK, Lind PA, Medland SE, Montgomery GW, Nyholt DR, Martin NG. Replication of the association of common rs9939609 variant of FTO with increased BMI in an Australian adult twin population but no evidence for gene by environment ( $\mathrm{G} \times \mathrm{E}$ ) interaction. Int J Obes (Lond) 2009;33:75-9.

88. Franks PW, Jablonski KA, Delahanty LM, McAteer JB, Kahn SE, Knowler WC, Florez JC. Assessing gene-treatment interactions at the FTO and INSIG2 loci on obesity-related traits in the Diabetes Prevention Program. Diabetologia 2008;51:2214-23.

89. Freathy RM, Timpson NJ, Lawlor DA, Pouta A, Ben-Shlomo Y, Ruokonen A, Ebrahim S, Shields B, Zeggini E, Weedon MN, et al. Common variation in the FTO gene alters diabetes-related metabolic traits to the extent expected given its effect on BMI. Diabetes 2008;57:1419-26.

90. Johnson L, van Jaarsveld CH, Emmett PM, Rogers IS, Ness AR, Hattersley AT, Timpson NJ, Smith GD, Jebb SA. Dietary energy density affects fat mass in early adolescence and is not modified by FTO variants. PLoS One 2009;4:e4594.

91. Lappalainen TJ, Tolppanen AM, Kolehmainen M, Schwab U, Lindstrom J, Tuomilehto J, Pulkkinen L, Eriksson JG, Laakso M, Gylling H, et al. The common variant in the FTO gene did not modify the effect of lifestyle changes on body weight: the Finnish Diabetes Prevention Study. Obesity (Silver Spring) 2009;17:832-6.

92. Haupt A, Thamer C, Heni M, Tschritter O, Machann J, Schick F, Machicao F, Haring HU, Staiger H, Fritsche A. Impact of variation near MC4R on whole-body fat distribution, liver fat, and weight loss. Obesity (Silver Spring) 2009;17:1942-5. 
93. Kring SI, Holst C, Toubro S, Astrup A, Hansen T, Pedersen O, Sorensen TI. Common variants near MC4R in relation to body fat, body fat distribution, metabolic traits and energy expenditure. Int J Obes (Lond) 2010;34:182-9.

94. Loos RJ, Lindgren CM, Li S, Wheeler E, Zhao JH, Prokopenko I, Inouye M, Freathy RM, Attwood AP, Beckmann JS, et al. Common variants near MC4R are associated with fat mass, weight and risk of obesity. Nat Genet 2008;40:768-75. 


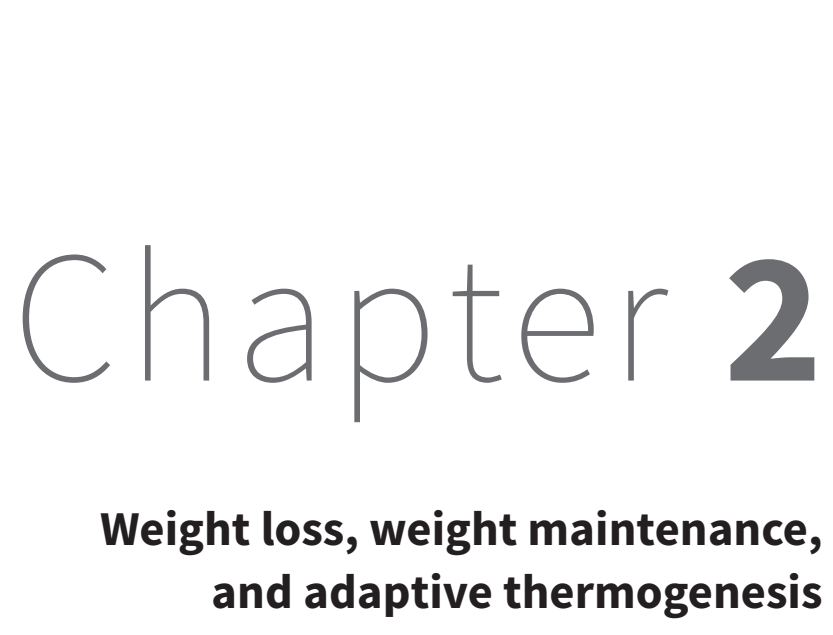

Camps SG, Verhoef SP, Westerterp KR

Am J Clin Nutr. 2013 May;97(5):990-4. doi: 10.3945/ajcn.112.050310. 


\section{Abstract}

\section{Background}

Diet-induced weight loss is accompanied by adaptive thermogenesis, i.e. a disproportional or greater than expected reduction of resting metabolic rate (RMR).

\section{Objective}

The aim of this study was to investigate whether adaptive thermogenesis is sustained during weight maintenance after weight loss.

\section{Design}

Subjects were 22 men and 69 women (age: $40 \pm 9$ years, BMI: $31.9 \pm 3.0 \mathrm{~kg} / \mathrm{m}^{2}$ ). They followed a very low energy diet for 8 weeks, followed by a 44-week period of weight maintenance. Body composition was assessed with a three-compartment model based on body weight, total body water (deuterium dilution) and body volume (BodPod System, Life Measurement Corporation). RMR was measured (RMRm) with a ventilated hood. In addition, RMR was predicted (RMRp) based on the measured body composition: RMRp (MJ/d) $=0.024 \times$ Fat Mass $(\mathrm{kg})+0.102 \times$ Fat Free Mass $(\mathrm{kg})+0.85$. Measurements took place before the diet and 8, 20 and 52 weeks after the start of the diet.

\section{Results}

The ratio RMRm vs. RMRp decreased from $1.00 \pm 0.08$ before the diet to $0.96 \pm 0.07$ after the diet $(\mathrm{P}<0.001)$ and the decrease was sustained after 20 weeks $(0.98 \pm 0.06, P<0.01)$ and 52 weeks (0.98 $\pm 0.07, P<0.01)$. RMRm / RMRp was correlated to the weight loss after 8 weeks $(P<0.01), 20$ weeks $(P<0.05)$ and at 52 weeks $(P<0.05)$.

\section{Conclusions}

Weight loss results in adaptive thermogenesis and there is no indication for a change in adaptive thermogenesis up to one year, when weight loss is maintained. 


\section{Introduction}

The increasing prevalence of obesity and its comorbidities is one of the major health problems in our modern world (1). Although weight loss strategies target both sides of the energy balance, intake and expenditure, the success of long-term weight loss maintenance is low $(2,3)$. Adaptive thermogenesis, which is described as a decrease in energy expenditure beyond what can be predicted by the loss of fat-free mass (FFM) and fat mass (FM), could be an important factor that compromises the maintenance of a reduced body weight. In origin, this metabolic adaptation is a biologically meaningful survival mechanism that conserves energy in the face of starvation and dangerously low energy supplies $(4,5)$.

Studies performed in lean and obese subjects have shown significant reductions in energy expenditure during and shortly after weight loss, to values below predictions based on weight loss and body composition changes (6-13). Leibel et al. showed that a weight loss of $10 \%$ was accompanied by a reduction in resting metabolic rate (RMR) of $0.57 \mathrm{MJ} /$ day below what was predicted from the relationship of energy expenditure to FFM and FM at baseline in the same obese subjects (6). Doucet et al. showed similar results (7). They used a regression equation relating RMR of control participants to their FFM and FM in a context of weight stability to predict RMR after weight loss. Already after two weeks of energy restriction, RMR was observed to decrease by 0.47 and $0.64 \mathrm{MJ} / \mathrm{d}$ more than predicted and this difference was 0.96 and $0.61 \mathrm{MJ} / \mathrm{d}$ by week 8 , respectively, in men and women. Once body weight stability was reached at the end of the program at approximately 10\% weight loss, RMR remained below predicted values in men but not in women. Astrup et al. conducted a meta-analysis on a large sample of data on RMR in formerly obese subjects and never-obese control subjects. They showed that, after differences in body size and composition were taken into account, formerly obese subjects had a 3-5\% lower RMR than never-obese controls subjects (14). Moreover, there is proof for a longer-term disproportionate reduction in energy expenditure, even up to 6 years $(15,16)$. Van Gemert et al. followed subjects who underwent vertical gastric banding and found a disproportional reduction in RMR of $0.44 \mathrm{MJ} / \mathrm{d}$ after 36 months at an average weight loss of $40 \%$ (15).

A sustained adaptive thermogenesis favors a positive energy balance during weight maintenance and may predispose to weight regain. The aim of this study was to quantify adaptive thermogenesis after 8 weeks of a very low energy diet (VLED), and how this adaptation evolved during one year of follow-up. Adaptive thermogenesis was assessed from a comparison between measured and predicted resting metabolic rate (RMR), where the RMR prediction equation included fat-free mass and fat mass as independent variables (17). 


\section{Subjects and methods}

\section{Subjects}

Ninety-one healthy subjects (69 women and 22 men) with a mean age of $40 \pm 9$ years and with a mean body mass index (BMI) of $31.9 \pm 3.0 \mathrm{~kg} / \mathrm{m}^{2}$ (Table 2.1) were recruited by advertisements in local newspapers and on notice boards at the university. They underwent an initial screening that included measurements of body weight and height and the completion of a questionnaire on general health. All were in good health, not using medication (except for contraception), nonsmokers and at most moderate alcohol consumers. They were weight stable as defined by a weight change $<5 \mathrm{~kg}$ for at least 3 months prior to the study. The study was conducted according to the guidelines laid down in the Declaration of Helsinki and procedures were approved by the Ethics Committee of the Maastricht University Medical Centre. Written informed consent was obtained from all participants.

Table 2.1. Subject characteristics (mean \pm SD)

\begin{tabular}{lll}
\hline & Women $(\mathrm{n}=69)$ & Men $(\mathrm{n}=22)$ \\
\hline Age (years) & $39 \pm 10$ & $44 \pm 7$ \\
Weight $(\mathrm{kg})$ & $89.0 \pm 10.0$ & $103.6 \pm 13.0$ \\
Height $(\mathrm{m})$ & $1.67 \pm 0.05$ & $1.81 \pm 0.08$ \\
BMI $\left(\mathrm{kg} / \mathrm{m}^{2}\right)$ & $32.1 \pm 3.1$ & $31.0 \pm 2.5$ \\
\hline
\end{tabular}

BMI, body mass index

\section{Study design}

The study covered a full year, starting with a very low energy diet (VLED) for 8 weeks, followed by a 44-week period of weight maintenance (Figure 2.1). Subjects came to the university for measurements on four occasions: the day before the start of the diet (baseline), 8 weeks after the start of the diet (end of the diet), 20 weeks after the start of the diet and 52 weeks after the start of the diet. On each occasion, measurements included RMR followed by body composition and were performed from 08.00 in the morning onwards in the fasting state.

\section{Resting Metabolic Rate}

To reach the university for RMR measurements, subjects were instructed to travel by public transport or by car to avoid physical activity that would increase RMR. After arrival, they rested on a bed for 30 minutes, followed by 30 minutes of measuring their RMR in the supine position using an open-circuit ventilated hood-system (18). Gas analyses were performed by a paramagnetic oxygen analyzer (Servomex, type 500A, Crowborough, East Sussex, UK) and 


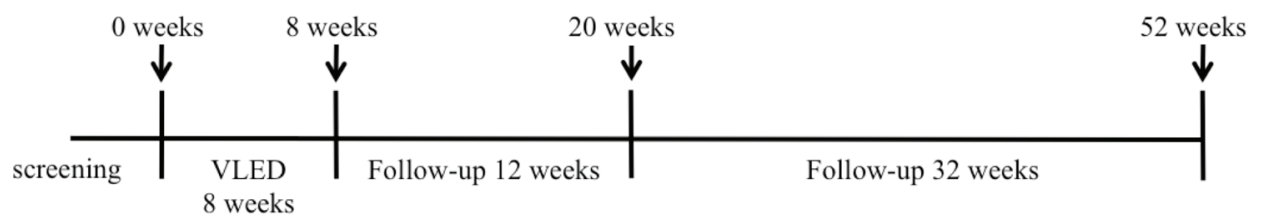

Figure 2.1. Flowchart of the 1-year program the subjects followed, with the measurement points indicated.

an infrared carbon dioxide analyzer (Servomex, type 500A, Crowborough, East Sussex, UK) while flow was kept at a constant rate of $80 \mathrm{l} / \mathrm{min}$ and additionally measured as described by Schoffelen et al. (19). The within individual coefficient of variation for this system is $3.3 \% \pm 2.1$ (18). Calculation of RMR from measured oxygen consumption and carbon dioxide production was based on Brouwer's formula (20).

\section{Body Composition}

Height was measured at screening to the nearest $0.1 \mathrm{~cm}$ with the use of a wall-mounted stadiometer (model 220; Seca, Hamburg, Germany). Body composition was determined according to Siri's three-compartment model based on body weight, body volume and total body water (21). Body weight was measured using a calibrated scale (Life Measurement Corporation, Inc, Concord, CA, USA). Body volume was measured via air-displacement plethysmography with the BodPod System (Life Measurement Corporation, Inc, Concord, CA, USA) (22, 23). Total body water was determined using deuterium dilution during the preceding night, according to the Maastricht protocol (24). Body mass index (BMI) was calculated by dividing body weight by height squared $\left(\mathrm{kg} / \mathrm{m}^{2}\right)$.

\section{Diet}

The weight loss diet (Modifast; Nutrition et Santé Benelux, Breda, The Netherlands) was followed for a period of 8 weeks. The diet was a protein-enriched formula that provided 2.1 $\mathrm{MJ} /$ day (51.9 grams of protein, 50.2 grams of Carbohydrates and 6.9 grams of Lipids) and a micronutrient content, which meets the Dutch recommended daily allowance. The VLED was provided to the subjects as sachets with powder. Each sachet represented one meal and 3 sachets were consumed every day. Besides the provided meal-replacements, subjects were allowed to eat vegetables when feeling hungry. Subjects were instructed to mix the powder with the amount of water indicated on the packages and were advised to drink water sufficiently throughout the diet period. 


\section{Calculations and statistical analysis}

In addition to measuring RMR with the ventilated hood system (RMRm), RMR was predicted (RMRp) with the equation: $\operatorname{RMRp}(\mathrm{MJ} / \mathrm{d})=0.024 \times$ fat mass $(\mathrm{kg})+0.102 \times$ fat free mass $\mathrm{x}$ $(\mathrm{kg})+0.85$ (17). Since FM and FFM are used to calculate RMRp, the equation can be used independently for gender. Adaptive thermogenesis was calculated as RMRm divided by RMRp. The obtained ratio was then compared between the different time points. A value above 1 indicates measured RMR is higher than what is expected based on the body composition, a value lower than 1 indicates measured RMR is lower than what is expected based on the body composition. One-way repeated measures ANOVA with Bonferroni adjustment for multiple comparisons and one-way between-groups analysis of covariance (ANCOVA) with weight loss percentage as covariate were used to compare the ratios across 0, 8, 20 and 52 weeks. The Data were analyzed using SPSS 20.0 (SPSS, Inc., Chicago, IL, USA). All data are presented as mean and standard deviation (SD).

\section{Results}

\section{Body composition}

After the 8 weeks VLED, weight loss was on average $9.6 \pm 4.1 \mathrm{~kg}(P<0.001$ (Table 2.2). After 20 weeks and 52 weeks, there still was a significant average weight loss compared to baseline, respectively $8.5 \pm 5.3 \mathrm{~kg},(P<0.001)$ and $6.0 \pm 5.7 \mathrm{~kg}(\mathrm{P}<0.001)$ (Figure 2.2). As a percentage of the starting weight, subjects had lost on average $10.3 \pm 4.4 \%(p<0.001)$ after the 8 weeks VLED. After 20 weeks, weight loss was $9.1 \pm 5.7 \%(P<0.001)$ and after 52 weeks $6.5 \pm 6.1 \%$ $(P<0.001)$. There was a large inter-individual variation in weight loss, indicating a difference in the success of weight loss and of maintaining the lost weight.

\section{Resting Metabolic Rate}

RMRm decreased significantly from $7.31 \pm 1.04 \mathrm{MJ} / \mathrm{d}$ at baseline to $6.64 \pm 0.88 \mathrm{MJ} / \mathrm{d}$ after the VLED ( $P<0.001$, Table 2.2). The decrease of the RMRm compared to baseline was also observed after 20 weeks ( $6.92 \pm 1.05 \mathrm{MJ} / \mathrm{d}, \mathrm{P}<0.001)$ and 52 weeks (6.97 $\pm 1.00 \mathrm{MJ} / \mathrm{d}, \mathrm{P}<0.001)$. The decrease of the RMRm was expected, because body weight was reduced at all time points compared to baseline. Thus, the expected decrease in energy expenditure was observed in the predicted RMR as well. RMRp decreased significantly from baseline $(7.29 \pm$ $1.03 \mathrm{MJ} / \mathrm{d})$ to after the $\operatorname{VLED}(6.91 \pm 0.97 \mathrm{MJ} / \mathrm{d}, \mathrm{P}<0.001)$. After 20 weeks $(7.04 \pm 1.04 \mathrm{MJ} / \mathrm{d}$, $\mathrm{P}<0.001)$ and 52 weeks $(7.12 \pm 1.01 \mathrm{MJ} / \mathrm{d}, \mathrm{P}<0.001)$ the RMRp was also lower than at baseline. Comparing RMRm with RMRp at baseline, the ratio RMRm / RMRp was on average $1.004 \pm$ 0.077 . Values were highly correlated $\left(R^{2}=0.72 ; P<0.001\right)$ and confirmed the validity of the prediction equation for the subject group under study. One-way repeated measures ANOVA and ANCOVA controlling for weight loss percentage were used to compare the average ratios 
Table 2.2. Subject characteristics (mean \pm SD) at baseline, after 8 weeks on a very low energy diet (VLED), and after 20 and 52 weeks weight maintenance

\begin{tabular}{|c|c|c|c|c|}
\hline & Baseline $(n=91)$ & 8 wks $(n=91)$ & 20 wks (n=91) & 52 wks $(n=91)$ \\
\hline Weight (kg) & $92.9 \pm 12.6$ & $83.3 \pm 11.4^{* * *}$ & $84.5 \pm 12.4^{* * *}$ & $87.5 \pm 13.4^{\star \star *}$ \\
\hline FM (kg) & $38.7 \pm 7.2$ & $30.9 \pm 6.9^{\star \star \star \star}$ & $31.2 \pm 7.2^{\star \star \star}$ & $33.7 \pm 7.8^{* \star \star}$ \\
\hline FFM (kg) & $54.2 \pm 10.1$ & $52.4 \pm 9.8^{* \star \star}$ & $53.3 \pm 10.3^{*}$ & $53.8 \pm 9.9^{*}$ \\
\hline $\operatorname{RMRm}(\mathrm{MJ} / \mathrm{d})$ & $7.31 \pm 1.04$ & $6.64 \pm 0.88^{\star \star *}$ & $6.92 \pm 1.05^{\star \star *}$ & $6.97 \pm 1.00^{\star \star *}$ \\
\hline $\operatorname{RMRp}(\mathrm{MJ} / \mathrm{d})$ & $7.29 \pm 1.03$ & $6.91 \pm 0.97^{\star * *}$ & $7.04 \pm 1.04^{* * *}$ & $7.12 \pm 1.01^{\star \star \star}$ \\
\hline RMRm/RMRp & $1.004 \pm 0.077$ & $0.963 \pm 0.073^{* *}$ & $0.983 \pm 0.063^{*}$ & $0.984 \pm 0.068^{*}$ \\
\hline RMRm/RMRp adj. & & $0.967 \pm 0.007^{\star}$ & $0.985 \pm 0.007^{*}$ & $0.979 \pm 0.007^{*}$ \\
\hline
\end{tabular}

One-way repeated measures ANOVA with Bonferroni adjustment for multiple comparisons and one-way betweengroups analysis of covariance (ANCOVA) with weight loss percentage as covariate were used to compare the ratios across $0,8,20$ and 52 weeks. * $\mathrm{P}<0.05$ compared with baseline. ${ }^{* *} \mathrm{P}<0.01$ compared with baseline. ${ }^{* *} \mathrm{P}<0.001$ compared with baseline.

FM, fat mass, FFM, fat free mass, RMRm, measured resting metabolic rate, RMRp, predicted resting metabolic rate, RMRm/RMRp adjusted for weight loss percentage ( \pm SE)

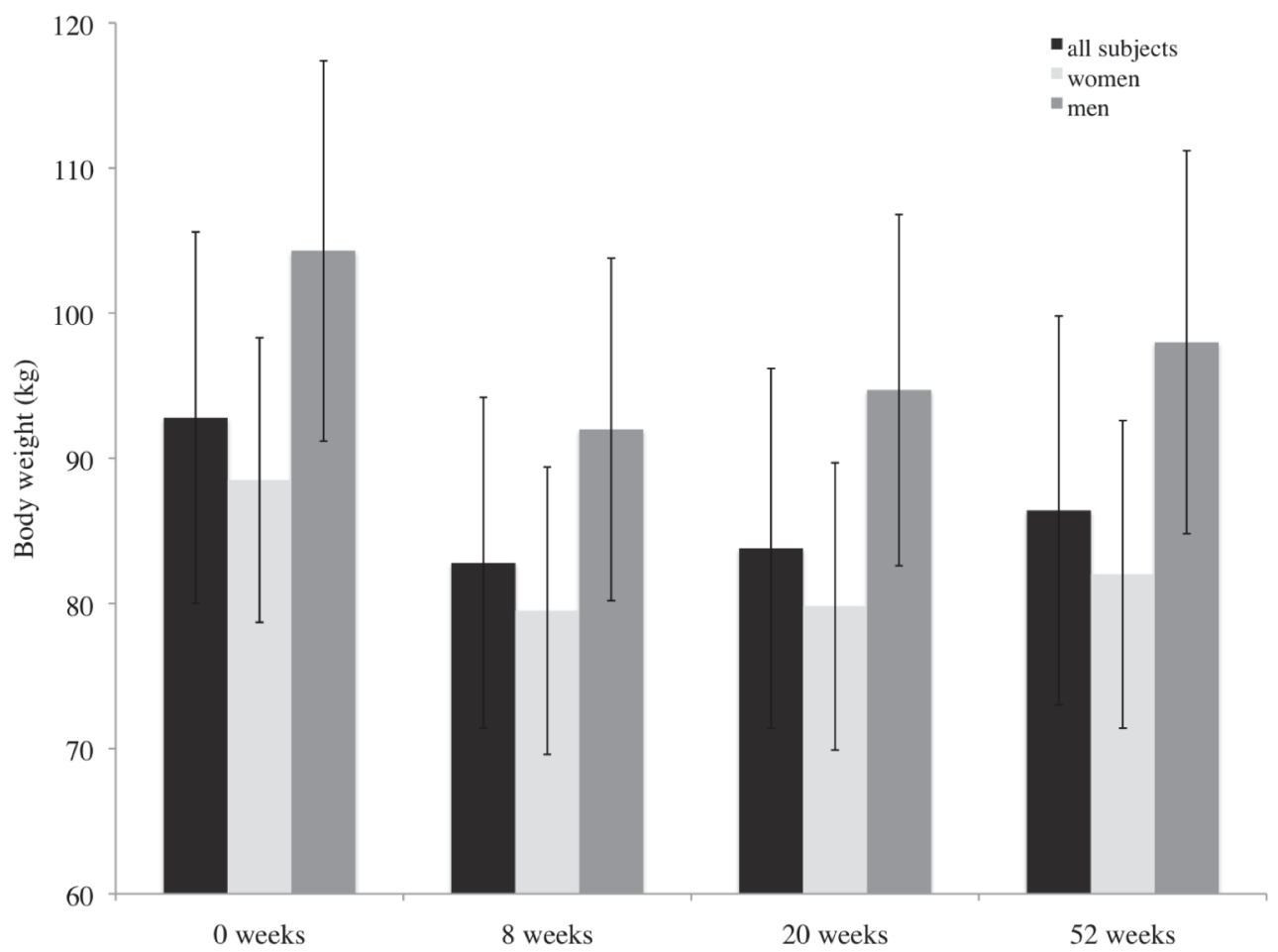

Figure 2.2. Body weight on the $y$-axis at $0,8,20$ and 52 weeks of the 1 -year study (mean \pm SD). The black bars represents the average body weight of all subjects and additionally women (light-grey) and men (dark-grey) are shown separately (men: n=22, women: $n=69$ ). 
across 8,20 and 52 weeks to baseline. The ratio decreased significantly to $0.963 \pm 0.073$ after the VLED $(P<0.01)$. Additionally, after 20 weeks $(0.983 \pm 0.063, P<0.05)$ and 52 weeks $(0.984 \pm$ $0.068, P<0.05)$, the ratio was still lower in comparison to the ratio at baseline. There was no significant difference $(P=0.206)$ between the ratios after 8, 20 and 52 weeks after controlling for weight loss percentage. Additionally, adjusted means delivered by ANCOVA analysis controlling for weight loss percentage differences across 8, 20 and 52 weeks confirm these results (table 2.2). RMRm / RMRp showed a large inter-individual variation and individual values were related to weight loss percentage (Figure $\mathbf{2 . 3}$ ). There are no gender differences in the change of BMRm/BMRp over time. There was a correlation between the ratio and weight loss percentage after 8 weeks $\left(R^{2}=0.05, P<0.05\right), 20$ weeks $\left(R^{2}=0.05, P<0.05\right)$, and 52 weeks ( $\left.R^{2}=0.06, P<0.05\right)$, indicating subjects with a larger weight loss percentage showed a proportionally larger reduction in RMR. Additionally, the reduction in RMR, as indicated by the slope and intercept of the regression lines, was similar after 8, 20, and 52 weeks.
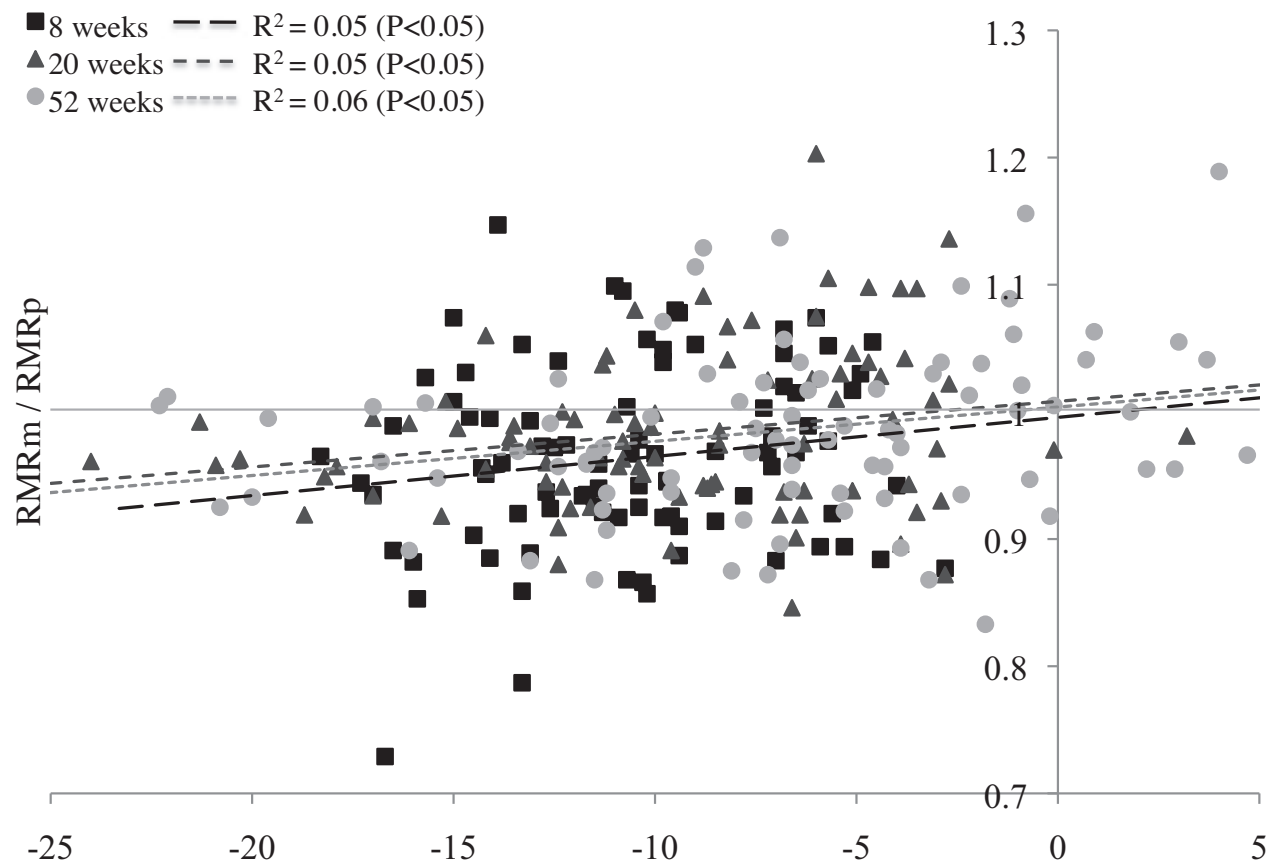

Weight change $(\%)$

Figure 2.3. RMRm / RMRp on the y-axis plotted against the weight loss (\%) on the x-axis at 8 weeks (black squares), 20 weeks (dark grey triangles) and 52 weeks (light grey circles) after the start of the very low energy diet (VLED). RMRm / RMRp is correlated to weight loss after 8 weeks ( $\left.R^{2}=0.05, P<0.05\right), 20$ weeks $\left(R^{2}=0.05, P<0.05\right)$, and 52 weeks $\left(R^{2}=0.06, P<0.05\right)$. One-way repeated measures ANOVA with Bonferroni adjustment for multiple comparisons and one-way between-groups analysis of covariance (ANCOVA) were used to compare the ratios across 0, 8, 20 and 52 weeks. ( $n=91$ ) RMRm, measured resting metabolic rate, RMRp, predicted resting metabolic rate. 


\section{Discussion}

Measuring energy expenditure and body composition before and after an 8-week VLED and during and after a 44-week period of follow-up showed that adaptive thermogenesis develops during weight loss and that it is sustained up to 44 weeks when bodyweight is maintained below the initial pre-diet weight. In addition, there is a significant correlation between the adaptive thermogenesis and weight loss percentage after 8,20 and 52 weeks, indicating that subjects with a larger weight loss showed a greater reduction in RMR and that in case of an unsuccessful maintenance of the lost weight and a return to or beyond the starting weight is reached, the adaptive thermogenesis is no longer observed.

Consequent to the changes in body composition, there was a decrease in RMRp and RMRm after the diet. However, the observed reduction of RMRm was $0.27 \mathrm{MJ} / \mathrm{d}$ beyond the calculated reduction of RMRp, indicating that moderate weight loss is accompanied by adaptive thermogenesis. This is in accordance with the results that have been described before in literature (6-13). Furthermore the observed disproportional decrease of RMRm after the VLED was correlated to the weight loss percentage, showing that subjects with greater weight loss had more adaptive thermogenesis. Although adaptive thermogenesis acts in response to energy restriction to slow weight loss, subjects with the greatest adaptation had the greatest weight loss. This supports the suggestion that the compliance to and the energy restriction itself play a role in the amount of weight loss and that the amount of weight loss determines the degree of adaptive thermogenesis (25). In 1995, Leibel et al. suggested that the maximal adaptation to the maintenance of a reduced body weight was already attained at a 10 percent weight loss (6). This could not be confirmed by our data in which adaptive thermogenesis correlates with weight loss up to 25 percent in a linear way.

During and after 44 weeks of follow-up after 8 weeks VLED, RMRm was still disproportionally decreased, extending the knowledge about sustained adaptive thermogenesis shown previously by Van Gemert et al. up to 6 years but after severe weight loss (>50 kg) by means of gastric banding (15) and by Rosenbaum et al. up to just 7 weeks of follow-up after $10 \%$ weight loss (26). Contrary to Doucet et al. (7), who showed a sustained adaptive thermogenesis only in men and not in women up to 4 weeks after weight loss, we found a sustained disproportional reduction of RMRm independent of gender. Moreover, the same correlation between the lost weight and adaptive thermogenesis that was obtained after the VLED is found up to 44 weeks after weight loss, indicating that when weight is still below the initial weight from before the diet, adaptive thermogenesis is sustained. At the same time this indicates that in case of an unsuccessful maintenance of the lost weight and a return to the starting weight is reached, the adaptive thermogenesis is no longer observed. The disproportionate reduction in energy expenditure favors a positive energy balance during weight maintenance and may predispose to weight regain and could be one of the factors contributing to the high recidivism to obesity $(2,3)$. 
A limitation of this study is that diet and physical activity were not standardized during the 44 weeks of follow-up. On the other hand, due to the absence of an advice on diet and physical activity, this study reflects achievements in free-living conditions. Another limitation of this study is generated by the large inter-individual variation in the results. However, the observed variation allowed adaptive thermogenesis to be correlated to a wide range from unsuccessful to successful weight maintenance during follow-up. One of the major advantages with regard to other studies is the 44 weeks of follow-up to investigate sustained thermogenesis after moderate weight loss.

For future research it is important to elucidate metabolic, neuroendocrine, autonomic and behavioral changes involved in the adaptive responses, distinct from changes in body weight per se (27). Changes in leptin (26, 28), insulin (29) and thyroid hormones (10, 26, 30, 31 ), as well as changes in sympathetic tone (30-32) have been shown to be associated with a disproportional reduction in energy expenditure induced by weight loss.

In conclusion, our study shows that moderate weight loss induced by energy restriction leads to a disproportional reduction in resting metabolic rate. Additionally, the adaptive thermogenesis is not only observed after the diet but is sustained up to 44 weeks of followup and is positively correlated to the amount of lost weight. As a consequence, the adaptive thermogenesis favors a positive energy balance during weight maintenance and may increase the risk for weight regain.

\section{Acknowledgements}

K.R. Westerterp and S.P.M. Verhoef designed the study. S.G.J.A. Camps and S.P.M. Verhoef collected the data. S.G.J.A. Camps analyzed the data and wrote the manuscript. K.R. Westerterp contributed to the interpretation of the data and reviewed the manuscript. The study was executed under supervision of K.R. Westerterp. All authors read and approved the final manuscript. None of the authors had any conflict of interest. 


\section{References}

1. Catenacci VA, Hill JO, Wyatt HR. The obesity epidemic. Clin Chest Med 2009;30:415-44, vii.

2. Kraschnewski JL, Boan J, Esposito J, et al. Long-term weight loss maintenance in the United States. Int J Obes (Lond) 2010;34:1644-54.

3. Wing RR, Phelan S. Long-term weight loss maintenance. Am J Clin Nutr 2005;82:222S-225S.

4. Keys A. The residues of malnutrition and starvation. Science 1950;112:371-3.

5. Taylor HL, Keys A. Adaptation to caloric restriction. Science 1950;112:215-8.

6. Leibel RL, Rosenbaum M, Hirsch J. Changes in energy expenditure resulting from altered body weight. N Engl J Med 1995;332:621-8.

7. Doucet E, St-Pierre S, Almeras N, Despres JP, Bouchard C, Tremblay A. Evidence for the existence of adaptive thermogenesis during weight loss. Br J Nutr 2001;85:715-23.

8. Dulloo AG, Jacquet J. Adaptive reduction in basal metabolic rate in response to food deprivation in humans: a role for feedback signals from fat stores. Am J Clin Nutr 1998;68:599-606.

9. Martin CK, Heilbronn LK, de Jonge L, et al. Effect of calorie restriction on resting metabolic rate and spontaneous physical activity. Obesity (Silver Spring) 2007;15:2964-73.

10. Johannsen DL, Knuth ND, Huizenga R, Rood JC, Ravussin E, Hall KD. Metabolic Slowing with Massive Weight Loss despite Preservation of Fat-Free Mass. J Clin Endocrinol Metab 2012;97.

11. Schwartz A, Doucet E. Relative changes in resting energy expenditure during weight loss: a systematic review. Obes Rev 2010;11:531-47.

12. Tremblay A, Chaput JP. Adaptive reduction in thermogenesis and resistance to lose fat in obese men. Br J Nutr 2009;102:488-92.

13. Weyer C, Walford RL, Harper IT, et al. Energy metabolism after 2 y of energy restriction: the biosphere 2 experiment. Am J Clin Nutr 2000;72:946-53.

14. Astrup A, Gotzsche PC, van de Werken K, et al. Meta-analysis of resting metabolic rate in formerly obese subjects. Am J Clin Nutr 1999;69:1117-22.

15. van Gemert WG, Westerterp KR, Greve JW, Soeters PB. Reduction of sleeping metabolic rate after vertical banded gastroplasty. Int J Obes Relat Metab Disord 1998;22:343-8.

16. Rosenbaum M, Hirsch J, Gallagher DA, Leibel RL. Long-term persistence of adaptive thermogenesis in subjects who have maintained a reduced body weight. Am J Clin Nutr 2008;88:906-12.

17. Westerterp KR, Donkers JH, Fredrix EW, Boekhoudt P. Energy intake, physical activity and body weight: a simulation model. Br J Nutr 1995;73:337-47.

18. Adriaens MP, Schoffelen PF, Westerterp KR. Intra-individual variation of basal metabolic rate and the influence of daily habitual physical activity before testing. Br J Nutr 2003;90:419-23.

19. Schoffelen PF, Westerterp KR, Saris WH, Ten Hoor F. A dual-respiration chamber system with automated calibration. J Appl Physiol 1997;83:2064-72.

20. Brouwer E. On simple formulae for calculating the heat expenditure and the quantities of carbohydrate and fat oxidized in metabolism of men and animals, from gaseous exchange (Oxygen intake and carbonic acid output) and urine-N. Acta Physiol Pharmacol Neerl 1957;6:795-802.

21. Siri WE. Body composition from fluid spaces and density: analysis of methods. 1961. Nutrition 1993;9:480-91; discussion 480, 492.

22. Ginde SR, Geliebter A, Rubiano F, et al. Air displacement plethysmography: validation in overweight and obese subjects. Obes Res 2005;13:1232-7. 
23. Dempster P, Aitkens S. A new air displacement method for the determination of human body composition. Med Sci Sports Exerc 1995;27:1692-7.

24. Westerterp KR, Wouters L, van Marken LichtenbeltWD. The Maastricht protocol for the measurement of body composition and energy expenditure with labeled water. Obes Res 1995;3 Suppl 1:49-57.

25. Heymsfield SB, Harp JB, Reitman ML, et al. Why do obese patients not lose more weight when treated with low-calorie diets? A mechanistic perspective. Am J Clin Nutr 2007;85:346-54.

26. Rosenbaum M, Goldsmith R, Bloomfield D, et al. Low-dose leptin reverses skeletal muscle, autonomic, and neuroendocrine adaptations to maintenance of reduced weight. J Clin Invest 2005;115:3579-86

27. Rosenbaum M, Leibel RL. Adaptive thermogenesis in humans. Int J Obes (Lond) 2010;34 Suppl 1:S47-55.

28. Kissileff HR, Thornton JC, Torres MI, et al. Leptin reverses declines in satiation in weight-reduced obese humans. Am J Clin Nutr 2012;95:309-17.

29. Porte D, Jr., Baskin DG, Schwartz MW. Leptin and insulin action in the central nervous system. Nutr Rev 2002;60:S20-9; discussion S68-84, 85-7.

30. Rosenbaum M, Hirsch J, Murphy E, Leibel RL. Effects of changes in body weight on carbohydrate metabolism, catecholamine excretion, and thyroid function. Am J Clin Nutr 2000;71:1421-32.

31. Flier JS, Harris M, Hollenberg AN. Leptin, nutrition, and the thyroid: the why, the wherefore, and the wiring. J Clin Invest 2000;105:859-61.

32. Kim MS, Small CJ, Stanley SA, et al. The central melanocortin system affects the hypothalamopituitary thyroid axis and may mediate the effect of leptin. J Clin Invest 2000;105:1005-11. 


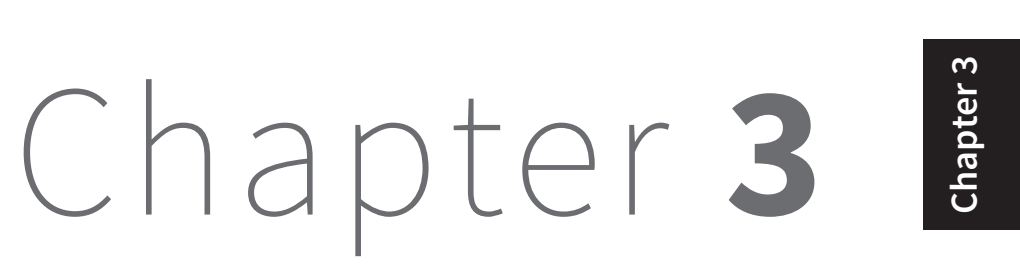

Weight loss-induced reduction in physical activity recovers during weight maintenance 


\section{Abstract}

\section{Background}

Weight loss due to a negative energy balance is considered to be accompanied by a decrease in physical activity.

\section{Objective}

The aim of this study was to investigate whether a decrease of physical activity is sustained during weight maintenance.

\section{Methods}

Subjects were 20 men and 31 women (age: $42 \pm 8$ years, BMl: $31.4 \pm 2.8 \mathrm{~kg} / \mathrm{m}^{2}$ ). Weight loss was achieved by an 8-week very low energy diet period, followed by 44 weeks of weight maintenance. Physical activity measures were total energy expenditure expressed as a multiple of sleeping metabolic rate $\left(P A L_{S M R}\right)$ and resting metabolic rate $\left(P A L_{R M R}\right)$, activity induced energy expenditure divided by body weight (AEE/kg), and activity counts measured by a tri-axial accelerometer. Measurements took place at 0, 8 and 52 weeks.

\section{Results}

Body mass decreased significantly during the diet-period $(10.5 \pm 3.8 \%, \mathrm{P}<0.001)$ and this reduction was sustained after 52 weeks $(6.0 \pm 5.1 \%, P<0.001)$. $P A L_{S M R}$ and $P A L_{R M R}$ decreased respectively from $1.81 \pm 0.23$ and $1.70 \pm 0.22$ before the diet to $1.69 \pm 0.20$ and $1.55 \pm 0.19$ after the diet $(P<0.001)$ and increased again after weight maintenance to $1.85 \pm 0.27$ and $1.71 \pm 0.23$ compared to 8 weeks $(P<0.001)$. AEE $/ \mathrm{kg}$ decreased from $0.043 \pm 0.015 \mathrm{MJ} / \mathrm{kg}$ at baseline to $0.037 \pm 0.014 \mathrm{MJ} / \mathrm{kg}$ after the diet $(P<0.001)$ and was higher after 52 weeks $(0.044 \pm 0.17 \mathrm{MJ} /$ $\mathrm{kg})$ compared to 8 weeks $(P<0.001)$. Activity counts decreased from $1.64 \pm 0.37$ Mcounts $/ d$ at baseline to $1.54 \pm 0.35$ Mcounts/d after the diet $(P<0.05)$ and were higher after 52 weeks $(1.73 \pm 0.49$ Mcounts/d) compared to 8 weeks $(P<0.01)$.

\section{Conclusion}

A weight loss induced reduction in physical activity returns to baseline values when weight loss is maintained. 


\section{Introduction}

The increasing prevalence of obesity and its comorbidities is one of the major health problems in our modern world (1). Although weight loss strategies target both sides of the energy balance, intake and expenditure, the success of long-term weight loss maintenance is low $(2,3)$. Weight gain and obesity occur when energy intake exceeds energy expenditure. Total energy expenditure (TEE) consists of resting metabolic rate (RMR), activity-induced energy expenditure (AEE) and the diet-induced thermogenesis (DIT), sleeping metabolic rate (SMR) is considered as RMR without the energy cost of arousal (4-6). Firstly, the amount of physical activity can be expressed as the physical activity level (PAL), calculated by expressing TEE as a multiple of RMR (PAL = TEE/RMR) and has a value between 1.2 and 2.5 in the general population (7). Secondly, Schoeller and Jefford suggested AEE divided by body weight to normalize the energy expenditure of physical activity (8). Thirdly, physical activity can be expressed as activity counts measured by accelerometers (9). In origin, a decrease in physical activity is a biologically meaningful survival mechanism to conserve energy in the face of starvation and dangerously low energy supplies $(10,11)$.

The correlation between body mass index (BMI) and physical activity is still up for debate as studies have shown no difference between mean PAL of lean and obese subjects $(12,13)$ while other studies have shown a negative effect of BMI on physical activity (14-16). Furthermore, there is no agreement yet on the influence of energy restriction on physical activity, as studies have not systematically shown alterations in physical activity. Ravussin et al. showed no change in AEE as a fraction of TEE during energy restriction in respiration chambers compared to weight maintenance (17). Furthermore, Levine et al. concluded that interindividual differences in posture allocations are biologically determined and are independent from losing or gaining weight (18). On the other hand, several studies did demonstrate a decrease in physical activity as a result of weight loss. De Groot et al. showed a reduction of spontaneous activities during slimming studies in a respiration chamber (19). Velthuis-te Wierik et al showed for a group of 8 men that there was a trend towards a decrease of PAL ( $P=0.06$ ) (20). Additionally, Martin et al. and Redman et al. similarly showed that PAL decreased after 12 weeks of energy restriction. However this was no longer evident after further weight loss or weight loss maintenance at 24 weeks (21, 22). Recently, Bonomi et al. concluded that weight loss induced a decrease in AEE while they found a small increase in body movement (23). They used an AEE doubly labeled water prediction model, which included body weight and body movement.

Understanding the influence of energy restriction on physical activity is essential for the success of weight maintenance. It is hypothesized that physical activity decreases during energy restriction. The aim of this study was to measure physical activity before and after a very low energy diet (VLED) and how this evolved during one year of follow-up. Physical activity measures were PAL, calculated as free-living TEE expressed as a multiple of SMR and 
RMR, AEE divided by body weight, and activity counts measured by a tri-axial accelerometer, where AEE/kg is the favored parameter.

\section{Subjects and methods}

\section{Subjects}

Fifty-one healthy subjects (31 women and 20 men), mean + SD age of $42 \pm 8$ years and mean \pm SD BMI of $31.4 \pm 2.8 \mathrm{~kg} / \mathrm{m}^{2}$ were recruited by advertisements in local newspapers and on notice boards at the university. They underwent an initial screening that included measurements of body weight and height and the completion of a questionnaire on general health. All were in good health, not using medication (except for contraception), nonsmokers and at most moderate alcohol consumers. They were weight stable as defined by a weight change $<5 \mathrm{~kg}$ for at least 3 months prior to the study. The study was conducted according to the guidelines laid down in the Declaration of Helsinki and procedures were approved by the Ethics Committee of the Maastricht University Medical Centre. Written informed consent was obtained from all participants. This trial was registered at clinicaltrials.gov as NCT01015508.



Figure 3.1. Flowchart of the 1-year program the subjects followed with the measurement points indicated. Two weeks prior to each measurement day, subjects received an accelerometer to measure body movement and a subject-specific dose of doubly labeled water to measure simultaneously TEE over 14 days.

VLED: Very low energy diet, TEE: total energy expenditure

\section{Study design}

The study covered a full year, starting with a very low energy diet (VLED) for 8 weeks, followed by a 44-week period of weight maintenance (Figure 3.1). Subjects came to the university for measurements on three occasions: the day before the start of the diet (baseline), 8 weeks after the start of the diet (end of the diet) and 52 weeks after the start of the diet. Measurements included an overnight stay at the university to assess SMR followed by RMR and body composition from 08.00 in the morning onwards in the fasting state. Two weeks prior to each measurement day, subjects received an accelerometer to measure physical activity and a subject-specific dose of doubly labeled water to measure simultaneously TEE over 14 days. 


\section{Sleeping Metabolic Rate}

Subjects reported to the university at $2000 \mathrm{~h}$ in the evening for an overnight stay in a respiration chamber until $0800 \mathrm{~h}$ in the morning. The room measured $14 \mathrm{~m}^{3}$ and was equipped with a bed, table, chair, freeze toilet, washing bowl, radio, television and computer. Subjects were instructed to sleep from at least $2300 \mathrm{~h}$ until $0700 \mathrm{~h}$ and in case of insomnia during these eight hours to lie quietly in bed. SMR was defined as the lowest observed energy expenditure for three consecutive hours during the night and was measured and calculated as described before (24).

\section{Resting Metabolic Rate}

At $0800 \mathrm{~h}$ in the morning, after the overnight stay in the respiration chamber, subjects slowly walked to a separate room where they rested on a bed for 30 minutes, followed by 30 minutes of measuring their RMR in the supine position using an open-circuit ventilated hood-system (25). Gas analyses were performed with a paramagnetic oxygen analyzer (Servomex, type 1158, Crowborough, East Sussex, UK) and an infrared carbon dioxide analyzer (Servomex, type 1520, Crowborough, East Sussex, UK) while flow was kept at a constant rate of $80 \mathrm{l}$ min and additionally measured as described by Schoffelen et al (24). The within individual coefficient of variation for this system is 3.3\% \pm 2.1 (25). Calculation of RMR from measured oxygen consumption and carbon dioxide production was based on Brouwer's formula (26).

\section{Energy Expenditure}

TEE was measured over two weeks intervals with the doubly labeled water method according to the Maastricht protocol (27). On the evening of day 1 , shortly after the collection of a background urine sample, subjects drank a weighed amount of ${ }^{2} \mathrm{H}_{2}{ }^{18} \mathrm{O}$ such that baseline levels were increased by $100-150$ ppm for ${ }^{2} \mathrm{H}$ and $200-250$ ppm for ${ }^{18} \mathrm{O}$. Subsequently, urine samples were collected in the morning of day 2 (second voiding), day 8 and day 14 and in the evening of day 1,8 and 13 . The doubly labeled water method gives precise and accurate information on carbon dioxide $\left(\mathrm{CO}_{2}\right)$ production. $\mathrm{CO}_{2}$ production was subsequently converted to TEE with the use of the energy equivalent of $\mathrm{CO}_{2}$, which can be calculated with additional information on the substrate mixture being oxidized (28). The energy equivalent at baseline and after 52 weeks was calculated based on a normal Western diet with a mixed macronutrient composition and energy respectively for 55\% from carbohydrate, 30\% from fat and $15 \%$ from protein. At the end of the diet, the energy equivalent of $\mathrm{CO}_{2}$ was based on the consumption of the Modifast diet, the actual loss of fat mass and fat free mass and additional energy intake. The additional food intake was the calculated compensation for the difference between weight loss and the expected weight loss based on the consumption of the Modifast diet alone, with the assumption of $1 \mathrm{~kg}$ weight change to be equivalent to 30 MJ (29). The additional food intake was also assumed to be a normal mixed diet. 
At baseline and after 52 weeks, AEE was calculated as (0.9 X TEE) - RMR, assuming DIT to be $10 \%$ of TEE, which is based on a normal mixed diet (4) and DIT values for the separate macronutrients to be $10 \%$ for carbohydrate, 3\% for fat and $25 \%$ for protein. At the end of the diet, the percentage DIT was calculated based on the intake of the Modifast diet and the additional food intake with a normal mixed composition, which accounted for the difference between the expected weight loss and the real weight loss. DIT was calculated to be $8 \%$ of the TEE at the end of the diet; therefore AEE was calculated as (0.92 X TEE) - RMR.

The physical activity level was calculated as $\mathrm{PAL}_{\mathrm{SMR}}=\mathrm{TEE} / \mathrm{SMR}$ and $\mathrm{PAL}_{\mathrm{RMR}}=\mathrm{TEE} / \mathrm{RMR}(7)$. $A E E$ was adjusted for body weight $\left(A E E_{k g}=A E E / B M\right)$ to normalize the energy expenditure of physical activity (8).

\section{Physical activity monitoring}

Physical activity was monitored in two-week intervals using the previously validated DirectLife triaxial accelerometer (Philips Research, Eindhoven, The Netherlands). The device is small and lightweight and was carried at an elastic belt around the waist. Subjects were instructed to wear the accelerometer during waking hours, except during showering and water activities. A diary was used to report periods in which the subject was not wearing the accelerometer during the day. The accelerometer output was processed to determine body movement by measuring activity counts. Total activity counts were calculated over the twoweek monitoring period, and the sum of counts was divided by the number of monitoring days to determine the average activity counts per day $(30,31)$.

\section{Body Composition}

Height was measured at screening to the nearest $0.1 \mathrm{~cm}$ with the use of a wall-mounted stadiometer (model 220; Seca, Hamburg, Germany). Body composition was determined according to Siri's three-compartment model based on body weight, body volume and total body water. Body weight was measured using a calibrated scale (Life Measurement Corporation, Inc, Concord, CA, USA). Body volume was measured via air-displacement plethysmography with the BodPod System (Life Measurement Corporation, Inc, Concord, CA, USA) (32, 33). Total body water was determined using deuterium dilution during the preceding night, according to the Maastricht protocol. Body mass index (BMI) was calculated by dividing body weight by height squared $\left(\mathrm{kg} / \mathrm{m}^{2}\right)$.

\section{Diet}

The weight loss diet (Modifast; Nutrition et Santé Benelux, Breda, The Netherlands) was followed for a period of 8 weeks. The diet was a protein-enriched formula that provided 2.1 MJ/day (51.9 grams of protein, 50.2 grams of Carbohydrates and 6.9 grams of Lipids) and a micronutrient content, which meets the Dutch recommended daily allowance. The VLED 
was provided to the subjects as sachets with powder. Each sachet represented one meal and 3 sachets were consumed every day. Besides the provided meal-replacements, subjects were allowed to eat vegetables when feeling hungry. Subjects were instructed to mix the powder with the amount of water indicated on the packages and were advised to drink water sufficiently throughout the diet period.

\section{Calculations and statistical analysis}

One-way repeated measures ANOVA with Bonferroni adjustment for multiple comparisons were used to compare the results across 0,8 , and 52 weeks. The data were analyzed using SPSS 20.0 (SPSS, Inc., Chicago, IL, USA). All data are presented as mean and standard deviation (SD).

\section{Results}

\section{Body composition}

After the 8 weeks of VLED, weight loss was on average $9.9 \pm 4.2 \mathrm{~kg}(P<0.001)$. After 52 weeks, there was still a significant average weight loss compared to baseline of $5.7 \pm 4.9 \mathrm{~kg}(P<0.001)$. As a percentage of the starting weight, subjects lost on average $10.5 \pm 3.8 \%(P<0.001)$ and weight loss was still $6.0 \pm 5.1 \%$ after 52 weeks $(P<0.001)$. The data showed a large interindividual variation in weight loss, indicating a difference in the success of weight loss and of maintaining the lost weight. In addition, the variation in weight loss and weight maintenance was not explained by different levels of physical activity at baseline, 8 or 52 weeks, or by a better maintenance of the amount of physical activity during the diet and follow-up.

\section{Energy Expenditure}

SMR and RMR decreased significantly from respectively $7.06 \pm 1.02 \mathrm{MJ} / \mathrm{d}$ and $7.51 \pm 1.04 \mathrm{MJ} / \mathrm{d}$ at baseline to $6.24 \pm 0.81 \mathrm{MJ} / \mathrm{d}(P<0.001)$ and $6.74 \pm 0.83 \mathrm{MJ} / \mathrm{d}(P<0.001)$ after 8 weeks of VLED. SMR and RMR were still lower after 52 weeks compared to baseline, at respectively $6.59 \pm 0.97$ $\mathrm{MJ} / \mathrm{d}(\mathrm{P}<0.001)$ and $7.13 \pm 0.95 \mathrm{MJ} / \mathrm{d}(\mathrm{P}<0.001)$ (SMR not shown). The decrease was explained by the reduced body weight and adaptive thermogenesis in response to the diet (Figure 3.2).

AEE decreased from $3.97 \pm 1.49 \mathrm{MJ} / \mathrm{d}$ at baseline to $3.06 \pm 1.36 \mathrm{MJ} / \mathrm{d}$ after 8 weeks of energy restriction $(P<0.001$ ). After 52 weeks, AEE recovered to $3.77 \pm 1.41 \mathrm{MJ} / \mathrm{d}$ compared to 8 weeks $(P<0.001)$. After 52 weeks, AEE was not significantly different compared to baseline (Figure 3.2).

TEE also decreased from $12.76 \pm 2.13 \mathrm{MJ} / \mathrm{d}$ at baseline to $10.31 \pm 1.96 \mathrm{MJ} / \mathrm{d}(\mathrm{P}<0.001)$ after the VLED. After 52 weeks, TEE was significantly higher compared to 8 weeks $(12.10 \pm 2.03$ $\mathrm{MJ} / \mathrm{d}, \mathrm{P}<0.001$ ) and there was a trend of a lower TEE compared to baseline $(P=0.06)$ (Figure 3.2). 


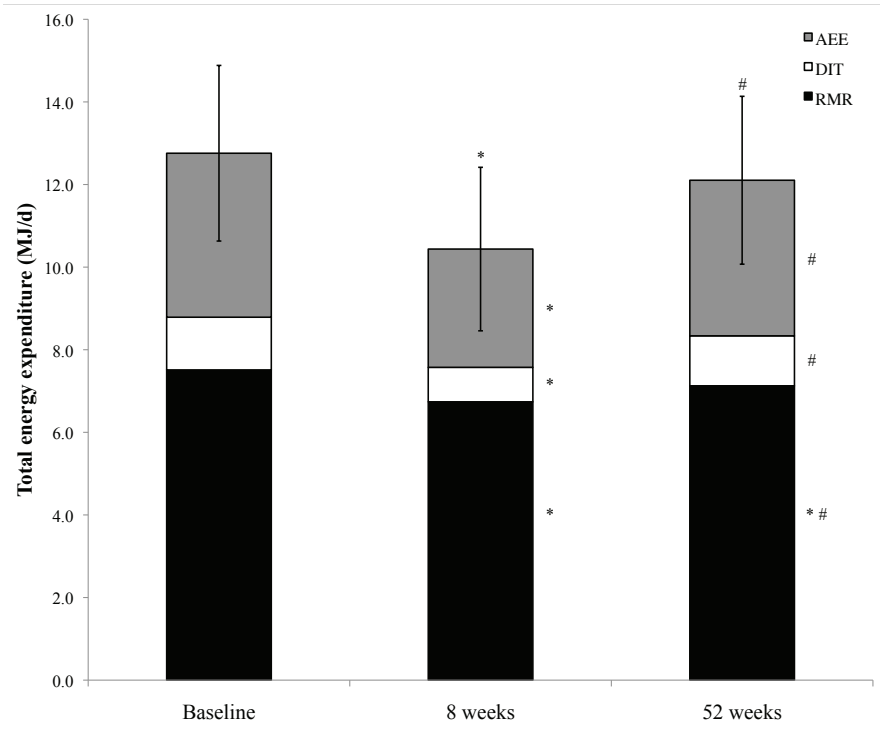

Figure 3.2. Total energy expenditure on the $y$-axis at baseline, 8 and 52 weeks. TEE is partitioned in its components RMR (dark grey), DIT (white) and AEE (light grey). A significant difference compared to baseline is indicated with symbol * $(P<0.001)$, while significant difference compared to 8 weeks is indicated with symbol \# $(P<0.001)$. Significant differences in TEE are indicated above the bars while significant differences for the individual components are specified next to the bar. One-factor repeatedmeasures ANOVA with Bonferroni adjustment for multiple comparisons were used to compare changes over time. All data are presented as mean and standard deviation (SD). $(n=51)$

TEE: total energy expenditure, RMR: resting metabolic rate, DIT: diet induced thermogenesis, AEE: activity induced energy expenditure

\section{Physical activity}

$\mathrm{PAL}_{\text {SMR }}$ was on average $1.81 \pm 0.23$ at baseline and decreased to $1.65 \pm 0.19(\mathrm{P}<0.001)$ after

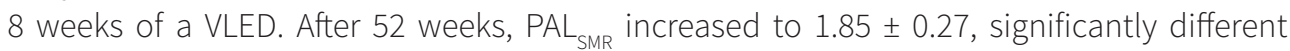
compared to 8 weeks $(P<0.001)$ however not significantly different from baseline. $P A L_{R M R}$ was on average $1.70 \pm 0.22$ at baseline and decreased to $1.55 \pm 0.19$ after 8 weeks $(P<0.001)$. After 52 weeks, $\mathrm{PAL}_{\mathrm{RMR}}$ increased back to $1.71 \pm 0.23$, significantly higher compared to 8 weeks $(\mathrm{P}<0.001)$ however not significantly different from baseline. (Figure 3.3A). There were no differences between men and women regarding the changes in $P A L_{S M R}$ and $P A L_{R M R}$ during the VLED or the 44-week follow-up (data not shown).

AEE/kg was on average $0.043 \pm 0.015 \mathrm{MJ} / \mathrm{kg}$ at baseline and decreased to $0.037 \pm 0.014$ $\mathrm{MJ} / \mathrm{kg}$ after 8 weeks of VLED ( $P<0.001)$. After 52 weeks, AEE/kg increased to $0.044 \pm 0.17 \mathrm{MJ} / \mathrm{kg}$, significantly higher compared to 8 weeks $(P<0.001)$ but not different from baseline (Figure

3.3B).

Activity counts were on average $1.64 \pm 0.37$ Mcounts/d at baseline and decreased to 1.54 \pm 0.35 Mcounts/d $(P<0.05)$ after 8 weeks of energy restriction. After 52 weeks, activity counts 
increased significantly to $1.73 \pm 0.49$ Mcounts/d compared to 8 weeks $(P<0.01)$. There was no significant difference between baseline and 52 weeks (Figure 3.3C).

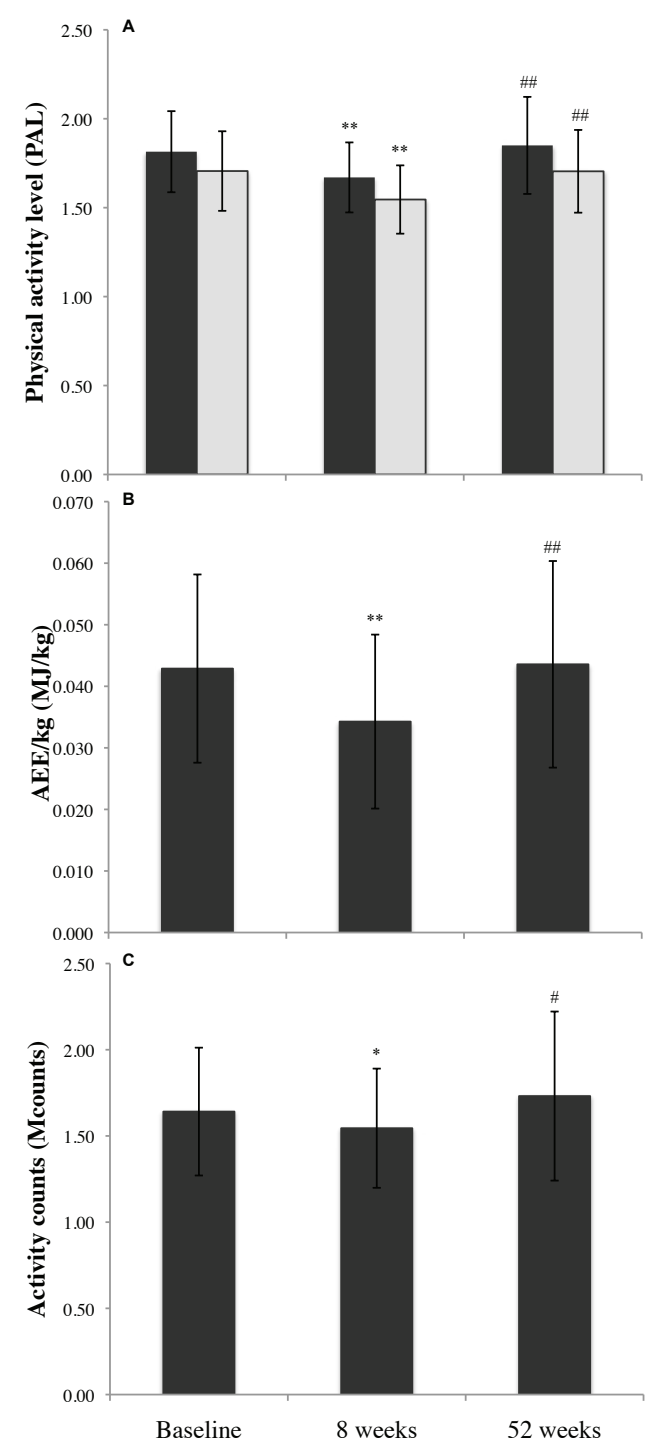

Figure 3.3. $P A L_{S M R}$ (dark grey) and $P A L_{R M R}$ (light grey) (A), AEE/kg (B) and body movement expressed as activity counts (C) on the three $y$-axes at baseline, 8 and 52 weeks. A significant difference compared to baseline is indicated with symbol * ( ${ }^{*} \mathrm{P}<0.05,{ }^{* *} \mathrm{P}<0.001$ ), while significant difference compared to 8 weeks is indicated with symbol \# (\# P $<0.05$, \# $P<$ 0.001). One-factor repeated-measures ANOVA with Bonferroni adjustment for multiple comparisons were used to compare changes over time. All data are presented as mean and standard deviation (SD). $(n=51)$

PAL: physical activity level, AEE: activity induced energy expenditure 


\section{Discussion}

In addition to the earlier described development of adaptive thermogenesis on resting metabolic rate during weight loss, this study shows that physical activity also decreases in a period of energy restriction. However in contrast with the sustained adaptive thermogenesis after 52 weeks, physical activity returns to baseline levels when the lost weight is maintained. In addition, the variation in weight loss and weight maintenance was not explained by different levels of physical activity at baseline, 8 or 52 weeks, or by a better maintenance of the amount of physical activity during the diet and follow-up.

Average PAL $L_{\text {RMR }}$ values at baseline ( $\left.1.70 \pm 0.22\right)$ of the obese subjects were comparable to average values of the general population (6). This is in line with previous studies $(12,13)$, though contradictory to other studies (14-16).

Consequent to energy restriction and weight loss, all physical activity parameters measured and calculated, decreased significantly during 8 weeks of VLED. PAL, AEE, AEE/kg and activity counts per day all decreased significantly. These results are in line with results described in literature $(19-23,34)$. Studies, which do not agree, measured the physical activity in the confined space of a respiration chamber $(17,18)$. The recent study of Bonomi et al., where AEE was calculated with a doubly labeled water based prediction model including body weight and body movement to determine the independent contribution of the weight loss and of the change in body movement to the change in AEE, showed a similar decrease in AEE after weight loss despite a small increase in activity counts (23). The main difference of this study compared to our study was a two-week period of weight maintenance after the diet before the measurements of energy expenditure and physical activity. Thus, discrepancy in body movement could be explained by the negative energy balance at the end of 8 weeks VLED in our study.

During the 44 weeks of follow-up after the 8 weeks VLED, physical activity returned again to baseline values. PAL, AEE, AEE/kg and activity counts per day all increased significantly compared to 8 weeks and were not different from baseline values. This supports the results previously described by both Martin et al. and Redman et al. who showed an increase in PAL, three months after an energy restriction induced decrease in activity $(21,22)$.

These results suggest that energy restriction for a longer period induces a biologically meaningful survival mechanism which decreases physical activity in order to keep energy expenditure at a low level and conserve energy storages $(10,11)$. Adaptive thermogenesis, which is also seen during and after dieting, is also described as part of this adaptation of an organism in the face of starvation and dangerously low energy supplies (10, 11, 35-40). Differently from the sustained adaptive thermogenesis after 1 year, our results show that physical activity returns again to baseline after the energy restriction.

As shown, physical activity is spontaneously decreased during the diet and therefore the thought of increasing activity via exercise to improve the weight loss seems plausible. However, Wu et al showed in a meta-analysis that additional exercise will be compensated 
by a reduction of non-training activity (41). While energy restriction leads to a decrease of physical activity, most evidence suggests that overeating does not lead to an increase in physical activity $(29,42-46)$. Similarly, an exercise-induced increase in energy expenditure will lead to energy intake that compensates for the additional requirement, while change from a physically active to a more sedentary lifestyle does not induce an equivalent reduction of energy intake (47). These interactions implicate that eating less instead of moving more is the way to weight loss and the best method for weight maintenance is to prevent overeating. Additionally, there are studies that do imply an increase in physical activity in response to excess energy intake $(34,48)$. Levine et al. concluded that an increase in non-exercise activity thermogenesis is the principal mediator of resistance to fat gain with overfeeding. However, their accelerometer results were not consistent and did not show an increase in body movement after overfeeding. Rosenbaum et al. showed an increase in AEE divided through FFM (kg). Though, they did not take the increased FM into account and did not use the doubly labeled water technique to measure TEE.

A limitation of this study is that diet and physical activity were not standardized during the 44 weeks of follow-up. On the other hand, due to the absence of an advice on diet and physical activity, this study reflects achievements in free-living conditions. Another limitation of this study is generated by the large interindividual variation in activity between subjects. However, the significance of the results on the total group, proof the persistence of the adaptation of physical activity for average individuals. Another limitation of this study is no inclusion of lean subjects. Therefore no clear conclusion can be made on mean $\mathrm{PAL}_{\mathrm{RMR}}$ in the obese population compared to the lean population. Another limitation is that interpreting PAL values during weight changes may be affected by the effect of weight loss on RMR. However, there is no indication for a significant change in the results and moreover, PAL results are in line with the results expressed as AEE/ $\mathrm{kg}$ and with activity counts. One of the main strengths of this study is the use of the gold standard in measuring free-living TEE: doubly labeled water. Therefore, PAL, AEE and AEE/kg reflect the physical activity and energy expenditure in normal daily life and are not confounded by restrictions of body movement. A second strength is the use of two independent methods based on measurement of energy expenditure and body movement.

Because it includes changes in body weight and is based on the doubly labeled water method, AEE/kg is the favored parameter to express changes in the amount of physical activity in this study. However, other methods may be preferred if for example the contextual information or activity structure is the primary endpoint of the research (49).

For future research it would be interesting to look further into the adaptation of physical activity and investigate whether and how fast adaptation of physical activity will occur as a consequence to different levels of energy restriction.

In conclusion, our study shows that moderate weight loss induced by energy restriction leads to a large decrease in physical activity. However, physical activity returns to baseline levels when weight loss is maintained. 


\section{Acknowledgements}

K.R. Westerterp and S.P.M. Verhoef designed the study. S.G.J.A. Camps and S.P.M. Verhoef collected the data. S.G.J.A. Camps analyzed the data and wrote the manuscript. K.R. Westerterp contributed to the interpretation of the data and reviewed the manuscript. The study was executed under supervision of K.R. Westerterp. All authors read and approved the final manuscript. None of the authors had any conflict of interest. 


\section{References}

1. Catenacci VA, Hill JO, Wyatt HR. The obesity epidemic. Clin Chest Med 2009;30:415-44, vii.

2. Kraschnewski JL, Boan J, Esposito J, Sherwood NE, Lehman EB, Kephart DK, Sciamanna CN. Longterm weight loss maintenance in the United States. Int J Obes (Lond) 2010;34:1644-54.

3. Wing RR, Phelan S. Long-term weight loss maintenance. Am J Clin Nutr 2005;82:222S-225S.

4. Westerterp KR. Impacts of vigorous and non-vigorous activity on daily energy expenditure. Proc Nutr Soc 2003;62:645-50.

5. van Mil EA, Westerterp KR, Gerver WJ, Curfs LM, Schrander-Stumpel CT, Kester AD, Saris WH. Energy expenditure at rest and during sleep in children with Prader-Willi syndrome is explained by body composition. Am J Clin Nutr 2000;71:752-6.

6. Black AE, Coward WA, Cole TJ, Prentice AM. Human energy expenditure in affluent societies: an analysis of 574 doubly-labelled water measurements. Eur J Clin Nutr 1996;50:72-92.

7. Westerterp KR, Plasqui G. Physical activity and human energy expenditure. Curr Opin Clin Nutr Metab Care 2004;7:607-13.

8. Schoeller DA, Jefford G. Determinants of the energy costs of light activities: inferences for interpreting doubly labeled water data. Int J Obes Relat Metab Disord 2002;26:97-101.

9. Plasqui G, Westerterp KR. Physical activity assessment with accelerometers: an evaluation against doubly labeled water. Obesity (Silver Spring) 2007;15:2371-9.

10. Keys A. The residues of malnutrition and starvation. Science 1950;112:371-3.

11. Taylor HL, Keys A. Adaptation to caloric restriction. Science 1950;112:215-8.

12. Prentice AM, Black AE, Coward WA, Cole TJ. Energy expenditure in overweight and obese adults in affluent societies: an analysis of 319 doubly-labelled water measurements. Eur J Clin Nutr 1996;50:93-7.

13. Westerterp KR. Obesity and physical activity. Int J Obes Relat Metab Disord 1999;23 Suppl 1:59-64.

14. Martinez JA, Kearney JM, Kafatos A, Paquet S, Martinez-Gonzalez MA. Variables independently associated with self-reported obesity in the European Union. Public Health Nutr 1999;2:125-33.

15. Ball K, Owen N, Salmon J, Bauman A, Gore CJ. Associations of physical activity with body weight and fat in men and women. Int J Obes Relat Metab Disord 2001;25:914-9.

16. Ekelund U, Aman J, Yngve A, Renman C, Westerterp K, Sjostrom M. Physical activity but not energy expenditure is reduced in obese adolescents: a case-control study. Am J Clin Nutr 2002;76:935-41.

17. Ravussin E, Burnand B, Schutz Y, Jequier E. Energy expenditure before and during energy restriction in obese patients. Am J Clin Nutr 1985;41:753-9.

18. Levine JA, Lanningham-Foster LM, McCrady SK, Krizan AC, Olson LR, Kane PH, Jensen MD, Clark MM. Interindividual variation in posture allocation: possible role in human obesity. Science 2005;307:584-6.

19. de Groot LC, van Es AJ, van Raaij JM, Vogt JE, Hautvast JG. Adaptation of energy metabolism of overweight women to alternating and continuous low energy intake. Am J Clin Nutr 1989;50:131423.

20. Velthuis-te Wierik E, Westerterp K, van den Berg H. Impact of a moderately energy-restricted diet on energy metabolism and body composition in non-obese men. International journal of obesity and related metabolic disorders : journal of the International Association for the Study of Obesity 1995;19:318-324. 
21. Martin CK, Heilbronn LK, de Jonge L, DeLany JP, Volaufova J, Anton SD, Redman LM, Smith SR, Ravussin E. Effect of calorie restriction on resting metabolic rate and spontaneous physical activity. Obesity (Silver Spring) 2007;15:2964-73.

22. Redman LM, Heilbronn LK, Martin CK, de Jonge L, Williamson DA, Delany JP, Ravussin E. Metabolic and behavioral compensations in response to caloric restriction: implications for the maintenance of weight loss. PLoS One 2009;4:e4377.

23. Bonomi AG, Soenen S, Goris AH, Westerterp KR. Weight-Loss Induced Changes in Physical Activity and Activity Energy Expenditure in Overweight and Obese Subjects before and after Energy Restriction. PLoS One 2013;8:e59641.

24. Schoffelen PF, Westerterp KR, Saris WH, Ten Hoor F. A dual-respiration chamber system with automated calibration. J Appl Physiol 1997;83:2064-72.

25. Adriaens MP, Schoffelen PF, Westerterp KR. Intra-individual variation of basal metabolic rate and the influence of daily habitual physical activity before testing. Br J Nutr 2003;90:419-23.

26. Brouwer E. On simple formulae for calculating the heat expenditure and the quantities of carbohydrate and fat oxidized in metabolism of men and animals, from gaseous exchange (Oxygen intake and carbonic acid output) and urine-N. Acta Physiol Pharmacol Neerl 1957;6:795-802.

27. Westerterp KR, Wouters L, van Marken LichtenbeltWD. The Maastricht protocol for the measurement of body composition and energy expenditure with labeled water. Obes Res 1995;3 Suppl 1:49-57.

28. Black A, Prentice A, Coward W. Use of food quotients to predict respiratory quotients for the doublylabelled water method of measuring energy expenditure. Human nutrition. Clinical nutrition 1986;40:381-391.

29. Westerterp KR. Physical activity, food intake, and body weight regulation: insights from doubly labeled water studies. Nutr Rev 2010;68:148-54.

30. Bonomi AG, Plasqui G, Goris AH, Westerterp KR. Estimation of free-living energy expenditure using a novel activity monitor designed to minimize obtrusiveness. Obesity (Silver Spring);18:1845-51.

31. Bonomi AG, Plasqui G, Goris AH, Westerterp KR. Improving assessment of daily energy expenditure by identifying types of physical activity with a single accelerometer. J Appl Physiol 2009;107:65561.

32. Ginde SR, Geliebter A, Rubiano F, Silva AM, Wang J, Heshka S, Heymsfield SB. Air displacement plethysmography: validation in overweight and obese subjects. Obes Res 2005;13:1232-7.

33. Dempster P, Aitkens S. A new air displacement method for the determination of human body composition. Med Sci Sports Exerc 1995;27:1692-7.

34. Rosenbaum M, Vandenborne K, Goldsmith R, Simoneau JA, Heymsfield S, Joanisse DR, Hirsch J, Murphy E, Matthews D, Segal KR, et al. Effects of experimental weight perturbation on skeletal muscle work efficiency in human subjects. Am J Physiol Regul Integr Comp Physiol 2003;285:R18392.

35. Doucet E, St-Pierre S, Almeras N, Despres JP, Bouchard C, Tremblay A. Evidence for the existence of adaptive thermogenesis during weight loss. Br J Nutr 2001;85:715-23.

36. Leibel RL, Rosenbaum M, Hirsch J. Changes in energy expenditure resulting from altered body weight. N Engl J Med 1995;332:621-8.

37. van Gemert WG, Westerterp KR, Greve JW, Soeters PB. Reduction of sleeping metabolic rate after vertical banded gastroplasty. Int J Obes Relat Metab Disord 1998;22:343-8.

38. Tremblay A, Chaput JP. Adaptive reduction in thermogenesis and resistance to lose fat in obese men. Br J Nutr 2009;102:488-92. 
39. Camps SG, Verhoef SP, Westerterp KR. Weight loss, weight maintenance, and adaptive thermogenesis. Am J Clin Nutr 2013;97:990-4.

40. Rosenbaum M, Goldsmith R, Bloomfield D, Magnano A, Weimer L, Heymsfield S, Gallagher D, Mayer L, Murphy E, Leibel RL. Low-dose leptin reverses skeletal muscle, autonomic, and neuroendocrine adaptations to maintenance of reduced weight. J Clin Invest 2005;115:3579-86.

41. Wu T, Gao X, Chen M, van Dam R. Long-term effectiveness of diet-plus-exercise interventions vs. diet-only interventions for weight loss: a meta-analysis. Obesity reviews : an official journal of the International Association for the Study of Obesity 2009;10:313-323.

42. Joosen AM, Westerterp KR. Energy expenditure during overfeeding. Nutr Metab (Lond) 2006;3:25.

43. Roberts SB, Young VR, Fuss P, Fiatarone MA, Richard B, Rasmussen H, Wagner D, Joseph L, Holehouse E, Evans WJ. Energy expenditure and subsequent nutrient intakes in overfed young men. Am J Physiol 1990;259:R461-9.

44. DiazEO, Prentice AM, Goldberg GR, Murgatroyd PR, Coward WA. Metabolic response to experimental overfeeding in lean and overweight healthy volunteers. Am J Clin Nutr 1992;56:641-55.

45. Joosen AM, Bakker AH, Westerterp KR. Metabolic efficiency and energy expenditure during shortterm overfeeding. Physiol Behav 2005;85:593-7.

46. Siervo M, Fruhbeck G, Dixon A, Goldberg GR, Coward WA, Murgatroyd PR, Prentice AM, Jebb SA. Efficiency of autoregulatory homeostatic responses to imposed caloric excess in lean men. Am J Physiol Endocrinol Metab 2008;294:E416-24.

47. Stubbs RJ, Hughes DA, Johnstone AM, Horgan GW, King N, Blundell JE. A decrease in physical activity affects appetite, energy, and nutrient balance in lean men feeding ad libitum. Am J Clin Nutr 2004;79:62-9.

48. Levine JA, Eberhardt NL, Jensen MD. Role of nonexercise activity thermogenesis in resistance to fat gain in humans. Science 1999;283:212-4.

49. Westerterp KR. Assessment of physical activity: a critical appraisal. Eur J Appl Physiol 2009;105:8238. 





Physical activity and weight loss are independent predictors of improved insulin sensitivity following energy restriction 


\section{Abstract}

\section{Background}

Low physical activity and short and long sleeping times are associated with a higher risk of developing obesity and concomitantly insulin resistance.

\section{Objective}

To determine the role of physical activity and the joint effect with sleep duration on insulin sensitivity during energy restriction followed by weight maintenance.

\section{Design}

102 subjects (28 males) [mean \pm SD age: $40 \pm 9$ y; body mass index (BMI; in kg/m²): $31.9 \pm 3.0$ ]. They followed a very low energy diet for 8 weeks, followed by a 44-week period of weight maintenance. Body composition (three-compartment model based on body weight, total body water and body volume), physical activity (tri-axial accelerometer), sleep (questionnaire, Epworth Sleepiness Scale), and fasting plasma insulin and glucose concentrations were assessed before the diet and 8, 20 and 52 weeks after the start of the diet.

\section{Results}

Body mass decreased significantly during the diet-period $(10 \pm 4 \%, \mathrm{P}<0.01)$ and this reduction was sustained after 20 weeks $(9 \pm 4 \%, P<0.01)$ and 52 weeks $(6 \pm 5 \%, P<0.01)$ compared to baseline. Insulin sensitivity improved significantly after 8 weeks compared to before the diet $(P<0.001)$. Compared to baseline, insulin sensitivity was significantly higher after 20 weeks $(P<0.001)$ and 52 weeks $(P<0.05)$. After 8, 20 weeks and 52 weeks, respectively 23\% $(P<0.01), 19 \%(P<0.05)$ and $13 \%(P<0.05)$ of the variance in insulin sensitivity improvement was explained by weight loss percentage and change in activity counts; the change in sleep duration had no predictive value.

\section{Conclusions}

Maintaining total daily activity during energy restriction is as important as weight loss itself in the improvement of insulin sensitivity, while there was no additional effect of change in sleep duration. During weight maintenance, improved insulin sensitivity is maintained better if physical activity returns to baseline or higher. 


\section{Introduction}

The increasing prevalence of obesity and its association with an impaired insulin homeostasis are major health problems in our modern world $(1,2)$; both are linked closely to the development of non-communicable diseases as type 2 diabetes and cardiovascular diseases $(3,4)$. Overweight and obesity are characterized by the accumulation of excessive fat mass and more free fatty acids in the blood which can lead to an impaired glucose metabolism and a reduced insulin sensitivity (5). Independent from adiposity, physical inactivity or increased length of time without movement, merely a reduction in body movement and not in activity induced energy expenditure is associated with a reduced clearance of free fatty acids and ingested glucose and less glucose-stimulated insulin secretion, increasing the risk for type 2 Diabetes (6-8). Short and long sleep duration are associated with an increased risk for insulin insensitivity (9-16) and although several mechanisms have been proposed, the relationship with physical activity might be pivotal as short and long sleep duration decrease daytime physical activity (16-21).

Losing weight and increasing physical activity independently have a beneficial effect on the glucose metabolism and insulin sensitivity (22-28). However, the addition of aerobic or resistance exercise training to a diet does not enhance the reductions in plasma insulin and glucose levels induced by weight loss (29-33). On the other hand, increasing physical activity in overweight or obese subjects improves insulin sensitivity in the absence of weight loss (34-36). The ambiguous results can be explained by the fact that energy restriction leads to a decrease in physical activity $(37,38)$ and that additional exercise training to an energy restricted diet will often be compensated by a reduction of non-training activity (39).

While physical activity and sleep have been studied separately in relation to insulin sensitivity, little is known about the interaction of sleep and physical activity with insulin sensitivity. Recently, Zuo et al showed that mainly occupational physical activity was negatively associated with insulin resistance and that there was a synergistic effect of low physical activity and short sleep duration on insulin sensitivity (40).

The primary aim of this study was to determine the role of physical activity on insulin sensitivity during energy restriction followed by weight maintenance and secondly the joint effect of sleep duration and physical activity. It was hypothesized that maintaining body movement during energy restriction increases insulin sensitivity and moreover that there is a synergistic effect of physical activity and sleep duration on insulin sensitivity during weight loss and weight maintenance on top of the effect of weight loss itself. Therefore, physical activity, sleep duration, fasting glucose and insulin were measured before and after a very low energy diet (VLED) and during 44 weeks of follow-up. 


\section{Subjects and Methods}

\section{Subjects}

One-hundred two healthy subjects (74 women and 28 men) with a mean age of $40 \pm 9$ years and with a mean body mass index (BMI) of $31.9 \pm 3.0 \mathrm{~kg} / \mathrm{m}^{2}$ were recruited by advertisements in local newspapers and on notice boards at the university. They underwent an initial screening that included measurements of body weight and height and the completion of a questionnaire on general health. All were in good health, not using medication (except for contraception), nonsmokers and at most moderate alcohol consumers. They were relatively weight stable as defined by a weight change $<5 \mathrm{~kg}$ for at least 3 months prior to the study. The study was conducted according to the guidelines laid down in the Declaration of Helsinki and procedures were approved by the Ethics Committee of the Maastricht University Medical Centre. Written informed consent was obtained from all participants. This trial was registered at www.clinicaltrials.gov as NCT01015508.

\section{Study design}

The study covered a full year, starting with a very low energy diet (VLED) for 8 weeks, followed by a 44-week period of weight maintenance (Figure 4.1). Subjects came to the university for measurements on four occasions: the day before the start of the diet (baseline), 8 weeks after the start of the diet (end of the diet), 20 weeks after the start of the diet and 52 weeks after the start of the diet. On each occasion, measurements included body composition, the collection of fasting blood and sleep-questionnaires and were performed from 08.00 in the morning onwards with subjects in a fasted state. Two weeks prior to each measurement day, subjects received an accelerometer to measure physical activity. Subjects were instructed to maintain their newly achieved body weight without specific dietary, activity or sleep instructions.

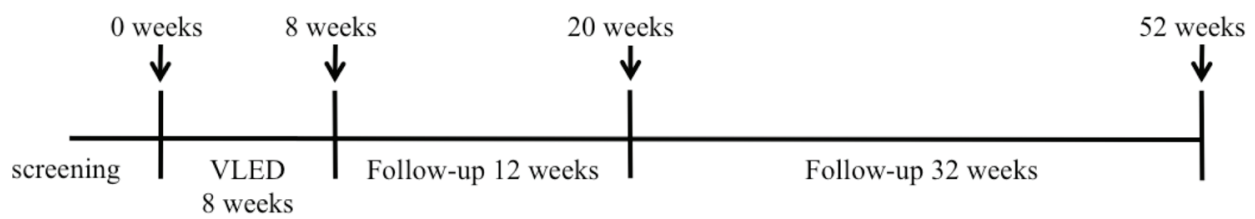

Figure 4.1: Flow chart of the 52-weeks program the subjects followed; the measurement points are indicated. VLED: very-low-energy diet.

\section{Diet}

The weight loss diet (Modifast; Nutrition et Santé Benelux, Breda, The Netherlands) was followed for a period of 8 weeks. The diet was a protein-enriched formula that provided 2.1 
MJ/day (51.9 grams of protein, 50.2 grams of Carbohydrates and 6.9 grams of Lipids) and a micronutrient content, which meets the Dutch recommended daily allowance. The VLED was provided to the subjects as sachets with powder. Each sachet represented one meal and 3 sachets were consumed every day. Besides the provided meal-replacements, subjects were allowed to eat vegetables when feeling hungry with the exception of starchy vegetables and legumes, which are relatively high in energy density like potatoes and beans. Subjects were instructed to mix the powder with the amount of water indicated on the packages and were advised to drink water sufficiently throughout the diet period.

\section{Body Composition}

Height was measured at screening to the nearest $0.1 \mathrm{~cm}$ with the use of a wall-mounted stadiometer (model 220; Seca, Hamburg, Germany). Body composition was determined according to Siri's three-compartment model based on body weight, body volume and total body water (41). Body weight was measured using a calibrated scale (Life Measurement Corporation, Inc, Concord, CA, USA). Body volume was measured via air-displacement plethysmography with the BodPod System (Life Measurement Corporation, Inc, Concord, CA, USA) (42). The average thoracic gas volume was measured by the BodPod by using a standard plethysmographic technique (43). Total body water was determined using deuterium dilution during the preceding night, according to the Maastricht protocol (44). The calculation of total body water from isotope decay involves assumptions on the isotope dilution spaces for ${ }^{2} \mathrm{H}$, in this case a fixed ratio based on the population mean of the study group as suggested by Speakman et al (45). Body mass index (BMI) was calculated by dividing body weight by height squared $\left(\mathrm{kg} / \mathrm{m}^{2}\right)$.

\section{Physical activity monitoring}

Physical activity was monitored in two-week intervals using the previously validated Tracmor triaxial accelerometer (DirectLife, Philips Consumer Lifestyle) (46). The device is small and lightweight and was carried at an elastic belt around the waist. Subjects were instructed to wear the accelerometer during waking hours, except during showering and water activities. A diary was used to report periods in which the subject was not wearing the accelerometer during the day to check for missing data and wearing time. The accelerometer output was processed to determine body movement by force and duration, and not energy expenditure, by measuring activity counts. Total activity counts were calculated over the two-week monitoring period, and the sum of counts was divided by the number of monitoring days to determine the average activity counts per day (46). Days during which data were missing or subjects carried the accelerometer for $<10 \mathrm{~h}$ were excluded and the average was calculated on the remaining data, considering daily physical activity an ergodic process. Subjects with less than seven days would have been excluded, however all subjects met these criteria and non were excluded. 


\section{Sleep}

Questionnaires were used to assess sleep duration and daytime sleepiness. For sleep duration the question was: 'How many hours do you usually sleep per night during week days?' and 'How many hours do you usually sleep during weekend days?'. A total weekly sleep score was calculated as follows: [(hours sleep week days $\times 5$ ) + (hours sleep weekend days $\times 2$ ) / 7] (18). Subjects with between 7 and 9 hours of sleep (average sleepers) were included to exclude very short and very long sleepers (12). Daytime sleepiness was assessed through the Epworth Sleepiness Scale (ESS). Subjects rated the likelihood of falling asleep in eight specific situations on a 0-3 scale, with 0 meaning no chance at all to fall asleep and 3 meaning a high chance of falling asleep. The total score can range from 0 to 24 , with a score of 10 or higher suggesting excessive daytime sleepiness (47).

\section{Biochemical analysis}

Blood was collected into EDTA-containing tubes and centrifuged (1000 $\times \mathrm{g}, 10 \mathrm{~min}, 4^{\circ} \mathrm{C}$ ), and the plasma was immediately frozen in liquid nitrogen and stored at $-80^{\circ} \mathrm{C}$ until analysis. Plasma glucose concentration was analyzed enzymatically on a Cobas Mira automated spectrophotometer (Roche Diagnostica). Plasma insulin was measured with a doubleantibody radioimmunoassay (Insulin RIA 100, Kabi-Pharmacia, Uppsala, Sweden). Insulin sensitivity was assessed by the homeostasis model assessment index for insulin resistance $\left(\mathrm{HOMA}_{\mathbb{R}}\right)$, calculated as [plasme glucose $(\mathrm{mmol} / \mathrm{l})$ times plasma insulin $(\mathrm{mU} / \mathrm{l})$ ] divided by $22.5(48)$.

\section{Calculations and statistical analysis}

One-way repeated measures ANOVA with Bonferroni adjustment for multiple comparisons were used to compare the results across 0, 8, 20 and 52 weeks. Linear and multiple hierarchical regression analysis have been performed independently for each time point to determine relations and interactions between dependant and independent variables. Collinearity diagnostics as part of the multiple regression procedure were performed to check for problems with multicollinearity between the independent variables. Tolerance values were not below 0.8 and variance inflation factor (VIF) values were not higher than 1.2, indicating there was no problem of collinearity. Age and gender were used as covariates in all tests. The data were analyzed using SPSS 20.0 (SPSS, Inc., Chicago, IL, USA). All data are presented as means \pm standard deviations (SDs). 


\section{Results}

\section{Body composition}

After the 8 weeks of VLED, weight loss was on average $9.4 \pm 4.2 \mathrm{~kg}(P<0.001)$ consisting of 7.6 $\pm 3.3 \mathrm{~kg}$ of fat mass (FM) and $1.8 \pm 2.2 \mathrm{~kg}$ of fat free mass (FFM). After 20 and 52 weeks, there was a significant average weight loss compared to baseline, respectively $8.4 \pm 4.9 \mathrm{~kg}(P<0.001)$ and $5.9 \pm 4.9 \mathrm{~kg}(\mathrm{P}<0.001)$. Weight loss after 52 weeks was significantly less compared to 8 and 20 weeks $(P<0.05)$. After 20 weeks, this was $7.7 \pm 4.6 \mathrm{~kg}$ of FM and $0.7 \pm 2.0 \mathrm{~kg}$ of FFM and after 52 weeks $5.6 \pm 5.2 \mathrm{~kg}$ of FM and $0.3 \pm 2.0 \mathrm{~kg}$ of FFM. As a percentage of the starting weight, subjects lost on average $10.2 \pm 4.1 \%$ ( $P<0.001$ ). After 20 weeks, weight loss was 9.1 $\pm 5.0 \%(P<0.001)$ and weight loss was still $6.2 \pm 6.1 \%$ after 52 weeks compared to baseline $(P<0.001)$. FM decreased from $41.8 \pm 6.3 \%$ to $37.3 \pm 7.5 \%$ ( $P<0.001)$. After 20 and 52 weeks, FM was significantly lower compared to baseline, respectively $36.8 \pm 7.6 \%(P<0.001)$ and $38.3 \pm$ $6.5 \%(P<0.001)$. The data showed a large inter-individual variation in weight loss, indicating a difference in the success of weight loss and of maintaining the lost weight. In addition, the variation in weight loss and weight maintenance was not explained by different levels of physical activity or sleep duration at baseline, 8, 20 or 52 weeks, or by a better maintenance of the amount of physical activity during the diet and follow-up.

\section{Glucose/insulin homeostasis}

Fasting glucose concentration at baseline was on average $4.9 \pm 0.4 \mathrm{mmol} / \mathrm{l}$ and did not change after 8,20 and 52 weeks with values of respectively $4.8 \pm 0.4,4.9 \pm 0.4$ and $5.0 \pm 0.4 \mathrm{mmol} / \mathrm{l}$.

Fasting insulin concentration decreased from $17.0 \pm 6.7 \mathrm{mU} / \mathrm{l}$ at baseline to $11.7 \pm 4.9 \mathrm{mU} / \mathrm{l}$ after 8 weeks of VLED $(P<0.001)$. After 20 weeks, fasting insulin concentration did not change compared to 8 weeks with an average value of $11.9 \pm 4.7 \mathrm{mU} / \mathrm{l}$ and was still significantly lower compared to baseline $(\mathrm{P}<0.001)$. After 52 weeks, fasting insulin concentration did not change significantly compared to 8 weeks with an average value of $13.7 \pm 7.2 \mathrm{mU} / \mathrm{l}$, and was still significantly lower compared to baseline $(P<0.05)$.

$\mathrm{HOMA}_{\mathbb{R}}$ decreased from $3.7 \pm 1.6$ at baseline to $2.5 \pm 1.2$ after 8 weeks of $\mathrm{VLED}(\mathrm{P}<0.001)$. After 20 weeks, $\mathrm{HOMA}_{\mathbb{R}}$ did not change significantly compared to 8 weeks with an average value of $2.6 \pm 1.1$ and was still significantly lower compared to baseline $(P<0.001)$. After 52 weeks, HOMA $A_{\mathbb{R}}$ was still significantly lower compared to baseline with an average value of 3.0 $\pm 1.7(P<0.01)$, however, the value was higher compared to 8 weeks $(P<0.01)$.

\section{Physical activity}

Activity was on average $1.63 \pm 0.36$ Mcounts/d at baseline and decreased to $1.56 \pm 0.45$ Mcounts/d $(P<0.05)$ after 8 weeks of energy restriction. After 20 weeks, activity increased significantly to $1.65 \pm 0.43$ Mcounts/d compared to 8 weeks $(P<0.01)$. There was no significant 
difference between baseline and 20 weeks. After 52 weeks, activity increased significantly to $1.66 \pm 0.52$ Mcounts/d compared to 8 weeks $(P<0.01)$. There was no significant difference between baseline and 52 weeks.

\section{Sleep duration}

Average sleep duration at baseline was on average $8.1 \pm 0.6 \mathrm{~h} /$ day and increased significantly to $8.4 \pm 0.7 \mathrm{~h} /$ day after weight loss $(\mathrm{P}<0.05)$. After 20 weeks and 52 weeks, average sleep duration was respectively $8.3 \mathrm{~h} /$ day and $8.2 \mathrm{~h} /$ day; this was not significantly different from baseline or 8 weeks. Moreover, after 8 weeks there was a significant negative correlation between change in body weight and the change in average hours sleep $\left(R^{2}=0.04, P<0.05\right)$.

\section{Interaction}

Regression analysis revealed that baseline $\mathrm{HOMA}_{\mathrm{IR}}$ explained almost $40 \%(\mathrm{P}<0.001)$ of the variance in the decrease in $\mathrm{HOMA}_{\mathbb{R}}$ after weight loss. Furthermore, after 20 and 52 weeks, respectively $49 \%(\mathrm{P}<0.001)$ and $23 \%(\mathrm{P}<0.01)$ of the variance in the change in $\mathrm{HOMA}_{\mathbb{R}}$ was explained by the baseline value of $\mathrm{HOMA}_{\mathbb{I R}}$.

Besides baseline $\mathrm{HOMA}_{\mathbb{R}}$, the regression model combining age, gender, change in body weight, change in sleep duration and change in physical activity counts explained an additional 23\% $(P<0.01)$ of the variance in the change in $\mathrm{HOMA}_{\mathbb{R}}$ after 8 week of VLED. The independent contributions of change in body weight $\left(R^{2}=0.08, P<0.01\right)$ and the change in activity counts $\left(R^{2}=0.14\right.$. $\left.P<0.01\right)$ were statistically significant (Figure 4.2).

Table 4.1: Multiple regression results of a model combining gender, age, weight loss percentage, activity counts change and hours sleep change to predict changes in insulin resistance after 8, 20 and 52 weeks.

\begin{tabular}{|c|c|c|c|}
\hline & Beta; 8 weeks & Beta; 20 weeks & Beta; 52 weeks \\
\hline Gender & 0.016 & -0.26 & -0.072 \\
\hline Age & 0.032 & 0.160 & 0.019 \\
\hline Weight loss \% & $0.283^{*}$ & $0.262^{*}$ & $0.273^{*}$ \\
\hline Counts change & $-0.376^{\star \star}$ & $-0.298^{*}$ & -0.217 \\
\hline Hours sleep change & -0.094 & 0.066 & -0.042 \\
\hline Baseline $\mathrm{HOMA}_{\mathbb{R}}$ & $-0.631^{* \star *}$ & $-0.699^{\star \star *}$ & $-0.480^{\star *}$ \\
\hline Total R²-value & $0.63^{* * *}$ & $0.68^{* * *}$ & $0.36^{* *}$ \\
\hline
\end{tabular}

Hierarchical multiple regression analysis was used to analyze the effect on insulin sensitivity of a model combining: gender, age, weight loss percentage, activity counts change and hours sleep change. Standardized Beta-values are shown for each individual parameter and for the total model at 8, 20 and 52 weeks. In the bottom row, the total $\mathrm{R}^{2}$-value for the model combining all parameters are shown for 8, 20 and 52 weeks. Significance is indicated with symbol * $\left({ }^{*} \mathrm{P}<0.05,{ }^{* *} \mathrm{P}<0.01,{ }^{* * *} \mathrm{P}<0.001\right)$.

$\mathrm{HOMA}_{\mathbb{I R}}:$ homeostasis model assessment index for insulin resistance 
After 20 weeks, the regression model explained an additional 19\% ( $P<0.05)$ of the variance in the change of $\mathrm{HOMA}_{\mathbb{R}}$ besides baseline $\mathrm{HOMA}_{\mathbb{R}}$, with significant independent contributions of change in body weight $\left(R^{2}=0.07, P<0.05\right)$ and the change in activity counts $\left(R^{2}=0.09, P<0.05\right)$.

After 52 weeks, the regression model explained an additional 13\% $(P<0.05)$ of the variance in the change of $\mathrm{HOMA}_{\mathbb{R}}$ on top of the explained variance by baseline $\mathrm{HOMA}_{\mathbb{R}}$; with a significant independent contribution of change in body weight $\left(R^{2}=0.08, P=0.05\right)$. There was a trend for a significant contribution of change in activity counts $\left(R^{2}=0.05, P=0.10\right)$ (Table 4.1). The decrease in explained variation after 52 weeks is due to the increased variance and increased influences from variables that were not controlled for during follow-up.

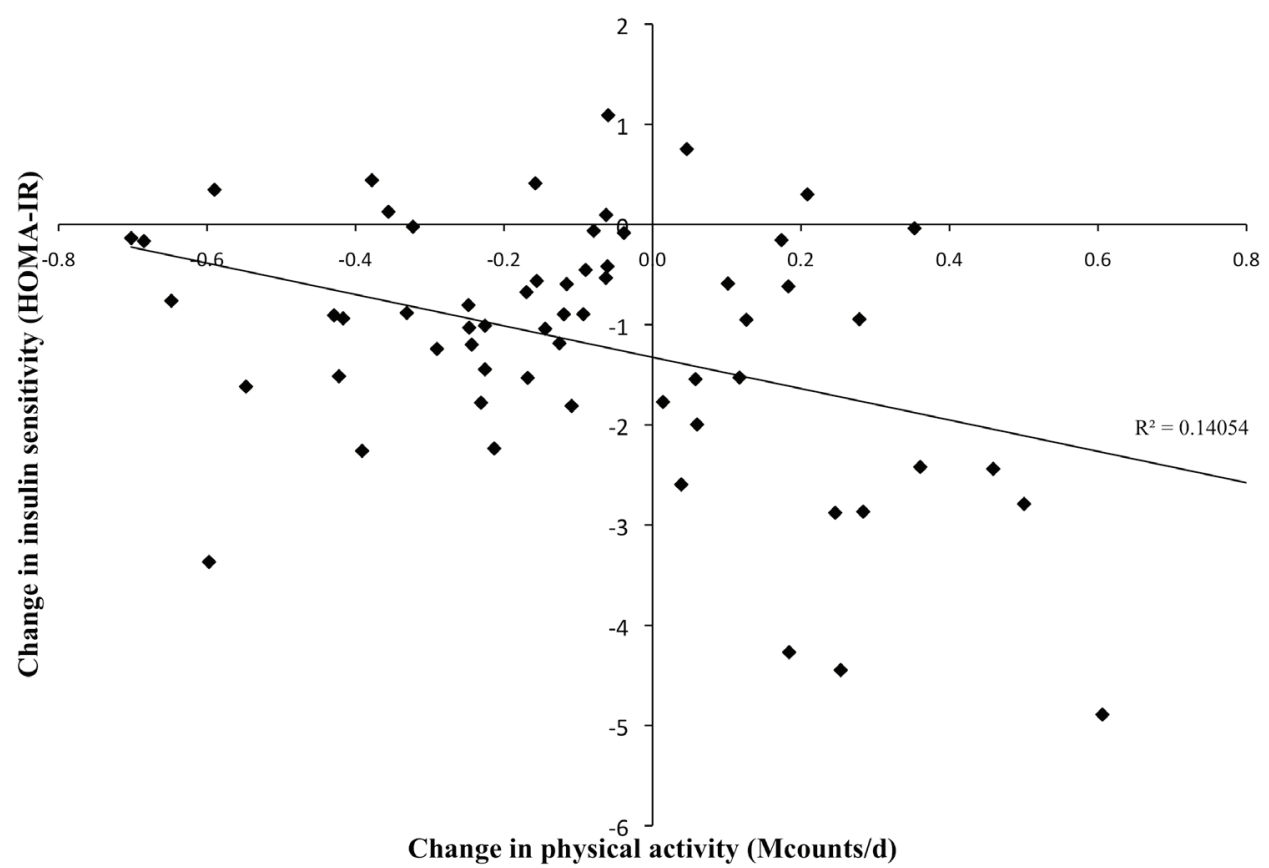

Figure 4.2: Correlation of the change in insulin sensitivity $\left(\mathrm{HOMA}_{\mathbb{R}}\right)$ against the change in physical activity (Mcounts/d) after 8 weeks of VLED $\left(R^{2}=0.14, P<0.01\right)$.

$\mathrm{HOMA}_{\mathbb{R}}$ : homeostasis model assessment index for insulin resistance

VLED: very low energy diet 


\section{Discussion}

Measurements of physical activity, sleep duration, fasting glucose and insulin before and after a very low energy diet (VLED) and during 44 weeks (week 52) of follow-up showed that the improvement in insulin sensitivity is mostly dependent on the amount of weight loss and total daily activity and not on sleep duration. During the weight loss phase, to improve insulin sensitivity, maintaining physical activity is as important as weight loss itself.

These results confirm the improvement of insulin sensitivity as a result of energy restriction $(22,23)$ and indicate that maintaining physical activity or a smaller decrease in physical activity during weight loss is beneficial for the glucose metabolism on top of the weight loss solely which is in line with prior studies showing that physical activity improves insulin sensitivity (24-28). On average, the results show a decrease in physical activity during energy restriction, which is also seen in previous studies $(37,38)$. However, this study now points out that avoiding or minimizing the decrease in physical activity during energy restriction has a beneficial effect on insulin sensitivity improvement during weight loss. Furthermore, after 20 weeks, subjects who show a return to baseline activity or higher maintain more improved insulin sensitivity compared to subjects who retain a lower daily physical activity. These results seem contradictory to studies that show no effect of additional aerobic or resistance training to a diet on insulin sensitivity (29-33). However, previous studies have shown that energy restriction leads to a decrease in physical activity $(37,38)$ and that additional exercise during a diet will be compensated by a reduction of non-training activity (39). Since extra training will often be compensated, it seems of great importance to track daily physical activity patterns, which can be measured using portable accelerometers (49) to avoid more sedentariness during weight loss.

During 44 weeks of follow-up after the VLED, insulin sensitivity improvement was maintained; $\mathrm{HOMA}_{\mathbb{R}}$ decreased from a baseline of $3.7 \pm 1.6$ to $3.0 \pm 1.7$ after 44 weeks of follow-up $(\mathrm{P}<0.01)$. The improvement was a function of weight loss and physical activity, however the contribution decreased over time. In addition to their influence in, a large part of the variance in improvement of insulin sensitivity at 8, 20 and 52 weeks was explained by insulin sensitivity at baseline, which showed that a greater improvement was reached in subjects with a lower initial insulin sensitivity (Table 4.1). The results during follow-up are in line with higher insulin sensitivity during weight loss maintenance $(50,51)$ and with more physical activity (24-28). The sustained improved insulin sensitivity after 44 weeks despite the partial weight regain is in accordance with previous results (52-54).

Sleep duration was increased after 8 weeks of energy restriction as observed before (55). Sleeping longer was significantly related to a higher percentage weight loss. This could mean that people sleeping longer lose more weight, or that people losing more weight sleep longer. However, during 44 weeks of follow-up, sleep duration returned to baseline values while weight loss was maintained. This would indicate that the negative energy balance 
caused the increased sleep duration and not the other way around. Increasing sleep duration could be a way to reduce energy expenditure.

A limitation of this study is that diet and physical activity were not standardized during the 44-week follow-up. On the other hand, due to the absence of advice on diet and physical activity, this study reflects achievements in free-living conditions. Additionally, physical activity was measured objectively with accelerometers. Future research could focus on the influence of the amount of high, medium and low physical activity to gain more insight in what is beneficial for insulin sensitivity during weight loss, besides total daily activity. Another limitation is the use of self-reported sleep durations, although previous studies have shown a good agreement between self-reported and measured sleep duration $(56,57)$. The authors notice that $\mathrm{HOMA}_{\mathbb{R}}$ may not be the best measure for insulin sensitivity; still, it is a very useful approach in a longitudinal approach. The observed interindividual variation in the results allowed changes in insulin sensitivity to be correlated to a wide range from successful to unsuccessful weight maintenance. At the same time, the observed variation in the change of physical activity and sleep duration allowed us to correlate these variables over a wide range with insulin sensitivity. One of the major advantages with regard to other studies was the longitudinal approach in which an 8-week VLED was followed by a 44-week follow-up, to investigate the interaction between physical activity, sleep duration and insulin sensitivity during weight loss and weight maintenance.

In conclusion, the study shows that the improvement in insulin sensitivity is mostly dependent on the amount of weight loss and the quantity of total daily activity and not on sleep duration. During the weight loss phase, to improve insulin sensitivity, maintaining daily activity is as important as weight loss itself. Furthermore, during weight maintenance, improved insulin sensitivity is maintained better if physical activity returns to baseline or higher.

\section{Acknowledgements}

K.R. Westerterp and S.P.M. Verhoef designed the study. S.G.J.A. Camps and S.P.M. Verhoef collected the data. S.G.J.A. Camps analyzed the data and wrote the manuscript. K.R. Westerterp contributed to the interpretation of the data and reviewed the manuscript. The study was executed under supervision of K.R. Westerterp. All authors read and approved the final manuscript. None of the authors had any conflict of interest. 


\section{References}

1 Catenacci VA, Hill JO, Wyatt HR. The obesity epidemic. Clin Chest Med 2009;30:415-44, vii.

2 Shaw JE, Sicree RA, Zimmet PZ. Global estimates of the prevalence of diabetes for 2010 and 2030. Diabetes Res Clin Pract 2009;87:4-14.

3 Lorenzo C, Wagenknecht LE, D’Agostino RB, Jr., Rewers MJ, Karter AJ, Haffner SM. Insulin resistance, beta-cell dysfunction, and conversion to type 2 diabetes in a multiethnic population: the Insulin Resistance Atherosclerosis Study. Diabetes Care 2010;33:67-72.

4 Smith JD, Borel AL, Nazare JA, et al. Visceral adipose tissue indicates the severity of cardiometabolic risk in patients with and without type 2 diabetes: results from the INSPIRE ME IAA study. J Clin Endocrinol Metab 2012;97:1517-25.

5 Strasser B. Physical activity in obesity and metabolic syndrome. Ann N Y Acad Sci 2013;1281:14159.

6 Dunstan DW, Salmon J, Healy GN, et al. Association of television viewing with fasting and 2-h postchallenge plasma glucose levels in adults without diagnosed diabetes. Diabetes Care 2007;30:516-22.

7 Ford ES, Li C, Zhao G, Pearson WS, Tsai J, Churilla JR. Sedentary behavior, physical activity, and concentrations of insulin among US adults. Metabolism 2010;59:1268-75.

8 Thorp AA, Healy GN, Owen N, et al. Deleterious associations of sitting time and television viewing time with cardiometabolic risk biomarkers: Australian Diabetes, Obesity and Lifestyle (AusDiab) study 2004-2005. Diabetes Care 2010;33:327-34.

9 Chaput JP, Despres JP, Bouchard C, Astrup A, Tremblay A. Sleep duration as a risk factor for the development of type 2 diabetes or impaired glucose tolerance: analyses of the Quebec Family Study. Sleep Med 2009;10:919-24.

10 Grandner MA, Drummond SP. Who are the long sleepers? Towards an understanding of the mortality relationship. Sleep Med Rev 2007;11:341-60.

11 Patel SR. Reduced sleep as an obesity risk factor. Obes Rev 2009;10 Suppl 2:61-8.

12 Chaput JP, Despres JP, Bouchard C, Tremblay A. The association between sleep duration and weight gain in adults: a 6-year prospective study from the Quebec Family Study. Sleep 2008;31:51723.

13 Patel SR, Malhotra A, White DP, Gottlieb DJ, Hu FB. Association between reduced sleep and weight gain in women. Am J Epidemiol 2006;164:947-54.

14 Gonnissen HK, Adam TC, Hursel R, Rutters F, Verhoef SP, Westerterp-Plantenga MS. Sleep duration, sleep quality and body weight: Parallel developments. Physiol Behav 2013.

15 Andersson S, Ekman I, Friberg F, Bog-Hansen E, Lindblad U. The association between self-reported lack of sleep, low vitality and impaired glucose tolerance: a Swedish cross-sectional study. BMC Public Health 2013;13:700.

16 Tuomilehto H, Peltonen M, Partinen M, et al. Sleep duration, lifestyle intervention, and incidence of type 2 diabetes in impaired glucose tolerance: The Finnish Diabetes Prevention Study. Diabetes Care 2009;32:1965-71.

17 Yaggi HK, Araujo AB, McKinlay JB. Sleep duration as a risk factor for the development of type 2 diabetes. Diabetes Care 2006;29:657-61. 
18 Garaulet M, Ortega FB, Ruiz JR, et al. Short sleep duration is associated with increased obesity markers in European adolescents: effect of physical activity and dietary habits. The HELENA study. Int J Obes (Lond) 2011;35:1308-17.

19 Schmid SM, Hallschmid M, Jauch-Chara K, et al. Short-term sleep loss decreases physical activity under free-living conditions but does not increase food intake under time-deprived laboratory conditions in healthy men. Am J Clin Nutr 2009;90:1476-82.

20 Tasali E, Leproult R, Spiegel K. Reduced sleep duration or quality: relationships with insulin resistance and type 2 diabetes. Prog Cardiovasc Dis 2009;51:381-91.

21 Gottlieb DJ, Punjabi NM, Newman AB, et al. Association of sleep time with diabetes mellitus and impaired glucose tolerance. Arch Intern Med 2005;165:863-7.

22 Olefsky J, Reaven GM, Farquhar JW. Effects of weight reduction on obesity. Studies of lipid and carbohydrate metabolism in normal and hyperlipoproteinemic subjects. J Clin Invest 1974;53:6476.

23 Jimenez J, Zuniga-Guajardo S, Zinman B, Angel A. Effects of weight loss in massive obesity on insulin and C-peptide dynamics: sequential changes in insulin production, clearance, and sensitivity. J Clin Endocrinol Metab 1987;64:661-8.

24 Haskell WL, Lee IM, Pate RR, et al. Physical activity and public health: updated recommendation for adults from the American College of Sports Medicine and the American Heart Association. Circulation 2007;116:1081-93.

25 Hu G, Qiao Q, Silventoinen K, et al. Occupational, commuting, and leisure-time physical activity in relation to risk for Type 2 diabetes in middle-aged Finnish men and women. Diabetologia 2003;46:322-9.

26 Gill JM. Physical activity, cardiorespiratory fitness and insulin resistance: a short update. Curr Opin Lipidol 2007;18:47-52.

27 Lin CY, Chen PC, Kuo HK, Lin LY, Lin JW, Hwang JJ. Effects of obesity, physical activity, and cardiorespiratory fitness on blood pressure, inflammation, and insulin resistance in the National Health and Nutrition Survey 1999-2002. Nutr Metab Cardiovasc Dis 2009;20:713-9.

28 Meex RC, Schrauwen-Hinderling VB, Moonen-Kornips E, et al. Restoration of muscle mitochondrial function and metabolic flexibility in type 2 diabetes by exercise training is paralleled by increased myocellular fat storage and improved insulin sensitivity. Diabetes 2010;59:572-9.

29 Snel M, Gastaldelli A, Ouwens DM, et al. Effects of adding exercise to a 16-week very low-calorie diet in obese, insulin-dependent type 2 diabetes mellitus patients. J Clin Endocrinol Metab 2012;97:2512-20.

30 Weinstock RS, Dai H, Wadden TA. Diet and exercise in the treatment of obesity: effects of 3 interventions on insulin resistance. Arch Intern Med 1998;158:2477-83.

31 Fox AA, Thompson JL, Butterfield GE, Gylfadottir U, Moynihan S, Spiller G. Effects of diet and exercise on common cardiovascular disease risk factors in moderately obese older women. Am J Clin Nutr 1996;63:225-33.

32 Janssen I, Fortier A, Hudson R, Ross R. Effects of an energy-restrictive diet with or without exercise on abdominal fat, intermuscular fat, and metabolic risk factors in obese women. Diabetes Care 2002;25:431-8.

33 Trussardi Fayh AP, Lopes AL, Fernandes PR, Reischak-Oliveira A, Friedman R. Impact of weight loss with or without exercise on abdominal fat and insulin resistance in obese individuals: a randomised clinical trial. Br J Nutr 2013;110:486-92. 
34 LaMonte MJ, Blair SN, Church TS. Physical activity and diabetes prevention. J Appl Physiol (1985) 2005;99:1205-13.

35 Lee DC, Sui X, Blair SN. Does physical activity ameliorate the health hazards of obesity? Br J Sports Med 2009;43:49-51.

36 Laaksonen DE, Lindstrom J, Lakka TA, et al. Physical activity in the prevention of type 2 diabetes: the Finnish diabetes prevention study. Diabetes 2005;54:158-65.

37 Camps SV, SPM; Westerterp KR. Weight loss induced reduction in physical activity recovers during weight maintenance. Am J Clin Nutr 2013.

38 Redman LM, Heilbronn LK, Martin CK, et al. Metabolic and behavioral compensations in response to caloric restriction: implications for the maintenance of weight loss. PLoS One 2009;4:e4377.

39 Wu T, Gao X, Chen M, van Dam R. Long-term effectiveness of diet-plus-exercise interventions vs. diet-only interventions for weight loss: a meta-analysis. Obesity reviews : an official journal of the International Association for the Study of Obesity 2009;10:313-23.

40 Zuo H, Shi Z, Yuan B, et al. Interaction between physical activity and sleep duration in relation to insulin resistance among non-diabetic Chinese adults. BMC Public Health 2012;12:247.

41 Siri WE. Body composition from fluid spaces and density: analysis of methods. 1961. Nutrition 1993;9:480-91; discussion, 92.

42 Ginde SR, Geliebter A, Rubiano F, et al. Air displacement plethysmography: validation in overweight and obese subjects. Obes Res 2005;13:1232-7.

43 McCrory MA, Mole PA, Gomez TD, Dewey KG, Bernauer EM. Body composition by air-displacement plethysmography by using predicted and measured thoracic gas volumes. J Appl Physiol (1985) 1998;84:1475-9.

44 Westerterp KR, Wouters L, van Marken LichtenbeltWD. The Maastricht protocol for the measurement of body composition and energy expenditure with labeled water. Obes Res 1995;3 Suppl 1:49-57.

45 Speakman JR, Nair KS, Goran MI. Revised equations for calculating CO2 production from doubly labeled water in humans. Am J Physiol 1993;264:E912-7.

46 Bonomi AG, Plasqui G, Goris AH, Westerterp KR. Estimation of free-living energy expenditure using a novel activity monitor designed to minimize obtrusiveness. Obesity (Silver Spring) 2010;18:184551.

47 Johns MW. A new method for measuring daytime sleepiness: the Epworth sleepiness scale. Sleep 1991;14:540-5.

48 Wallace TM, Levy JC, Matthews DR. Use and abuse of HOMA modeling. Diabetes Care 2004;27:148795.

49 Bonomi AG, Plasqui G, Goris AH, Westerterp KR. Improving assessment of daily energy expenditure by identifying types of physical activity with a single accelerometer. J Appl Physiol 2009;107:65561.

50 McLaughlin T, Schweitzer P, Carter S, et al. Persistence of improvement in insulin sensitivity following a dietary weight loss programme. Diabetes Obes Metab 2008;10:1186-94.

51 Capel F, Klimcakova E, Viguerie N, et al. Macrophages and adipocytes in human obesity: adipose tissue gene expression and insulin sensitivity during calorie restriction and weight stabilization. Diabetes 2009;58:1558-67.

52 Lien LF, Haqq AM, Arlotto M, et al. The STEDMAN project: biophysical, biochemical and metabolic effects of a behavioral weight loss intervention during weight loss, maintenance, and regain. OMICS 2009;13:21-35. 
53 Foster GD, Wyatt HR, Hill JO, et al. A randomized trial of a low-carbohydrate diet for obesity. N Engl J Med 2003;348:2082-90.

54 Flechtner-Mors M, Ditschuneit HH, Johnson TD, Suchard MA, Adler G. Metabolic and weight loss effects of long-term dietary intervention in obese patients: four-year results. Obes Res 2000;8:399402.

55 Verhoef SP, Camps SG, Gonnissen HK, Westerterp KR, Westerterp-Plantenga MS. Concomitant changes in sleep duration and body weight and body composition during weight loss and 3-mo weight maintenance. Am J Clin Nutr 2013;98:25-31.

56 Hauri PJ, Wisbey J. Wrist actigraphy in insomnia. Sleep 1992;15:293-301.

57 Lockley SW, Skene DJ, Arendt J. Comparison between subjective and actigraphic measurement of sleep and sleep rhythms. J Sleep Res 1999;8:175-83. 


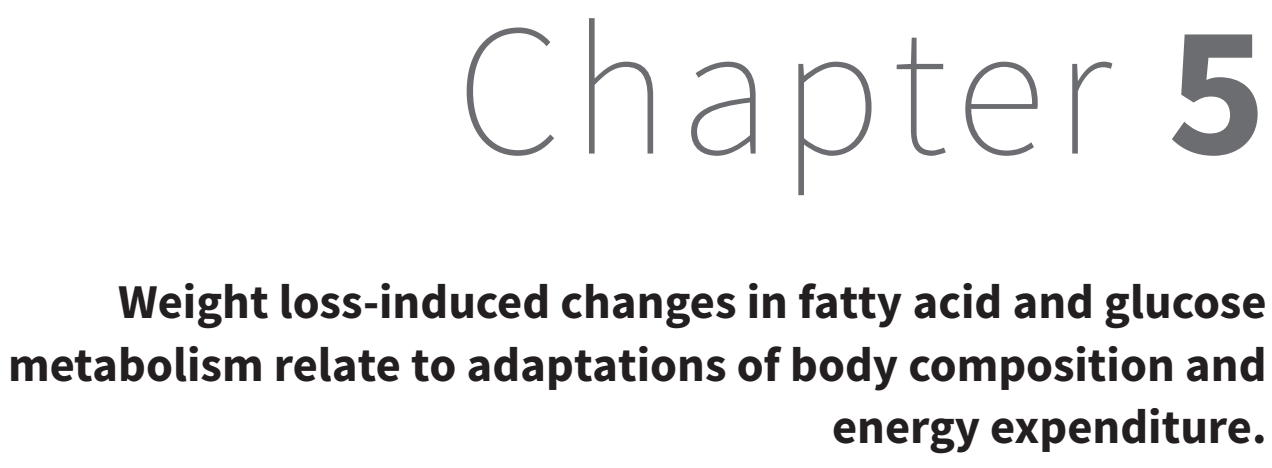

Camps SG, Verhoef SP, Roumans NJ, Bouwman FG, Mariman EC, Westerterp KR

In press 


\section{Abstract}

\section{Background}

Energy deficiency induced by energy restriction causes adaptations in energy expenditure (total-, TEE; resting-, REE; activity induced-, AEE).

\section{Objective}

To determine if changes in protein levels of markers for adipocyte glucose and fatty acid metabolism as indicators for energy deficiency are related to adaptations in energy expenditure during weight loss.

\section{Methods}

Forty-eight healthy subjects (18 men, 30 women), mean \pm SD age $42 \pm 8$ years and BMI $31.4 \pm 2.8$ $\mathrm{kg} / \mathrm{m}^{2}$, followed a very low energy diet for 8 weeks. Protein levels of fatty acid binding protein 4 (FABP4), fructose-bisphosphate aldolase C (AldoC) and short chain 3-hydroxyacyl-CoA dehydrogenase (HADHsc) (adipose tissue biopsy, western blot), TEE (doubly labeled water), REE (ventilated hood), and AEE were assessed before and after the 8-week diet.

\section{Results}

Subjects lost on average $10.7 \pm 4.1 \%$ body weight ( $P<0.001)$. FABP4 increased $31 \pm 87 \%(P<0.05)$. AldoC decreased 53 $\pm 37 \%(P<0.001)$. TEE, REE and AEE decreased respectively $17 \pm 12 \%$ $(P<0.001), 11 \pm 6 \%(P<0.001)$ and $23 \pm 29 \%(P<0.001)$. There was a positive correlation between the relative change in AldoC and the relative change in TEE $(R=0.438, P<0.01)$ and the relative change in AEE ( $R=0.439, P<0.01)$. Furthermore, there was a negative correlation between the relative change in HADHSC and the relative change in $\mathrm{REE}(\mathrm{R}=0.343, \mathrm{P}<0.05)$.

\section{Conclusion}

During energy restriction, the molecular metabolism in adipose tissue is linked to energy expenditure. More specifically, the decrease in AldoC is related to the decrease in AEE, which may be explained by the decreased glycolytic capacity. Additionally, the change in HADHsc is related to the adaptation in REE, which may be explained by changes in the $\beta$-oxidation. 


\section{Introduction}

The increasing prevalence of obesity and its comorbidities is one of the major health problems in our modern world (1). Although weight loss strategies target both sides of the energy balance, intake and expenditure, the success of long-term weight loss maintenance is low $(2,3)$. Adipose tissue is an important energy storing and releasing tissue and to fulfill this role adipocytes need to respond quickly to variations in the demand. Many studies have linked obesity to metabolic processes on a whole-body level, like reduced fat oxidation, as well as inside the adipocyte like a reduced metabolism of long chain fatty acids (4-7). Studies on weight loss indicate that energy restriction results in changes in the expression of genes involved in lipid, carbohydrate and energy metabolism in adipose tissue (8-13). During energy restriction, the limiting glucose availability must be compensated by an increased mitochondrial fatty acid oxidation to preserve blood glucose levels and supply glucosedependent tissues with sufficient energy, such as the brain or red blood cells (14).

The biological response to weight loss is causing the susceptibility to weight regain as reviewed by MacLean et al. (15). Mariman summarized this response as a network of adaptations with an energy gap promoting weight regain and physiological changes resulting in resistance for further weight loss (16). Two of these adaptations are decreases in energy expenditure in response to energy restriction, which can limit weight loss and could be important factors that compromise the maintenance of a reduced body weight. Firstly, studies performed in lean and obese subjects have shown significant reductions in resting energy expenditure (REE) during and shortly after weight loss, to values below predictions based on weight loss and body composition changes (17-22). The decrease in REE beyond what can be predicted by the loss of fat-free mass (FFM) and fat mass (FM) is defined as adaptive thermogenesis. Secondly, several studies demonstrated a decrease in physical activity and activity induced energy expenditure (AEE) as a result of weight loss (23-27).

Linking the metabolic adaptations to the glucose and fatty acid metabolism will give further insight in the underlying mechanisms. The aim of this study was to determine changes in markers for adipocyte glucose and fatty acid metabolism in adipose tissue during weight loss by measuring protein levels before and after an 8-week very low energy diet in order to find out whether these changes are associated with adaptations in energy expenditure. 


\section{Subjects and methods}

\section{Subjects}

Forty-eight healthy subjects (30 women and 18 men), mean + SD age of $42 \pm 8$ years and mean \pm SD body mass index (BMI) of $31.4 \pm 2.8 \mathrm{~kg} / \mathrm{m}^{2}$, were recruited by advertisements in local newspapers and on notice boards at the university. They underwent an initial screening that included measurement of body weight and height and the completion of a questionnaire on general health. All were in good health, not using medication (except for contraception), nonsmokers and at most moderate alcohol consumers. They were weight stable as defined by a weight change $<5 \mathrm{~kg}$ for at least 3 months prior to the study. The study was conducted according to the guidelines laid down in the Declaration of Helsinki and procedures were approved by the Ethics Committee of the Maastricht University Medical Centre. Written informed consent was obtained from all participants. This trial was registered at clinicaltrials. gov as NCT01015508.

\section{Study design}

The study covered an 8-week period of a very low energy diet (VLED). Subjects came to the university for measurements on two occasions: the day before the start of the diet (baseline) and 8 weeks after the start of the diet (end of the diet). The protocol included an overnight stay at the university followed by measurement of REE and body composition from 08.00 in the morning onwards in the fasting state. Two weeks prior to each measurement day, subjects received a subject-specific dose of doubly labeled water to measure total energy expenditure (TEE) over the following 14 days.

\section{Diet}

The weight loss diet (Modifast; Nutrition et Santé Benelux, Breda, The Netherlands) was followed for a period of 8 weeks. The diet was a protein-enriched formula that provided 2.1 MJ/day (51.9 grams of protein, 50.2 grams of Carbohydrates and 6.9 grams of Lipids) and a micronutrient content, which meets the Dutch recommended daily allowance. The VLED was provided to the subjects as sachets with powder. Each sachet represented one meal and 3 sachets were consumed every day. In addition to the provided meal-replacements, subjects were allowed to eat vegetables when feeling hungry. Subjects were instructed to mix the powder with the amount of water indicated on the packages and were advised to drink water sufficiently throughout the diet period. 


\section{Body Composition}

Height was measured at screening to the nearest $0.1 \mathrm{~cm}$ with the use of a wall-mounted stadiometer (model 220; Seca, Hamburg, Germany). Body composition was determined according to Siri's three-compartment model based on body weight, body volume and total body water. Body weight was measured using a calibrated scale (Life Measurement Corporation, Inc, Concord, CA, USA). Body volume was measured via air-displacement plethysmography with the BodPod System (Life Measurement Corporation, Inc, Concord, CA, USA) $(28,29)$. Total body water was determined using deuterium dilution during the preceding night, according to the Maastricht protocol (30). BMI was calculated by dividing body weight by height squared $\left(\mathrm{kg} / \mathrm{m}^{2}\right)$.

\section{Resting energy expenditure}

At $0800 \mathrm{~h}$ in the morning, after the overnight stay at the university, subjects slowly walked to a separate room where they rested on a bed for 30 minutes, followed by 30 minutes of measuring their REE in the supine position using an open-circuit ventilated hood-system (31). Gas analyses were performed with a paramagnetic oxygen analyzer (Servomex, type 1158, Crowborough, East Sussex, UK) and an infrared carbon dioxide analyzer (Servomex, type 1520, Crowborough, East Sussex, UK) while flow was kept at a constant rate of $80 \mathrm{l}$ min and additionally measured as described by Schoffelen et al (32). The within individual coefficient of variation for this system is $3.3 \% \pm 2.1$ (31). Calculation of REE from measured oxygen consumption and carbon dioxide production was based on Brouwer's formula (33).

In addition to measuring REE with the ventilated hood system (REEm), REE was predicted (REEp) with the equation: REEp $(\mathrm{MJ} / \mathrm{d})=0.024 \times$ fat mass $(\mathrm{kg})+0.102 \times$ fat free mass $\times(\mathrm{kg})+$ 0.85 (34). Since fat mass (FM) and fat free mass (FFM) are used to calculate REEp, the equation can be used independently for gender. Adaptive thermogenesis was calculated as REEm divided by REEp. The ratio after 8 weeks was divided by the ratio at baseline to adjust for initial over- or underestimations. A value above 1 indicates that the change of the measured REE is higher than what is expected based on the body composition, a value lower than 1 indicates measured REE is lower than what is expected based on the body composition.

\section{Energy Expenditure}

TEE was measured over two week intervals with the doubly labeled water method according to the Maastricht protocol (30). On the evening of day 1 , shortly after the collection of a background urine sample, subjects drank a weighed amount of ${ }^{2} \mathrm{H}_{2}{ }^{18} \mathrm{O}$ such that baseline levels were increased by $100-150$ ppm for ${ }^{2} \mathrm{H}$ and $200-250$ ppm for ${ }^{18} \mathrm{O}$. Subsequently, urine samples were collected in the morning of day 2 (second voiding), day 8 and day 14 and in the evening of day 1,8 and 13 . The doubly labeled water method gives precise and accurate information on carbon dioxide $\left(\mathrm{CO}_{2}\right)$ production. $\mathrm{CO}_{2}$ production was subsequently converted to TEE with the use of the energy equivalent of $\mathrm{CO}_{2}$, which can be calculated with additional 
information on the substrate mixture being oxidized (35). The energy equivalent at baseline was calculated based on a normal Western diet with a mixed macronutrient composition and energy respectively for 55\% from carbohydrate, 30\% from fat and 15\% from protein. At the end of the diet, the energy equivalent of $\mathrm{CO}_{2}$ was based on the consumption of the Modifast diet, the actual loss of fat mass and fat free mass and additional energy intake. The additional food intake was the calculated compensation for the difference between weight loss and the expected weight loss based on the consumption of the Modifast diet alone, with the assumption of $1 \mathrm{~kg}$ weight change to be equivalent to $30 \mathrm{MJ}$ (36). The additional food intake was also assumed to be a normal mixed diet.

At baseline, AEE was calculated as (0.9XTEE) - REE, assuming diet induced thermogenesis (DIT) to be $10 \%$ of TEE, which is based on a normal mixed diet (37) and DIT values for the separate macronutrients to be $10 \%$ for carbohydrate, $3 \%$ for fat and $25 \%$ for protein. At the end of the diet, the percentage DIT was calculated based on the intake of the Modifast diet and the additional food intake with a normal mixed composition, which accounted for the difference between the expected weight loss and the real weight loss. DIT was calculated to be $8 \%$ of the TEE at the end of the diet; therefore AEE was calculated as (0.92 X TEE) - REE. $A E E$ was adjusted for body weight $\left(A E E_{k g}=A E E / B M\right)$ to normalize the energy expenditure of physical activity (38).

\section{Western blot analysis}

Three proteins involved in glucose and fatty acid metabolisms were selected and measured in adipose tissue by Western blotting. Fructose-bisphosphate aldolase C (AldoC) is an enzyme of the glycolysis. Fatty acid binding protein 4 (FABP4) is an indicator for fatty acid handling inside the adipocyte by facilitating the intracellular transport of fatty acids. Short chain 3-hydroxyacyl-CoA dehydrogenase ( $\mathrm{HADHsc})$ is a rate-limiting enzyme of the mitochondrial beta-oxidation (11).

Abdominal subcutaneous adipose tissue biopsies (approximately $1.5 \mathrm{~g}$ ) were obtained by needle liposuction under local anaesthesia (2\% lidocaine, Fresenius Kabi BV, The Netherlands) after an overnight fast, before and after the diet. Samples were rinsed in sterile cold saline, frozen in liquid nitrogen and stored at $-80^{\circ} \mathrm{C}$ until protein isolation.

Frozen adipose tissue was grinded in a mortar and the powder was dissolved in $200 \mu \mathrm{l}$ of $8 \mathrm{M}$ urea, 2\% CHAPS, $65 \mathrm{mM}$ DTT per $100 \mathrm{mg}$ powder. The homogenate was vortexed for $5 \mathrm{~min}$ and centrifuged for $30 \mathrm{~min}$ at $14000 \mathrm{rpm}$ and $10^{\circ} \mathrm{C}$. The supernatant containing the adipose tissue proteome was carefully collected and aliquots were stored at $-80^{\circ} \mathrm{C}$. Protein concentrations were determined by a Biorad Bradfort-based protein assay (39).

Samples with equal amount of protein were run on a 12\% SDS polyacrylamide gel (180 V, Criterion Cell; Biorad, Hercules, CA) and then transferred (90 min, 100 V, Criterion blotter; Biorad) to $0.45-\mathrm{mm}$ nitrocellulose membranes. After Ponceau $\mathrm{S}$ staining and destaining with demineralized water, membranes were blocked in 5\% bovine serum albumin (BSA) in Tris-buffered saline containing 0.1\% Tween 20 (TBST) for AldoC, and in 5\% nonfat dry milk 
powder in TBST for FABP4 and HADHsc for $1 \mathrm{~h}$. Thereafter, the blots were incubated with the primary antibodies against AldoC (1:250 dilution, Santa Cruz sc-12066), FABP4 (1:1000 dilution, Cayman 10004944) and HADHsc (1:500 dilution, Santa Cruz sc-74650) in 5\% BSATBST (AldoC) or 5\% nonfat dry milk powder TBST (FABP4, HADHsC) overnight at $4^{\circ} \mathrm{C}$ on a shaker. Thereafter, the blots were washed three times for $10 \mathrm{~min}$ in TBST, and then incubated with 1:10000 dilution of the horseradish peroxidase-conjugated secondary antibody (DAKO) in 5\% BSA-TBST, $0.5 \%$ nonfat dry milk powder TBST or 5\% nonfat dry milk powder TBST for 1 h. The blots were washed three times for 10 min in TBST. A CCD camera (XRS-system, Biorad) was used to detect immunoreactive bands using chemiluminescent substrate (SuperSignal $\mathrm{CL}$; Pierce). The quantification was performed with the program Quantity One version 4.6.5 (Biorad). Blots were normalized to $\beta$-actin (1:1000 dilution, Santa Cruz sc-47778) to correct for differences in protein loading.

\section{Calculations and statistical analysis}

A paired t-test (two-tailed distribution) was carried out to determine possible differences between mean values. Spearman Rho's correlation coefficients were calculated for associations between parameters. One-way repeated measures ANOVA were used to compare the results across 0 and 8 weeks, with gender as covariate. Significance was defined as $P<0.05$. The power calculation was based on a weight loss study, in which a significant 2-fold increase in HADHsc level was measured with Western blotting during weight loss in 8 obese subjects (12). With an $\alpha$ of $0.05, \beta$ of 0.10 , mean change of 0.285 , and standard deviation of 0.223 for HADHsc, and taking into account an expected success-rate of $20 \%$ during weight maintenance and a dropout rate of $15 \%$, at least 29 subjects needed to be included at the start of the study. The data were analyzed using SPSS 20.0 (SPSS, Inc., Chicago, IL, USA). All data are presented as mean and standard deviation (SD). 


\section{Results}

\section{Body composition}

After the 8 weeks of VLED, weight loss was on average $9.9 \pm 4.1 \mathrm{~kg}(\mathrm{P}<0.001)$ consisting of 7.9 $\pm 3.3 \mathrm{~kg}$ of fat mass (FM) and $2.0 \pm 2.2 \mathrm{~kg}$ of fat free mass (FFM) (Table 5.1). Subjects lost on average $10.7 \pm 4.1 \%(P<0.001)$ of the starting weight. FM decreased from $41.8 \pm 6.3 \%$ to $37.3 \pm$ $7.5 \%(\mathrm{P}<0.001)$. The data showed a large inter-individual variation in weight loss, indicating a difference in the success of weight loss. In addition, the variation in weight loss was not explained by different levels of physical activity at baseline or 8 weeks.

\section{Energy Expenditure}

TEE decreased significantly from $12.65 \pm 2.08 \mathrm{MJ} / \mathrm{d}$ at baseline to $10.38 \pm 1.95 \mathrm{MJ} / \mathrm{d}(\mathrm{P}<0.001)$ after the VLED; a decrease of $17.5 \pm 11.9 \%(P<0.001)$.

REE decreased significantly from $7.54 \pm 1.05 \mathrm{MJ} / \mathrm{d}$ at baseline to $6.70 \pm 0.87 \mathrm{MJ} / \mathrm{d}$ $(P<0.001)$ after 8 weeks of VLED, which is a decrease of $10.8 \pm 6.6 \%(P<0.001)$. The decrease was explained by the reduced body weight and adaptive thermogenesis in response to the diet.

AEE decreased from $4.42 \pm 1.47 \mathrm{MJ} / \mathrm{d}$ at baseline to $3.27 \pm 1.24 \mathrm{MJ} / \mathrm{d}$ after 8 weeks of energy restriction $(P<0.001)$; a decrease of $22.8 \pm 28.7 \%(P<0.001)$ (Table 5.1).

Table 5.1. Subject characteristics (mean \pm SD) at baseline and after 8 weeks on a very low energy diet.

\begin{tabular}{llll}
\hline & Pre-WL (0 weeks) & Post-WL $(8$ weeks) & P-value \\
\hline Weight (kg) & $91.9 \pm 13.1$ & $82.0 \pm 11.2$ & $<0.001$ \\
FM (kg) & $36.3 \pm 7.3$ & $28.4 \pm 6.7$ & $<0.001$ \\
FFM (kg) & $56.1 \pm 10.3$ & $54.0 \pm 9.5$ & $<0.001$ \\
TEE $(\mathrm{MJ} / \mathrm{d})$ & $12.65 \pm 2.08$ & $10.38 \pm 1.95$ & $<0.001$ \\
REE $(\mathrm{MJ} / \mathrm{d})$ & $7.52 \pm 0.98$ & $6.74 \pm 0.85$ & $<0.001$ \\
AEE $(\mathrm{MJ} / \mathrm{d})$ & $4.42 \pm 1.47$ & $3.27 \pm 1.24$ & $<0.001$ \\
\hline
\end{tabular}

FM, fat mass

FFM, fat free mass

TEE, total energy expenditure

REE, resting energy expenditure

$A E E$, activity induced energy expenditure

\section{Proteins}

Fatty acid binding protein 4 (FABP4) increased significantly with $31.3 \pm 87.0 \%$ during the VLED $(P<0.05)$. Fructose-bisphosphate aldolase C (AldoC) decreased significantly with $53.2 \pm 37.0$ 
$\%$ during the diet $(\mathrm{P}<0.001)$. There was no significant change in short chain 3-hydroxyacylCoA dehydrogenase (HADHsc) during the VLED-period (Figure 5.1).

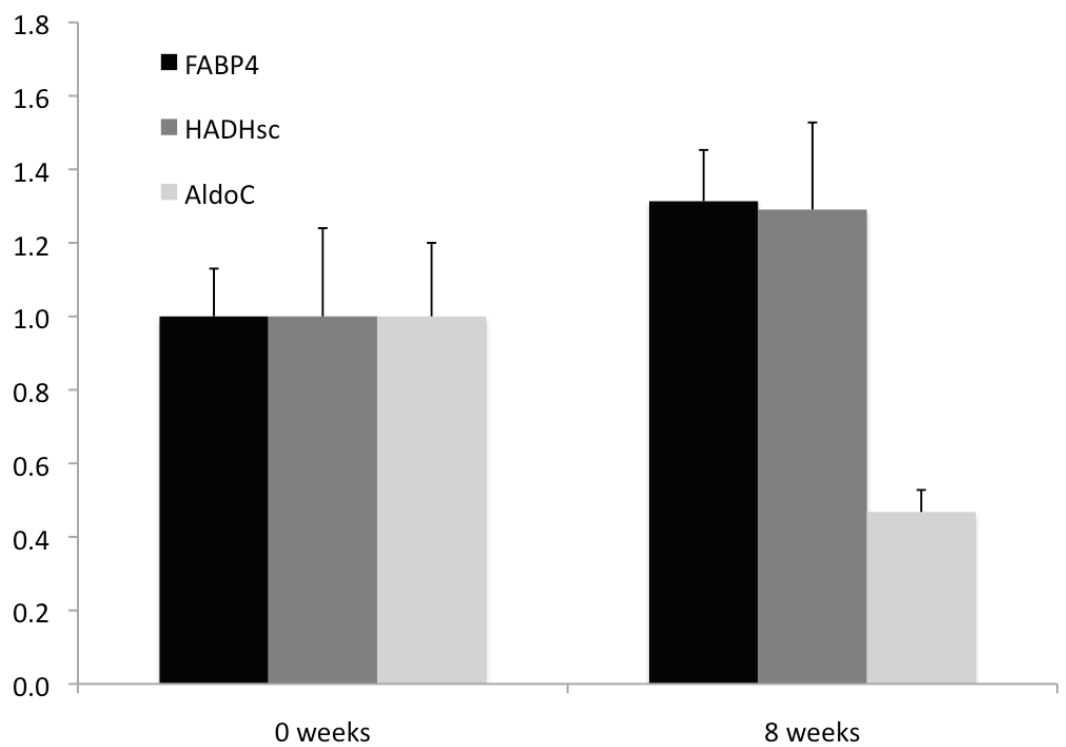

Figure 5.1. Fold changes of post-WL ( 8 weeks) compared to pre-WL ( 0 weeks). Fold changes are obtained by dividing the average spot intensity of the post-WL group by that of the pre-WL group.

${ }^{\star} \mathrm{P}<0.05$

${ }^{\star *} P<0.001$

FABP4, Fatty acid binding protein 4

HADHsc, Short chain 3-hydroxyacyl-CoA dehydrogenase

AldoC, Fructose-bisphosphate aldolase C

After 8 weeks, the change in FABP4 was significant negatively correlated with the change in $F M(R=-0.35, P<0.05)$, while the change in AldoC was significant positively correlated with the change in FFM ( $R=0.52, P<0.001)$ (Table 5.2).

After the diet, there was a significant positive correlation between the change in AldoC and the percentage change in TEE $(R=0.44, P<0.01)$; more specifically there was a significant positive correlation between the change in AldoC and the percentage change in $A E E(R=$ $0.44, P<0.01$ ). Furthermore, there was a significant positive correlation between the change in HADHsc and adaptive thermogenesis in REE after the VLED $(R=0.34, P<0.05)$.

After 8 weeks, there were significant positive correlations between the changes in FABP4 and HADHsc $(R=0.38, P<0.05)$, between FABP4 and AldoC $(R=0.47, P<0.01)$ and HADHsc and AldoC ( $R=0.46, P<0.01)$ (Table 5.2). 
Table 5.2. Spearman Rho's correlation coefficients of changes in protein levels with changes in body composition and energy expenditure parameters. Increased (+) and decreased (-) parameters are indicated in the first column.

\begin{tabular}{l|lll} 
& FABP4 & HADHsc & AldoC \\
\hline FABP4 (+) & & $0.38^{*}$ & $0.47^{\star \star}$ \\
HADHsc & $0.38^{\star}$ & & $0.46^{\star \star}$ \\
AldoC (-) & $0.47^{\star *}$ & $0.46^{\star \star}$ & \\
FM (-) & $-0.35^{*}$ & & \\
FFM (-) & & & $0.52^{\star \star \star}$ \\
REE (-) & & $0.34^{*}$ & \\
AEE (-) & & & $0.44^{\star}$ \\
TEE (-) & & & $0.44^{*}$
\end{tabular}

${ }^{\star} \mathrm{P}<0.05,{ }^{* \star} \mathrm{P}<0.01,{ }^{* \star *} \mathrm{P}<0.001$

FABP4, Fatty acid binding protein 4

HADHsc, Short chain 3-hydroxyacyl-CoA dehydrogenase

AldoC, Fructose-bisphosphate aldolase C

FM, fat mass

FFM, fat free mass

REE, resting energy expenditure

AEE, activity induced energy expenditure

TEE, total energy expenditure

\section{Discussion}

Measuring proteins involved in glucose and fatty acid metabolism in adipose tissue and body composition before and after an 8-week very low energy diet revealed that the molecular metabolism in adipose tissue is linked to energy expenditure. More specifically, the decreased marker for glycolysis (AldoC) is correlated to the decrease in AEE and the change in the marker for mitochondrial beta-oxidation (HADHsc) is negatively correlated to the adaptation in REE. Furthermore, there is a correlation between the increased marker for fatty acid transport (FABP4) and the decrease in fat mass, and a correlation between the decrease in AldoC and the decrease in fat free mass. FABP4, AldoC and HADHsc are all positively correlated.

The increased FABP4 during the diet is in accordance with previous results in obese subjects $(11,12)$. The correlation between the increase in FABP4 and the decrease in fat mass implies that there is an increased lipolysis in adipose tissue. The increase in FABP4 is in line with an elevation in intracellular trafficking of fatty acids that can be used for the mitochondrial beta-oxidation within the fat cell or be secreted from the cell to serve as energy source for other tissues.

The decreased AldoC during energy restriction is in accordance with previous results in obese subjects on a energy-restricted diet $(11,12)$. The decrease in AldoC indicates that the total glycolytic capacity in fat tissue is reduced to preserve blood glucose levels and preserve the glucose supply for glucose-dependent tissues, such as the brain or red blood cells during 
energy restriction (40). Moreover, the decrease in AldoC is related to the decrease in AEE, which can be explained by the decreased total body glycolytic capacity resulting from energy deficiency. This could mean that the preservation of glucose as an energy source for glucosedependant tissues is driven by a reduction in activity and muscle use. Indeed, the correlation between the decreased AldoC and the decrease in fat free mass suggests that there is an increased use of muscle protein as an energy source in case of physical activity when glucose is less available.

HADHsc is not significantly increased at the end of the 8-weeks VLED, which has been described before $(11,12)$. The correlation between the change in HADHsc and adaptive thermogenesis after the 8-weeks VLED is described as less adaptive thermogenesis when there is more mitochondrial beta-oxidation of long-chain fatty acids in the adipose tissue. This implies that if up-regulation of the mitochondrial beta-oxidation is possible during the diet there is a smaller reduction in resting energy expenditure. Or the other way around, a larger adaptation in REE is the cause for lower up-regulation of HADHsc and delayed increase of the mitochondrial beta-oxidation in fat cells during energy restriction. Previously, Bouwman et al. showed a positive correlation between three enzymes of the beta-oxidation (HADHsc, Acetyl-CoA acetyltransferase and Acyl-CoA dehydrogenase) and plasma free fatty acids (13). This is in line with the idea that up-regulated beta-oxidation leads to less adaptive thermogenesis because of the adipose tissues' ability to increase free fatty acids in the circulation.

The correlation between FABP4 and HADHsc shows that more intracellular trafficking of fatty acids is related to an increased beta-oxidation in adipose tissue. Additionally, an increased trafficking and beta-oxidation are positively correlated to AldoC a marker for the glycolytic capacity of the adipose tissue. This implies that when there is an increased fatty acid metabolism during energy restriction there is a better maintenance of the glycolytic capacity of the adipose tissue.

A limitation of this study is the use of total adipose tissue biopsy material for Western blotting, because this could have contained other celtypes in the stromal vascular fraction. However, the findings of our previous studies indicate that the majority of the isolated protein is derived from adipocytes (13). Furthermore, $\beta$-actin showed no significant changes and was chosen as a housekeeping control to be able to compare the present results with those of other studies. Although the selected proteins are involved in the major steps of the glucose and fatty acid metabolism and may reflect the capacity of metabolic pathways, it should be noted that protein levels do not represent the actual flux through the pathways.

In conclusion, during energy restriction, the molecular metabolism in adipose tissue is linked to energy expenditure. More specifically, the decrease in AldoC is related to the decrease in AEE, which can be explained by the decreased glycolytic capacity and the change in HADHsc is related to the adaptation in REE, which can be explained by changes in the $\beta$-oxidation. Overall, our findings reveal a clear link between changes on a physiological level and changes of the molecular metabolism in fat cells. This shows the important role 
of adipose tissue in obese people. The molecular changes in adipose tissue as a result of a negative energy balance could be the underlying driver of adaptations in body composition and energy expenditure (Figure 5.2). The latter should be the subject of future research.

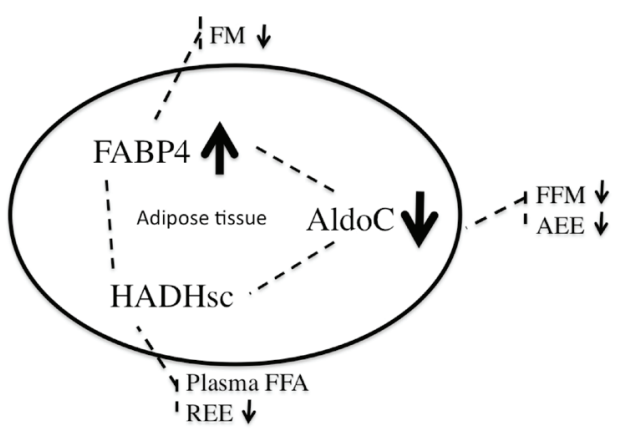

Figure 5.2: Overview of the network of changes inside the adipose tissue as a result of a negative energy balance and the found connections with adaptations in body composition and energy expenditure.

FABP4, Fatty acid binding protein 4

HADHsc, Short chain 3-hydroxyacyl-CoA dehydrogenase

AldoC, Fructose-bisphosphate aldolase C

FM, fat mass

FFM, fat free mass

FFA, free fatty acids

REE, resting energy expenditure

AEE, activity induced energy expenditure

TEE, total energy expenditure

\section{Acknowledgements}

K.R. Westerterp and S.P.M. Verhoef designed the study. S.G.J.A. Camps and S.P.M. Verhoef collected the data. S.G.J.A. Camps, S.P.M. Verhoef, N. Roumans and F.G. Bouwman analyzed the data. S.G.J.A. Camps, wrote the manuscript. K.R. Westerterp and E.M. Mariman contributed to the interpretation of the data and reviewed the manuscript. The study was executed under supervision of K.R. Westerterp. All authors read and approved the final manuscript. None of the authors had any conflict of interest. 


\section{References}

1 Catenacci VA, Hill JO, Wyatt HR. The obesity epidemic. Clin Chest Med 2009;30:415-44, vii.

2 Kraschnewski JL, Boan J, Esposito J, et al. Long-term weight loss maintenance in the United States. Int J Obes (Lond) 2010;34:1644-54.

3 Wing RR, Phelan S. Long-term weight loss maintenance. Am J Clin Nutr 2005;82:222S-5S.

4 Blaak EE, Hul G, Verdich C, et al. Fat oxidation before and after a high fat load in the obese insulinresistant state. J Clin Endocrinol Metab 2006;91:1462-9.

5 Frisancho AR. Reduced rate of fat oxidation: a metabolic pathway to obesity in the developing nations. Am J Hum Biol 2003;15:522-32.

6 Westerterp KR, Smeets A, Lejeune MP, Wouters-Adriaens MP, Westerterp-Plantenga MS. Dietary fat oxidation as a function of body fat. Am J Clin Nutr 2008;87:132-5.

7 Walewski JL, Ge F, Gagner M, et al. Adipocyte accumulation of long-chain fatty acids in obesity is multifactorial, resulting from increased fatty acid uptake and decreased activity of genes involved in fat utilization. Obes Surg 2010;20:93-107.

8 Speakman JR, Mitchell SE. Caloric restriction. Mol Aspects Med 2011;32:159-221.

9 Capel F, Viguerie N, Vega N, et al. Contribution of energy restriction and macronutrient composition to changes in adipose tissue gene expression during dietary weight-loss programs in obese women. J Clin Endocrinol Metab 2008;93:4315-22.

10 Johansson LE, Danielsson AP, Parikh H, et al. Differential gene expression in adipose tissue from obese human subjects during weight loss and weight maintenance. Am J Clin Nutr 2012;96:196207.

11 Verhoef SP, Camps SG, Bouwman FG, Mariman EC, Westerterp KR. Physiological response of adipocytes to weight loss and maintenance. PLoS One 2013;8:e58011.

12 Bouwman FG, Wang P, van Baak M, Saris WH, Mariman EC. Increased beta-oxidation with improved glucose uptake capacity in adipose tissue from obese after weight loss and maintenance. Obesity (Silver Spring) 2013.

13 Bouwman FG, Claessens M, van Baak MA, et al. The physiologic effects of caloric restriction are reflected in the in vivo adipocyte-enriched proteome of overweight/obese subjects. J Proteome Res 2009;8:5532-40.

14 Cahill GF, Jr., Herrera MG, Morgan AP, et al. Hormone-fuel interrelationships during fasting. J Clin Invest 1966;45:1751-69.

15 Maclean PS, Bergouignan A, Cornier MA, Jackman MR. Biology's response to dieting: the impetus for weight regain. Am J Physiol Regul Integr Comp Physiol 2011;301:R581-600.

16 Mariman EC. Human biology of weight maintenance after weight loss. J Nutrigenet Nutrigenomics 2012;5:13-25.

17 Leibel RL, Rosenbaum M, Hirsch J. Changes in energy expenditure resulting from altered body weight. N Engl J Med 1995;332:621-8.

18 Dulloo AG, Jacquet J. Adaptive reduction in basal metabolic rate in response to food deprivation in humans: a role for feedback signals from fat stores. Am J Clin Nutr 1998;68:599-606.

19 Schwartz A, Doucet E. Relative changes in resting energy expenditure during weight loss: a systematic review. Obes Rev 2010;11:531-47.

20 Tremblay A, Chaput JP. Adaptive reduction in thermogenesis and resistance to lose fat in obese men. Br J Nutr 2009;102:488-92. 
21 Weyer C, Walford RL, Harper IT, et al. Energy metabolism after 2 y of energy restriction: the biosphere 2 experiment. Am J Clin Nutr 2000;72:946-53.

22 Camps SG, Verhoef SP, Westerterp KR. Weight loss, weight maintenance, and adaptive thermogenesis. Am J Clin Nutr 2013;97:990-4.

23 Camps SV, SPM; Westerterp KR. Weight loss induced reduction in physical activity recovers during weight maintenance. Am J Clin Nutr 2013.

24 de Groot LC, van Es AJ, van Raaij JM, Vogt JE, Hautvast JG. Adaptation of energy metabolism of overweight women to alternating and continuous low energy intake. Am J Clin Nutr 1989;50:131423.

25 Martin CK, Heilbronn LK, de Jonge L, et al. Effect of calorie restriction on resting metabolic rate and spontaneous physical activity. Obesity (Silver Spring) 2007;15:2964-73.

26 Redman LM, Heilbronn LK, Martin CK, et al. Metabolic and behavioral compensations in response to caloric restriction: implications for the maintenance of weight loss. PLoS One 2009;4:e4377.

27 Bonomi AG, Soenen S, Goris AH, Westerterp KR. Weight-Loss Induced Changes in Physical Activity and Activity Energy Expenditure in Overweight and Obese Subjects before and after Energy Restriction. PLoS One 2013;8:e59641.

28 Ginde SR, Geliebter A, Rubiano F, et al. Air displacement plethysmography: validation in overweight and obese subjects. Obes Res 2005;13:1232-7.

29 Dempster P, Aitkens S. A new air displacement method for the determination of human body composition. Med Sci Sports Exerc 1995;27:1692-7.

30 Westerterp KR, Wouters L, van Marken LichtenbeltWD. The Maastricht protocol for the measurement of body composition and energy expenditure with labeled water. Obes Res 1995;3 Suppl 1:49-57.

31 Adriaens MP, Schoffelen PF, Westerterp KR. Intra-individual variation of basal metabolic rate and the influence of daily habitual physical activity before testing. Br J Nutr 2003;90:419-23.

32 Schoffelen PF, Westerterp KR, Saris WH, Ten Hoor F. A dual-respiration chamber system with automated calibration. J Appl Physiol 1997;83:2064-72.

33 Brouwer E. On simple formulae for calculating the heat expenditure and the quantities of carbohydrate and fat oxidized in metabolism of men and animals, from gaseous exchange (Oxygen intake and carbonic acid output) and urine-N. Acta Physiol Pharmacol Neerl 1957;6:795-802.

34 Westerterp KR, Donkers JH, Fredrix EW, Boekhoudt P. Energy intake, physical activity and body weight: a simulation model. Br J Nutr 1995;73:337-47.

35 Black A, Prentice A, Coward W. Use of food quotients to predict respiratory quotients for the doublylabelled water method of measuring energy expenditure. Human nutrition. Clinical nutrition 1986;40:381-91.

36 Westerterp KR. Physical activity, food intake, and body weight regulation: insights from doubly labeled water studies. Nutr Rev 2010;68:148-54.

37 Westerterp KR. Impacts of vigorous and non-vigorous activity on daily energy expenditure. Proc Nutr Soc 2003;62:645-50.

38 Schoeller DA, Jefford G. Determinants of the energy costs of light activities: inferences for interpreting doubly labeled water data. Int J Obes Relat Metab Disord 2002;26:97-101.

39 Bradford MM. A rapid and sensitive method for the quantitation of microgram quantities of protein utilizing the principle of protein-dye binding. Anal Biochem 1976;72:248-54.

40 Canto C, Jiang LQ, Deshmukh AS, et al. Interdependence of AMPK and SIRT1 for metabolic adaptation to fasting and exercise in skeletal muscle. Cell Metab 2010;11:213-9. 


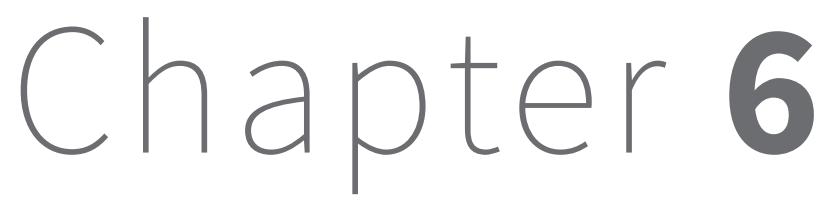

Leptin and energy restriction induced adaptations in resting energy expenditure and physical activity

Camps SG, Verhoef SP, Westerterp KR

Submitted for publication 


\section{Abstract}

\section{Background}

Diet-induced weight loss is accompanied by adaptive thermogenesis (AT), i.e. a disproportional reduction of resting energy expenditure (REE) a decrease in physical activity (PA) and increased movement economy.

\section{Objective}

To determine if energy restriction induced AT and the adaptations in PA are related to changes in leptin concentrations.

\section{Methods}

Eighty-two healthy subjects (23 men, 59 women), mean \pm SD age $41 \pm 8$ years and BMI $31.9 \pm 3.0$ $\mathrm{kg} / \mathrm{m}^{2}$, followed a very low energy diet for 8 weeks with measurements before and after the diet. Leptin concentrations were determined from fasting blood plasma. Body composition was assessed with a three-compartment model based on body weight, total body water (deuterium dilution) and body volume (BodPod). REE was measured (REEm) with a ventilated hood and predicted (REEp) from measured body composition. AT was calculated as REEm/REEp. Parameters for the amount of PA were total energy expenditure expressed as a multiple of REEm (PAL), activity-induced energy expenditure divided by body weight (AEE/kg) and activity counts measured by a tri-axial accelerometer. Movement economy was calculated as AEE/ $\mathrm{kg}(\mathrm{MJ} / \mathrm{kg} / \mathrm{d}$ ) divided by activity counts (Mcounts/d).

\section{Results}

Subjects lost on average $10.7 \pm 4.1 \%$ body weight $(P<0.001)$. Leptin decreased from $26.9 \pm 14.3$ before to $13.9 \pm 11.3 \mathrm{ug} / \mathrm{l}$ after the diet $(P<0.001)$. REEm/REEp after the diet $(0.963 \pm 0.08)$ was related to changes in leptin levels $\left(R^{2}=0.06 ; P<0.05\right)$. There was no significant correlation between changes in leptin concentrations and changes in amount of PA. Movement economy changed from $0.036 \pm 0.011 \mathrm{~J} / \mathrm{kg} /$ count to $0.028 \pm 0.010 \mathrm{~J} / \mathrm{kg} /$ count and was correlated to the changes in leptin concentrations $\left(R^{2}=0.07 ; P<0.05\right)$.

\section{Conclusion}

During energy restriction, the decrease in leptin explains variation in adaptation of resting energy expenditure. Changes in leptin are not related to the amount of physical activity but could partly explain the increased movement economy. 


\section{Introduction}

The increasing prevalence of obesity and its comorbidities is one of the major health problems in our modern society (1). Although weight loss strategies target both sides of the energy balance, intake and expenditure, the success of long-term weight loss maintenance is low $(2,3)$. Energy restriction induced weight loss is characterized by changes that promote a positive energy balance and cause the susceptibility for weight regain. On one side, appetite is elevated until the lost weight is regained (4-7). On the other side, a decrease in total energy expenditure is often described. Studies performed in lean and obese subjects have shown significant reductions in resting energy expenditure (REE) during and shortly after weight loss, to values below predictions based on weight loss and body composition changes (8-13). The decrease in REE beyond what can be predicted by the loss of fat-free mass (FFM) and fat mass (FM) is defined as adaptive thermogenesis. Additionally, several studies demonstrated a decrease in physical activity and activity induced energy expenditure (AEE) as a result of weight loss (14-18) as well as increased movement economy and skeletal muscle work efficiency $(8,19)$. Leibel stated that the hyperphagic, hypometabolic phenotype of weightreduced humans is similar to that of leptin-deficient or -unresponsive rodents (20).

Energy restriction and maintenance of reduced body weight is accompanied by declines in circulating leptin concentrations (21). This reduction in leptin is seen with different protocols to induce weight loss, indicating a consistent effect $(22,23)$. Experiments in mice revealed that part of the physiological response to weight loss can be prevented by leptin injections (24). Subsequent research in humans has indicated that administration of leptin that restores circulating leptin to levels present before weight loss reversed the increased energy intake (25) and decreased energy expenditure (26) as well as changes in sympathetic nervous system tone, thyroid function and movement economy (27). It is now believed that leptin or similar drug treatment may decrease or diminish the negative physiological consequence of energy restriction and could lead to more successful weight maintenance.

Linking adaptive thermogenesis, the decrease in physical activity and increased movement economy to changes in leptin concentrations during weight loss will give further insight in the underlying mechanisms and the pharmacotherapeutic relevance of the focus on leptin. The aim of this study was to determine if energy restriction induced adaptive thermogenesis, change in physical activity and increased movement economy is related to changes in leptin concentrations. 


\section{Subjects and methods}

\section{Subjects}

Eighty-two healthy subjects ( 59 women and 23 men) with a mean age of $41 \pm 8$ years and with a mean body mass index (BMI) of $31.9 \pm 3.0 \mathrm{~kg} / \mathrm{m}^{2}$ were recruited by advertisements in local newspapers and on notice boards at the university. They underwent an initial screening that included measurements of body weight and height and the completion of a questionnaire on general health. All were in good health, not using medication (except for contraception), nonsmokers and at most moderate alcohol consumers. They were weight stable as defined by a weight change $<5 \mathrm{~kg}$ for at least 3 months prior to the study. The study was conducted according to the guidelines laid down in the Declaration of Helsinki and procedures were approved by the Ethics Committee of the Maastricht University Medical Centre. Written informed consent was obtained from all participants.

Clinical Trial Registration Number: NCT01015508 at clinicaltrials.gov

\section{Study design}

The study consisted of a very low energy diet (VLED) for 8 weeks. Subjects came to the university for measurements on two occasions: the day before the start of the diet (baseline) and 8 weeks after the start of the diet (end of the diet). On each occasion, measurements included REE followed by body composition and the collection of a blood sample and were performed from 08.00 in the morning onwards in the fasting state. Total energy expenditure (TEE) and activity counts were measured during the two weeks prior to each measurement point.

\section{Diet}

The weight loss diet (Modifast; Nutrition et Santé Benelux, Breda, The Netherlands) was followed for a period of 8 weeks. The diet was a protein-enriched formula that provided 2.1 MJ/day (51.9 grams of protein, 50.2 grams of Carbohydrates and 6.9 grams of Lipids) and a micronutrient content, which meets the Dutch recommended daily allowance. The VLED was provided to the subjects as sachets with powder. Each sachet represented one meal and 3 sachets were consumed every day. Besides the provided meal-replacements, subjects were allowed to eat vegetables when feeling hungry. Subjects were instructed to mix the powder with the amount of water indicated on the packages and were advised to drink water sufficiently throughout the diet period. 


\section{Body composition}

Height was measured at screening to the nearest $0.1 \mathrm{~cm}$ with the use of a wall-mounted stadiometer (model 220; Seca, Hamburg, Germany). Body composition was determined according to Siri's three-compartment model based on body weight, body volume and total body water (28). Body weight was measured using a calibrated scale (Life Measurement Corporation, Inc, Concord, CA, USA). Body volume was measured via air-displacement plethysmography with the BodPod System (Life Measurement Corporation, Inc, Concord, CA, USA) (29, 30). Total body water was determined using deuterium dilution during the preceding night, according to the Maastricht protocol (31). Body mass index (BMI) was calculated by dividing body weight by height squared $\left(\mathrm{kg} / \mathrm{m}^{2}\right)$.

\section{Energy Expenditure}

To reach the university for REE measurements, subjects were instructed to travel by public transport or by car to avoid physical activity that would increase REE. After arrival, they rested on a bed for 30 minutes, followed by 30 minutes of measuring their REE in the supine position using an open-circuit ventilated hood-system (32). Gas analyses were performed by a paramagnetic oxygen analyzer (Servomex, type 500A, Crowborough, East Sussex, UK) and an infrared carbon dioxide analyzer (Servomex, type 500A, Crowborough, East Sussex, UK) while flow was kept at a constant rate of $80 \mathrm{l} / \mathrm{min}$ and additionally measured as described by Schoffelen et al. (33). The within individual coefficient of variation for this system is $3.3 \% \pm 2.1$ (32). Calculation of REE from measured oxygen consumption and carbon dioxide production was based on Brouwer's formula (34).

TEE ( $n=38$ ) was measured over two weeks intervals with the doubly labeled water method according to the Maastricht protocol (31). On the evening of day 1 , shortly after the collection of a background urine sample, subjects drank a weighed amount of ${ }^{2} \mathrm{H}_{2}{ }^{18} \mathrm{O}$ such that baseline levels were increased by $100-150$ ppm for ${ }^{2} \mathrm{H}$ and $200-250$ ppm for ${ }^{18} \mathrm{O}$. Subsequently, urine samples were collected in the morning of day 2 (second voiding), day 8 and day 14 and in the evening of day 1,8 and 13. The doubly labeled water method gives precise and accurate information on carbon dioxide $\left(\mathrm{CO}_{2}\right)$ production. $\mathrm{CO}_{2}$ production was subsequently converted to TEE with the use of the energy equivalent of $\mathrm{CO}_{2}$, which can be calculated with additional information on the substrate mixture being oxidized (35). The energy equivalent at baseline was calculated based on a normal Western diet with a mixed macronutrient composition and energy respectively for 55\% from carbohydrate, 30\% from fat and $15 \%$ from protein. At the end of the diet, the energy equivalent of $\mathrm{CO}_{2}$ was based on the consumption of the Modifast diet, the actual loss of fat mass and fat free mass and additional energy intake. The additional food intake was the calculated compensation for the difference between weight loss and the expected weight loss based on the consumption of the Modifast diet alone, with the assumption of $1 \mathrm{~kg}$ weight change to be equivalent to 30 MJ (36). The additional food intake was also assumed to be a normal mixed diet. 
At baseline, AEE was calculated as (0.9 X TEE) - REE, assuming DIT to be $10 \%$ of TEE, which is based on a normal mixed diet (37) and DIT values for the separate macronutrients to be $10 \%$ for carbohydrate, $3 \%$ for fat and $25 \%$ for protein. At the end of the diet, the percentage DIT was calculated based on the intake of the Modifast diet and the additional food intake with a normal mixed composition, which accounted for the difference between the expected weight loss and the real weight loss. DIT was calculated to be $8 \%$ of the TEE at the end of the diet; therefore AEE was calculated as (0.92 X TEE) - REE.

The physical activity level was calculated PAL = TEE/REE (38). AEE was adjusted for body weight $\left(A E E_{k g}=A E E / B M\right)$ to normalize the energy expenditure of physical activity (39).

\section{Physical activity monitoring}

Physical activity was monitored over two-week intervals using the previously validated DirectLife triaxial accelerometer (DirectLife, Philips Consumer Lifestyle, Amsterdam, The Netherlands). The device is small and lightweight and was carried at an elastic belt around the waist. Subjects were instructed to wear the accelerometer during waking hours, except during showering and water activities. A diary was used to report periods in which the subject was not wearing the accelerometer during the day. The accelerometer output was processed to determine body movement by measuring activity counts. Total activity counts were calculated over the two-week monitoring period, and the sum of counts was divided by the number of monitoring days to determine the average activity counts per day $(40,41)$. Days during which data were missing or subjects carried the accelerometer for $<10 \mathrm{~h}$ were excluded and the average was calculated on the remaining data, considering daily physical activity an ergodic process. Subjects with at least seven valid days were included. Following these criteria, no subject was excluded.

\section{Movement economy}

Movement economy was calculated as AEE/ $\mathrm{kg}(\mathrm{MJ} / \mathrm{kg} / \mathrm{d})$ divided by the activity counts (Mcounts/d). The outcome is expressed as J/kg/count.

\section{Blood parameters}

Fasted blood samples were taken and collected in EDTA containing tubes to prevent clotting. Plasma was obtained by centrifugation and stored at $-80^{\circ} \mathrm{C}$ until further analysis. Leptin and adiponectin concentrations were measured with the use of human RIA kit (Millipore, St. Charles, MO, USA)

\section{Calculations and statistical analysis}

In addition to measuring REE with the ventilated hood system (REEm), REE was predicted (REEp) with the equation: REEp $(\mathrm{MJ} / \mathrm{d})=0.024 \times$ fat mass $(\mathrm{kg})+0.102 \times$ fat free mass $x$ 
$(\mathrm{kg})+0.85$ (42). Since FM and FFM are used to calculate REEp, the equation can be used independently for gender. Adaptive thermogenesis was calculated as REEm divided by REEp. The obtained ratio was then compared between the different time points. A value above 1 indicates measured REE is higher than what is expected based on the body composition, a value lower than 1 indicates measured REE is lower than what is expected based on the body composition. One-way repeated measures ANOVA with Bonferroni adjustment for multiple comparisons and one-way between-groups analysis of covariance (ANCOVA) were used to compare the variables across 0 and 8 weeks.

Multiple hierarchical regression analysis has been performed to determine relations and interactions between dependant and independent variables. Age, gender, baseline FM (kg), baseline FFM (kg), change in FM (kg), change in FFM (kg) and baseline dependant variable were used as covariates in all tests; the regression model combining these recurring variables is referred to as the combined model.

The Data were analyzed using SPSS 20.0 (SPSS, Inc., Chicago, IL, USA). All data are presented as mean and standard deviation (SD).

\section{Results}

\section{Body composition}

After the 8 weeks VLED, weight loss was on average $9.3 \pm 4.0 \mathrm{~kg}(P<0.001)$. As a percentage of the starting weight, subjects had lost on average $10.0 \pm 3.8 \%(p<0.001)$ after the 8 weeks VLED. After 8 weeks, fat mass (FM) decreased from $38.9 \pm 7.6 \mathrm{~kg}$ to $31.5 \pm 7.8 \mathrm{~kg}(P<0.001)$ and fat free mass (FFM) decreased from $53.8 \pm 9.3 \mathrm{~kg}$ to $51.9 \pm 8.9 \mathrm{~kg}(P<0.001)$ (Table 6.1).

\section{Energy expenditure}

REEm decreased significantly from $7.29 \pm 1.01 \mathrm{MJ} / \mathrm{d}$ at baseline to $6.63 \pm 0.88 \mathrm{MJ} / \mathrm{d}$ after the VLED $(\mathrm{P}<0.001)$. Comparing REEm with REEp at baseline, the ratio REEm / REEp was on average $1.004 \pm 0.077$. Values were highly correlated $\left(R^{2}=0.72 ; P<0.001\right)$ and confirmed the validity of the prediction equation for the subject group under study. One-way repeated measures ANOVA and ANCOVA controlling for weight loss percentage were used to compare the average ratios of 8 weeks to baseline. The ratio decreased significantly to $0.963 \pm 0.073$ after the VLED $(\mathrm{P}<0.01)$, representing AT to be 4\% (Table 6.1).

\section{Physical activity}

PAL decreased significantly from $1.69 \pm 0.23$ at baseline to $1.52 \pm 0.19$ after the VLED $(P<0.001)$ AEE/kg decreased significantly from $0.056 \pm 0.018 \mathrm{MJ} / \mathrm{kg}$ at baseline to $0.043 \pm 0.016 \mathrm{MJ} /$ 
$\mathrm{kg}$ after the diet $(P<0.001)$. After 8 weeks VLED, activity counts decreased from $1.61 \pm 0.39$ Mcounts/d to $1.54 \pm 0.39$ Mcounts/d $(P<0.01)$ (Table 6.1).

\section{Movement economy}

After 8 weeks of VLED, AEE/kg/activity counts decreased significantly from $0.036 \pm 0.01 \mathrm{~J} / \mathrm{kg} /$ count to $0.028 \pm 0.01 \mathrm{~J} / \mathrm{kg} /$ count $(P<0.001)$ (Table 6.1).

\section{Leptin}

Leptin decreased from $26.9 \pm 14.3$ before to $13.9 \pm 11.3 \mathrm{ug} / \mathrm{l}$ after the diet $(P<0.001)$. After 8 weeks of VLED, leptin/FM was $-0.24 \pm 0.40 \mathrm{ug} / \mathrm{l} / \mathrm{kg}$ lower compared to baseline, $0.70 \pm 0.31$ ug/l/kg $(P<0.01)$ (Table 6.1).

Table 6.1 Subject characteristics (mean \pm SD) at baseline, after 8 weeks on a very low energy diet (VLED)

\begin{tabular}{|c|c|c|}
\hline & Baseline $(n=82)$ & $8 w k s(n=82)$ \\
\hline Weight (kg) & $92.8 \pm 11.9$ & $83.5 \pm 11.0^{* \star *}$ \\
\hline $\mathrm{FM}(\mathrm{kg})$ & $38.9 \pm 7.6$ & $31.5 \pm 7.8^{\star \star *}$ \\
\hline FFM (kg) & $53.8 \pm 9.3$ & $51.9 \pm 8.9^{\star \star \star}$ \\
\hline $\operatorname{REEm}(\mathrm{MJ} / \mathrm{d})$ & $7.29 \pm 1.01$ & $6.63 \pm 0.88^{* * *}$ \\
\hline $\operatorname{REEp}(\mathrm{MJ} / \mathrm{d})$ & $7.27 \pm 0.96$ & $6.90 \pm 0.90^{\star \star \star}$ \\
\hline REEm/REEp & $1.004 \pm 0.077$ & $0.963 \pm 0.073^{\text {** }}$ \\
\hline REEm/REEp adj. & & $0.967 \pm 0.007^{\star}$ \\
\hline $\operatorname{AEE}(\mathrm{MJ} / \mathrm{d})$ & $5.17 \pm 1.64$ & $3.64 \pm 1.49^{\star \star \star}$ \\
\hline PAL & $1.69 \pm 0.23$ & $1.52 \pm 0.19^{* \star *}$ \\
\hline $\mathrm{AEE} / \mathrm{kg}$ & $0.056 \pm 0.018$ & $0.043 \pm 0.016^{\star * *}$ \\
\hline Mcounts/d & $1.61 \pm 0.39$ & $1.54 \pm 0.39^{\star \star *}$ \\
\hline AEE/kg/activity counts ( $\mathrm{J} / \mathrm{kg} /$ count) & $0.037 \pm 0.011$ & $0.028 \pm 0.010^{* \star *}$ \\
\hline Leptin (ug/L) & $26.9 \pm 14.3$ & $13.9 \pm 11.3^{\star \star \star}$ \\
\hline
\end{tabular}

One-way repeated measures ANOVA with Bonferroni adjustment for multiple comparisons and one-way betweengroups analysis of covariance (ANCOVA) were used to compare the variables across 0 and 8 weeks

${ }^{*} \mathrm{P}<0.05$ compared with baseline, ${ }^{* *} \mathrm{P}<0.01$ compared with baseline, ${ }^{* \star *} \mathrm{P}<0.001$ compared with baseline

FM, fat mass

FFM, fat free mass

REEm, measured resting energy expenditure

REEp, predicted resting energy expenditure

REEm/REEp adjusted for weight loss percentage ( \pm SE)

AEE, activity induced energy expenditure

PAL, physical activity level 


\section{Interaction}

The combined model including age, gender, baseline body composition, changes in body composition and baseline value of the dependant variable explained part $47 \%$ of the variance in the change in REEm after 8 weeks of VLED $(p<0.001)$ with no significant additional value of the change in leptin concentration (Table 6.2).

Six percent of the variation in REEm/REEp after the diet was explained by the decrease in leptin $(p<0.05)$ on top of the explained variation by the combined model $\left(R^{2}=0.35 ; p<0.001\right)$.

The combined model explained $61 \%$ of the variation in the change in PAL $(p<0.001)$, $59 \%$ of the change in AEE/kg ( $p<0.001)$ and $23 \%$ of the change in activity counts $(p<0.01)$ after 8 weeks of VLED, with no significant additional explanation from the change in leptin concentration.

Seven percent of the variation in AEE/kg/activity counts after the diet was explained by the decrease in leptin $(p<0.05)$ on top of the explained variation by the combined model $\left(R^{2}=0.69 ; p<0.001\right)$.

Table 6.2: Multiple regression results of a model combining age, gender, baseline fat mass, baseline fat free mass, fat mass loss, fat free mass loss, baseline dependent variable and change in leptin concentration to predict changes after 8 weeks VLED.

\begin{tabular}{|c|c|c|c|c|c|c|}
\hline & $\begin{array}{l}\text { change } \\
\text { in REE }\end{array}$ & $\begin{array}{l}\text { REEm/REEp } \\
\text { (8wks) }\end{array}$ & $\begin{array}{l}\text { change } \\
\text { in PAL }\end{array}$ & $\begin{array}{l}\text { change in } \\
\mathrm{AEE} / \mathrm{kg}\end{array}$ & $\begin{array}{l}\text { change in } \\
\text { counts/d }\end{array}$ & $\begin{array}{l}\text { change in AEE/ } \\
\mathrm{kg} / \text { counts }\end{array}$ \\
\hline \multicolumn{7}{|l|}{ Age } \\
\hline \multicolumn{7}{|l|}{ gender } \\
\hline baseline FM & $0.03^{*}$ & & & & & \\
\hline baseline FFM & $0.05^{*}$ & & & & & \\
\hline \multicolumn{7}{|l|}{ change in FM } \\
\hline change in FFM & $0.05^{*}$ & $0.03^{*}$ & & & & $0.08^{*}$ \\
\hline $\begin{array}{l}\text { baseline dependent } \\
\text { variable }\end{array}$ & $0.24^{\star \star \star}$ & $0.22^{* \star *}$ & $0.45^{\star * \star}$ & $0.41^{\star \star \star}$ & $0.21^{\star \star \star}$ & $0.50^{\star \star \star}$ \\
\hline change in leptin & & $0.06^{*}$ & & & & $0.07^{*}$ \\
\hline Total: & $0.47^{\star \star \star}$ & $0.35^{\star \star \star}$ & $0.64^{* * *}$ & $0.61^{\star \star \star}$ & $0.24^{\star \star \star}$ & $0.69^{* \star \star}$ \\
\hline
\end{tabular}

Multiple regression analysis results in predicting variation in the change in REE, 8-week REEm/REEp, change in PAL, change in AEE/ $\mathrm{kg}$, change in activity counts/d and change in AEE/ $\mathrm{kg} / \mathrm{count}$ (change is the difference between before and after the diet).

Significant $R^{2}$ values are shown for age, gender, baseline fat mass, baseline fat free mass, fat mass loss, fat free mass loss, baseline dependent variable and change in leptin concentration as well as the total model.

REEm, measured resting energy expenditure

REEp, predicted resting energy expenditure

PAL, physical activity level

AEE, activity induced energy expenditure

FM, fat mass; FFM, fat free mass 


\section{Discussion}

Measuring energy expenditure, physical activity and circulating leptin concentration before and after a diet showed that the decrease in leptin in response to energy restriction is significantly and independently related to the greater than expected decrease in resting energy expenditure. The decrease in leptin is not correlated to the reduction in the amount of physical activity, however leptin is independently correlated to the increased movement economy. These results indicate that the change in plasma leptin levels could be part of the underlying mechanism explaining more efficient resting energy expenditure and more efficient physical activity during energy restriction.

Energy restriction leads to a decrease in REE of which only a part can be attributed to the change in body composition. The greater decline is often indicated as adaptive thermogenesis. In accordance with previous findings, our results show a four percent greater decline in REE than expected from the diet-induced weight loss, which was correlated to the change in body composition $(8,13,43,44)$. In addition to these results, the energy restriction induced change in leptin concentration was independently related to the adaptive response, indicating that a greater decrease in leptin correlates with a greater disproportionate reduction in REE. Previously, leptin had been shown to be correlated to the weight loss induced decrease of REE $(45,46)$; our results specifically indicate a relation with adaptive thermogenesis, in line with Lecoultre et al (47). Rosenbaum et al. showed that leptin administration during a weight-reduced state returned energy expenditure to pre-weight loss levels $(26,27)$. The combined results suggest a central role for leptin in the underlying mechanisms of metabolic adaptation, where a leptin associated decrease in sympathetic nervous activity seems an important mediator (48), still the exact mechanism remains speculative (20).

Energy restriction and weight loss are associated with a reduction in physical activity (14-16) and increased movement economy $(8,19)$ as well. Our results showed a decline of physical activity during the diet and an increase in movement economy, expressed as AEE per kilogram body weight per activity count. Furthermore, there is no significant correlation between the decrease in leptin and the decrease in the amount of physical activity. However, the results do show an independent correlation of the change in leptin levels and the increase in movement economy. In accordance with our results, Doucet et al described a relation between the changes in leptin concentration and the difference between the predicted and the measured fall in net exercise energy expenditure (49). This implies that leptin does not play a role in the reduction of the amount of physical activity but that it points towards an effect on increased movement economy during energy restriction. Although the exact mechanism is not clear, a decrease in sympathetic nervous activity related to leptin during weight loss seems an important mediator (48).

A limitation of this study is generated by the inter-individual variation in the results. However, the observed variation allowed the induced metabolic adaptation to be correlated to a range from less to more successful weight loss and change in leptin levels. With regard to 
leptin, the researchers understand that 24-h leptin concentrations are preferable but indicate fasting leptin levels are a sufficient measure in a longitudinal study. Another limitation is that interpreting PAL values during weight changes may be affected by the effect of weight loss on RMR. However, there is no indication for a significant change in the results and moreover, $\mathrm{PAL}$ results are in line with the results expressed as AEE/kg and activity counts. One of the main strengths of this study is the use of the gold standard in measuring free-living TEE: doubly labeled water. Therefore, PAL, AEE and AEE/kg reflect the physical activity and energy expenditure in normal daily life and are not confounded by restrictions of body movement. A second strength is the use of two independent methods based on measurement of energy expenditure and body movement.

In conclusion, this study indicates that the change in plasma leptin levels could be part of the underlying mechanism explaining more efficient resting energy expenditure and increased movement economy during energy restriction. Though, the decrease in leptin does not seem to affect the decline in the amount of physical activity during a diet. This confirms leptin as an important target for drug treatment, to diminish the negative physiological consequence of energy restriction and improve weight maintenance.

\section{Acknowledgements}

K.R. Westerterp and S.P.M. Verhoef designed the study. S.G.J.A. Camps and S.P.M. Verhoef collected the data. S.G.J.A. Camps analyzed the data and wrote the manuscript. K.R. Westerterp contributed to the interpretation of the data and reviewed the manuscript. The study was executed under supervision of K.R. Westerterp. All authors read and approved the final manuscript. None of the authors had any conflict of interest. 


\section{References}

1. Catenacci VA, Hill JO, Wyatt HR. The obesity epidemic. Clin Chest Med 2009;30:415-44, vii.

2. Kraschnewski JL, Boan J, Esposito J, Sherwood NE, Lehman EB, Kephart DK, Sciamanna CN. Longterm weight loss maintenance in the United States. Int J Obes (Lond) 2010;34:1644-54.

3. Wing RR, Phelan S. Long-term weight loss maintenance. Am J Clin Nutr 2005;82:222S-225S.

4. Anton SD, Han H, York E, Martin CK, Ravussin E, Williamson DA. Effect of calorie restriction on subjective ratings of appetite. J Hum Nutr Diet 2009;22:141-7.

5. Doucet E, Imbeault P, St-Pierre S, Almeras N, Mauriege P, Richard D, Tremblay A. Appetite after weight loss by energy restriction and a low-fat diet-exercise follow-up. Int J Obes Relat Metab Disord 2000;24:906-14.

6. Dulloo AG, Calokatisa R. Adaptation to low calorie intake in obese mice: contribution of a metabolic component to diminished energy expenditures during and after weight loss. Int J Obes 1991;15:716.

7. Levin BE, Dunn-Meynell AA. Defense of body weight against chronic caloric restriction in obesityprone and -resistant rats. Am J Physiol Regul Integr Comp Physiol 2000;278:R231-7.

8. Leibel RL, Rosenbaum M, Hirsch J. Changes in energy expenditure resulting from altered body weight. N Engl J Med 1995;332:621-8.

9. Dulloo AG, Jacquet J. Adaptive reduction in basal metabolic rate in response to food deprivation in humans: a role for feedback signals from fat stores. Am J Clin Nutr 1998;68:599-606.

10. Schwartz A, Doucet E. Relative changes in resting energy expenditure during weight loss: a systematic review. Obes Rev 2010;11:531-47.

11. Tremblay A, Chaput JP. Adaptive reduction in thermogenesis and resistance to lose fat in obese men. Br J Nutr 2009;102:488-92.

12. Weyer C, Walford RL, Harper IT, Milner M, MacCallum T, Tataranni PA, Ravussin E. Energy metabolism after 2 y of energy restriction: the biosphere 2 experiment. Am J Clin Nutr 2000;72:946-53.

13. Camps SG, Verhoef SP, Westerterp KR. Weight loss, weight maintenance, and adaptive thermogenesis. Am J Clin Nutr 2013;97:990-4.

14. Camps SV, SPM; Westerterp KR. Weight loss induced reduction in physical activity recovers during weight maintenance. Am J Clin Nutr 2013.

15. de Groot LC, van Es AJ, van Raaij JM, Vogt JE, Hautvast JG. Adaptation of energy metabolism of overweight women to alternating and continuous low energy intake. Am J Clin Nutr 1989;50:131423.

16. Martin CK, Heilbronn LK, de Jonge L, DeLany JP, Volaufova J, Anton SD, Redman LM, Smith SR, Ravussin E. Effect of calorie restriction on resting metabolic rate and spontaneous physical activity. Obesity (Silver Spring) 2007;15:2964-73.

17. Redman LM, Heilbronn LK, Martin CK, de Jonge L, Williamson DA, Delany JP, Ravussin E. Metabolic and behavioral compensations in response to caloric restriction: implications for the maintenance of weight loss. PLoS One 2009;4:e4377.

18. Bonomi AG, Soenen S, Goris AH, Westerterp KR. Weight-Loss Induced Changes in Physical Activity and Activity Energy Expenditure in Overweight and Obese Subjects before and after Energy Restriction. PLoS One 2013;8:e59641.

19. Rosenbaum M, Vandenborne K, Goldsmith R, Simoneau JA, Heymsfield S, Joanisse DR, Hirsch J, Murphy E, Matthews D, Segal KR, et al. Effects of experimental weight perturbation on skeletal 
muscle work efficiency in human subjects. Am J Physiol Regul Integr Comp Physiol 2003;285:R18392.

20. Leibel RL. The role of leptin in the control of body weight. Nutr Rev 2002;60:S15-9; discussion S6884, 85-7.

21. Rosenbaum M, Nicolson M, Hirsch J, Murphy E, Chu F, Leibel RL. Effects of weight change on plasma leptin concentrations and energy expenditure. J Clin Endocrinol Metab 1997;82:3647-54.

22. Sumithran P, Prendergast LA, Delbridge E, Purcell K, Shulkes A, Kriketos A, Proietto J. Long-term persistence of hormonal adaptations to weight loss. N Engl J Med 2011;365:1597-604.

23. Ozcelik O, Dogan H, Celik H, Ayar A, Serhatlioglu S, Kelestimur H. Effects of different weight loss protocols on serum leptin levels in obese females. Physiol Res 2005;54:271-7.

24. Ahima RS, Prabakaran D, Mantzoros C, Qu D, Lowell B, Maratos-Flier E, Flier JS. Role of leptin in the neuroendocrine response to fasting. Nature 1996;382:250-2.

25. Rosenbaum M, Sy M, Pavlovich K, Leibel RL, Hirsch J. Leptin reverses weight loss-induced changes in regional neural activity responses to visual food stimuli. J Clin Invest 2008;118:2583-91.

26. Rosenbaum M, Murphy EM, Heymsfield SB, Matthews DE, Leibel RL. Low dose leptin administration reverses effects of sustained weight-reduction on energy expenditure and circulating concentrations of thyroid hormones. J Clin Endocrinol Metab 2002;87:2391-4.

27. Rosenbaum M, Goldsmith R, Bloomfield D, Magnano A, Weimer L, Heymsfield S, Gallagher D, Mayer L, Murphy E, Leibel RL. Low-dose leptin reverses skeletal muscle, autonomic, and neuroendocrine adaptations to maintenance of reduced weight. J Clin Invest 2005;115:3579-86.

28. Siri WE. Body composition from fluid spaces and density: analysis of methods. 1961. Nutrition 1993;9:480-91; discussion 480, 492.

29. Ginde SR, Geliebter A, Rubiano F, Silva AM, Wang J, Heshka S, Heymsfield SB. Air displacement plethysmography: validation in overweight and obese subjects. Obes Res 2005;13:1232-7.

30. Dempster P, Aitkens S. A new air displacement method for the determination of human body composition. Med Sci Sports Exerc 1995;27:1692-7.

31. Westerterp KR, Wouters L, van Marken LichtenbeltWD. The Maastricht protocol for the measurement of body composition and energy expenditure with labeled water. Obes Res 1995;3 Suppl 1:49-57.

32. Adriaens MP, Schoffelen PF, Westerterp KR. Intra-individual variation of basal metabolic rate and the influence of daily habitual physical activity before testing. Br J Nutr 2003;90:419-23.

33. Schoffelen PF, Westerterp KR, Saris WH, Ten Hoor F. A dual-respiration chamber system with automated calibration. J Appl Physiol 1997;83:2064-72.

34. Brouwer E. On simple formulae for calculating the heat expenditure and the quantities of carbohydrate and fat oxidized in metabolism of men and animals, from gaseous exchange (Oxygen intake and carbonic acid output) and urine-N. Acta Physiol Pharmacol Neerl 1957;6:795-802.

35. Black A, Prentice A, Coward W. Use of food quotients to predict respiratory quotients for the doublylabelled water method of measuring energy expenditure. Human nutrition. Clinical nutrition 1986;40:381-391.

36. Westerterp KR. Physical activity, food intake, and body weight regulation: insights from doubly labeled water studies. Nutr Rev 2010;68:148-54.

37. Westerterp KR. Impacts of vigorous and non-vigorous activity on daily energy expenditure. Proc Nutr Soc 2003;62:645-50.

38. Westerterp KR, Plasqui G. Physical activity and human energy expenditure. Curr Opin Clin Nutr Metab Care 2004;7:607-13. 
39. Schoeller DA, Jefford G. Determinants of the energy costs of light activities: inferences for interpreting doubly labeled water data. Int J Obes Relat Metab Disord 2002;26:97-101.

40. Bonomi AG, Plasqui G, Goris AH, Westerterp KR. Estimation of free-living energy expenditure using a novel activity monitor designed to minimize obtrusiveness. Obesity (Silver Spring);18:1845-51.

41. Bonomi AG, Plasqui G, Goris AH, Westerterp KR. Improving assessment of daily energy expenditure by identifying types of physical activity with a single accelerometer. J Appl Physiol 2009;107:65561.

42. Westerterp KR, Donkers JH, Fredrix EW, Boekhoudt P. Energy intake, physical activity and body weight: a simulation model. Br J Nutr 1995;73:337-47.

43. Doucet E, St-Pierre S, Almeras N, Despres JP, Bouchard C, Tremblay A. Evidence for the existence of adaptive thermogenesis during weight loss. Br J Nutr 2001;85:715-23.

44. Johannsen DL, Knuth ND, Huizenga R, Rood JC, Ravussin E, Hall KD. Metabolic Slowing with Massive Weight Loss despite Preservation of Fat-Free Mass. J Clin Endocrinol Metab 2012;97.

45. Doucet E, St Pierre S, Almeras N, Mauriege P, Richard D, Tremblay A. Changes in energy expenditure and substrate oxidation resulting from weight loss in obese men and women: is there an important contribution of leptin? J Clin Endocrinol Metab 2000;85:1550-6.

46. Labayen I, Ortega FB, Ruiz JR, Lasa A, Simon E, Margareto J. Role of baseline leptin and ghrelin levels on body weight and fat mass changes after an energy-restricted diet intervention in obese women: effects on energy metabolism. J Clin Endocrinol Metab 2011;96:E996-1000.

47. Lecoultre V, Ravussin E, Redman LM. The fall in leptin concentration is a major determinant of the metabolic adaptation induced by caloric restriction independently of the changes in leptin circadian rhythms. J Clin Endocrinol Metab 2011;96:E1512-6.

48. Arone LJ, Mackintosh R, Rosenbaum M, Leibel RL, Hirsch J. Autonomic nervous system activity in weight gain and weight loss. Am J Physiol 1995;269:R222-5.

49. Doucet E, Imbeault P, St-Pierre S, Almeras N, Mauriege P, Despres JP, Bouchard C, Tremblay A. Greater than predicted decrease in energy expenditure during exercise after body weight loss in obese men. Clin Sci (Lond) 2003;105:89-95. 


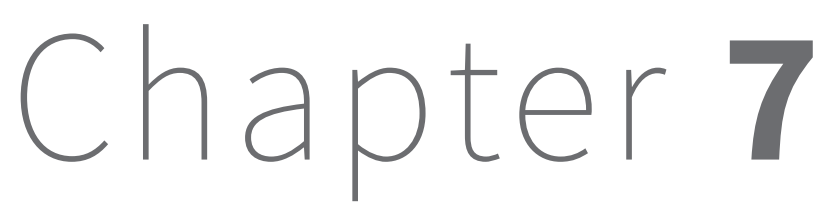

Genetic predisposition and energy restriction induced adaptations in resting energy expenditure and physical activity

Camps SG, Verhoef SP, Roumans NJ, Bouwman FG, Mariman EC, Westerterp KR 


\section{Abstract}

\section{Background}

Energy restriction induces adaptations in resting energy expenditure (REE) and physical activity (PA); interindividual variability could be ascribed to genetic predisposition.

\section{Objective}

To examine if changes in REE and PA as a result of weight loss were affected by candidate single nucleotide polymorphisms (SNPS).

Methods148 subjects (39 men, 109 women), mean \pm SD age: $41 \pm 9$ year; body mass index (BMI): $31.9 \pm 3.0 \mathrm{~kg} / \mathrm{m}^{2}$, followed a very low energy diet for 8 weeks. SNPs were selected from six candidate genes: ADRB2, FTO, MC4R, PPARG, PPARD and PPARGC1A. REE (ventilated hood) and physical activity (tri-axial accelerometer) were assessed before and after the diet. ANOVA analysis included gender, age and additional relevant covariates for all parameters.

\section{Results}

At baseline, the homozygotic wildtype genotype of FTO was associated with a lower amount of physical acitivity $(P<0.01)$ while the homozygotic minor genotype of ADRB2 was linked to a lower REE ( $\mathrm{P}<0.05)$. After weight loss, a larger decrease in REE was linked to the homozygotic minor genotype of ADRB2 $(\mathrm{P}<0.01)$. Additionally, carrying the homozygotic minor genotype of ADRB2 was linked to more adaptive thermogenesis after weight loss $(P<0.05)$.

\section{Conclusion}

Carrying the risk allele of FTO was associated with higher physical activity at baseline. Subjects, homozygous for the minor ADRB2 allele tend to have lower resting energy expenditure and show a larger energy restriction induced decrease in resting energy expenditure. 


\section{Introduction}

The increasing prevalence of obesity and its comorbidities is one of the major health problems in our modern world (1). Although weight loss strategies target both sides of the energy balance, intake and expenditure, the success of long-term weight loss maintenance is low $(2,3)$. It's the biological response to weight loss that increases this susceptibility to weight regain as reviewed by MacLean et al. (4). Mariman summarized the response as a network of adaptations with an energy gap promoting weight regain and physiological changes resulting in resistance for further weight loss (5). Two of these adaptations are decreases in energy expenditure in response to energy restriction, which can limit weight loss and could be important factors that compromise the maintenance of a reduced body weight. Firstly, studies performed in lean and obese subjects have shown significant reductions in resting energy expenditure (REE) during and shortly after weight loss, to values below predictions based on weight loss and body composition changes (6-14). The decrease in REE beyond what can be predicted by the loss of fat-free mass (FFM) and fat mass (FM) is defined as adaptive thermogenesis. Secondly, several studies demonstrated a decrease in physical activity and activity induced energy expenditure (AEE) as a result of weight loss (14-19).

Individuals respond differently to environmental changes and weight gain risk factors and this inter-individual variation in the susceptibility to develop obesity is partly explained by genetics, as family and twin studies have shown that the genetic contribution is $40-70 \%$ (20). A still increasing number of genetic loci have already been associated with obesity related traits (21). The small fraction of the total variation that is explained by the individual loci and inconsistent findings, suggests a multifactorial basis for obesity (22-24).

Linking the energy restriction induced metabolic adaptations to genetic variants will give further insight in the heritability of inter-individual variation in susceptibility to weight regain and underlying mechanisms. In this study, we tested the individual effects of six genetic variants, which had shown associations with obesity-related traits from different angles like physical activity, fat distribution, regulation of energy expenditure and energy intake: rs9939609 of fat mass and obesity associated (FTO) gene; rs 17782313 of melanocortin 4 receptor (MC4R) gene; rs1042713 of $\beta 2$-adrenergic receptor (ADRB2) gene; rs1801282 of peroxisome proliferator-activated receptory2 (PPARy2) gene; rs8192678 of peroxisome proliferator-activated receptory coactivator-1 $\alpha$ (PPARGC1 $\alpha$ ) gene; and rs2076168 of

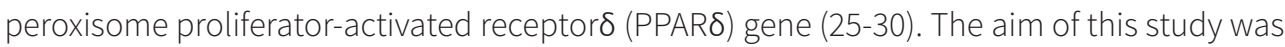
to examine if initial resting energy expenditure and physical activity in overweight subjects and if adaptations in resting energy expenditure and physical activity as a result of weight loss were affected by the six selected single nucleotide polymorphisms. 


\section{Subjects and methods}

\section{Subjects}

148 healthy subjects (109 women and 39 men), between 18 and 50 years old and with a body mass index (BMI) greater than 28, were recruited by advertisements in local newspapers and on notice boards at the university. They underwent an initial screening that included measurement of body weight and height and the completion of a questionnaire on general health. All had to be in good health, not using medication (except for contraception), nonsmokers and at most moderate alcohol consumers. They were weight stable as defined by a weight change $<5 \mathrm{~kg}$ for at least 3 months prior to the study. The study was conducted according to the guidelines laid down in the Declaration of Helsinki and procedures were approved by the Ethics Committee of the Maastricht University Medical Centre. Written informed consent was obtained from all participants. This trial was registered at clinicaltrials. gov as NCT01015508.

\section{Study design}

The study covered an 8-week period of a very low energy diet (VLED). Subjects came to the university for measurements on two occasions: the day before the start of the diet (baseline) and 8 weeks after the start of the diet (end of the diet). The protocol included measurement of REE and body composition from 08.00 in the morning onwards in the fasting state; only water was allowed in the twelve hours before the measurement. Two weeks prior to each measurement day, subjects received an accelerometer to measure physical activity over a two-week period. No physical activity instructions were given.

\section{Diet}

The weight loss diet (Modifast; Nutrition et Santé Benelux, Breda, The Netherlands) was followed for a period of 8 weeks. The diet was a protein-enriched formula that provided 2.1 MJ/day (51.9 grams of protein, 50.2 grams of Carbohydrates and 6.9 grams of Lipids) and a micronutrient content, which meets the Dutch recommended daily allowance (31). The VLED was provided to the subjects as sachets with powder. Each sachet represented one meal and 3 sachets were consumed every day. In addition to the provided meal-replacements, subjects were allowed to eat vegetables when feeling hungry, with the exception of starchy vegetables and legumes like potatoes or beans, which are relatively high in energy density. Subjects were instructed to mix the powder with the amount of water indicated on the packages and were advised to drink water sufficiently throughout the diet period. No dietary instructions were given in the two-week period before the baseline measurement. 


\section{Body Composition}

Height was measured at screening to the nearest $0.1 \mathrm{~cm}$ with the use of a wall-mounted stadiometer (model 220; Seca, Hamburg, Germany). Body composition was determined according to Siri's three-compartment model based on body weight, body volume and total body water. Body weight was measured using a calibrated scale (Life Measurement Corporation, Inc, Concord, CA, USA). Body volume was measured via air-displacement plethysmography with the BodPod System (Life Measurement Corporation, Inc, Concord, CA, USA) (32, 33). Total body water was determined using deuterium dilution during the preceding night, according to the Maastricht protocol (34). BMI was calculated by dividing body weight by height squared $\left(\mathrm{kg} / \mathrm{m}^{2}\right)$.

\section{Resting energy expenditure}

At $0800 \mathrm{~h}$ in the morning, subjects rested on a bed for 30 minutes, followed by 30 minutes of measuring their REE in the supine position using an open-circuit ventilated hood-system (35). Gas analyses were performed with a paramagnetic oxygen analyzer (Servomex, type 1158, Crowborough, East Sussex, UK) and an infrared carbon dioxide analyzer (Servomex, type 1520, Crowborough, East Sussex, UK) while flow was kept at a constant rate of $80 \mathrm{l}$ min and additionally measured as described by Schoffelen et al (36). The within individual coefficient of variation for this system is $3.3 \% \pm 2.1$ (35). Calculation of REE from measured oxygen consumption and carbon dioxide production was based on Brouwer's formula (37).

In addition to measuring REE with the ventilated hood system (REEm), REE was predicted (REEP) with the equation: REEp $(\mathrm{MJ} / \mathrm{d})=0.024 \times$ fat mass $(\mathrm{kg})+0.102 \times$ fat free mass $x(k g)+0.85$ (38). Since fat mass (FM) and fat free mass (FFM) are used to calculate REEp, the equation can be used independently for gender. Adaptive thermogenesis was calculated as REEm divided by REEp. A value above 1 indicates that the change of the measured REE is higher than what is expected based on the body composition; a value lower than 1 indicates measured REE is lower than what is expected based on the body composition.

\section{Physical activity monitoring}

Physical activity was monitored in two-week intervals using the previously validated DirectLife triaxial accelerometer (Philips Research, Eindhoven, The Netherlands). The device is small and lightweight and was carried at an elastic belt around the waist. Subjects were instructed to wear the accelerometer during waking hours, except during showering and water activities. A diary was used to report periods in which the subject was not wearing the accelerometer during the day. The accelerometer output was processed to determine body movement by measuring activity counts. Total activity counts were calculated over the twoweek monitoring period, and the sum of counts was divided by the number of monitoring days to determine the average activity counts per day $(39,40)$. 


\section{DNA isolation and genotyping}

Blood was collected in an EDTA tube during screening and the buffy coat was stored at $-80^{\circ} \mathrm{C}$. Genomic DNA was isolated from the buffy coat using the QIAamp mini blood kit (Qiagen, Amsterdam, The Netherlands). Six SNPs that were associated earlier with relevant phenotypes, such as BMI or body composition, were selected and considered as indicators for genetic predisposition. These included rs9939609 of fat mass and obesity associated (FTO) gene; rs17782313 of melanocortin 4 receptor (MC4R) gene; rs1042713 of $\beta 2$-adrenergic receptor (ADRB2) gene; rs1801282 of peroxisome proliferator-activated receptory2 (PPAR 2) gene; rs8192678 of peroxisome proliferator-activated receptory coactivator-1 $\alpha$ (PPARGC1 $\alpha$ ) gene; and rs2076168 of peroxisome proliferator-activated receptor $\delta$ (PPAR $\delta$ ) gene.

Genotyping of five SNPS was performed using commercially available TaqMan SNP genotyping assays from Applied Biosystems (Foster City, California, USA). The procedure was performed according to the manufacturer's protocol and measured on an Applied Biosystems 7900 HT Fast Real-Time PCR system. Allelic calls were determined semi-automatically using the allelic discrimination software of Applied Biosystems. The Pro12Ala polymorphism of the PPARY2 gene was characterized using the polymerase chain reaction-restriction fragment length polymorphism (PCR-RFLP) assay. The primers used were 5'-GCCAATTCAAGCCCAGTC-3' and 5'-GATATGTTTGCAGACAGTGTATCAGTGAAGGAATCGCTTTCCG-3'. The cycling conditions were $95^{\circ} \mathrm{C}$ for $5 \mathrm{~min}, 30$ cycles of $95^{\circ} \mathrm{C} / 30 \mathrm{~s}, 56^{\circ} \mathrm{C} / 45 \mathrm{~s}, 68^{\circ} \mathrm{C} / 45 \mathrm{~s}$ and followed by $68^{\circ} \mathrm{C}$ for 7 $\mathrm{min}$. The restriction enzym BstU-I was used, which generated the following fragments: $270 \mathrm{bp}$ (Pro12Pro); 270, 227, 43bp (Pro12Ala) and 227, 43bp (Ala12Ala).

\section{Calculations and statistical analysis}

To determine the genetic contribution of the selected SNPS, differences in measured resting energy expenditure, physical activity and REEm/REEp at baseline and changes in REEm, PA and REEm/REEp during short-term weight loss were compared between the different genotypes. A paired t-test (two-tailed distribution) was carried out to determine possible differences between mean values. Spearman Rho's correlation coefficients were calculated for associations between parameters. One-way repeated measures ANOVA were used to compare the results across 0 and 8 weeks, with gender as covariate. Significance was defined as $P<0.05$. Bonferroni adjustment was used to correct for multiple comparisons and reduce the possibility for false positive findings. The power calculation was based on a weight loss study, in which a significant decrease in REE from 2068 to 1778 after 10\% weight loss in obese subjects was found (41). With an $\alpha$ of 0.05 and $\beta$ of 0.10 (power $=1-\beta=0.90$ ) the number of subjects needed is: $\mathrm{N}=\left[21 \times(\mathrm{SD})^{2} /(\text { mean } 1 \text {-mean2 })^{2}\right]+0.96=36$. Taking into account a dropout rate of $10 \%$ a total of 40 subjects is needed. Assuming a minor FTO allele frequency of $40 \%$ (42), at least 100 subjects were included.

The data were analyzed using SPSS 20.0 (SPSS, Inc., Chicago, IL, USA). All data are presented as mean and standard deviation (SD). 


\section{Results}

\section{Body composition}

After the 8 weeks of VLED, subjects ( $41 \pm 9$ years; BMI of $31.9 \pm 3.0 \mathrm{~kg} / \mathrm{m}^{2}$ ) lost on average 9.4 $\pm 4.1 \mathrm{~kg}(\mathrm{P}<0.001)$ consisting of $7.4 \pm 3.3 \mathrm{~kg}$ of fat mass $(F M)$ and $1.8 \pm 2.2 \mathrm{~kg}$ of fat free mass (FFM) (Table 7.1). Subjects lost on average $10.5 \pm 4.1 \%(P<0.001)$ of the starting weight. FM decreased from $41.8 \pm 6.3 \%$ to $37.4 \pm 7.3 \%$ ( $P<0.001)$. The data showed a large interindividual variation in weight loss, indicating a difference in the success of weight loss. In addition, the variation in weight loss was not explained by different levels of physical activity at baseline or 8 weeks.

\section{Resting energy expenditure}

REEm decreased significantly from $7.30 \pm 1.02 \mathrm{MJ} / \mathrm{d}$ at baseline to $6.65 \pm 0.90 \mathrm{MJ} / \mathrm{d}$ after the $\operatorname{VLED}(\mathrm{P}<0.001)$. The decrease of the REEm was expected, because body weight was reduced at all time points compared to baseline. Thus, the expected decrease in energy expenditure was observed in the predicted REE as well. REEp decreased significantly from baseline (7.29 $\pm 0.98 \mathrm{MJ} / \mathrm{d})$ to after the VLED $(6.92 \pm 0.91 \mathrm{MJ} / \mathrm{d}, \mathrm{P}<0.001)$.

Comparing REEm with REEp at baseline, the ratio REEm / REEp was on average 1.00 \pm 0.08 . Values were highly correlated $\left(R^{2}=0.72\right.$; $\left.P<0.001\right)$ and confirmed the validity of the prediction equation for the subject group under study. The ratio decreased significantly to $0.96 \pm 0.08$ after the VLED $(P<0.01)$.

\section{Physical activity}

Activity counts were on average $1.60 \pm 0.38$ Mcounts/d at baseline and decreased to $1.56 \pm$ 0.39 Mcounts/d $(P<0.05)$ after 8 weeks of energy restriction.

\section{Genetic predisposition}

Genotypic and allelic distributions per single nucleotide polymorphim are shown in Table

\section{2.}

At baseline, the homozygotic wildtype genotype of FTO was associated with a lower amount of physical acitivity $(P<0.01)$ (Figure 7.1) while subjects homozygous for the minor ADRB2 allele were linked to a lower REEm $(P<0.05)$ (Figure 7.2a) with age, gender, FM and FFM as covariates. After weight loss, a larger decrease in REE was associated with carrying the homozygotic minor genotype of ADRB2 $(P<0.01)$ (Figure 7.2b) with age, gender and baseline REE as covariates. Additionally, carrying the homozygotic minor genotype of ADRB2 was 
Table 7.1 Subject characteristics (mean \pm standard deviation) at baseline and after 8 weeks on a very low energy diet $(n=148)$.

\begin{tabular}{|c|c|c|}
\hline & Pre-WL (0 weeks) & Post-WL (8 weeks) \\
\hline Body weight (kg) & $92.9 \pm 12.2$ & $83.5 \pm 11.0^{\kappa * *}$ \\
\hline $\mathrm{BMI}\left(\mathrm{kg} / \mathrm{m}^{2}\right)$ & $31.9 \pm 3.0$ & $28.9 \pm 3.1^{\star * *}$ \\
\hline Fat mass (kg) & $38.7 \pm 7.7$ & $31.3 \pm 7.9^{* * *}$ \\
\hline Fat free mass (kg) & $54.0 \pm 9.5$ & $52.2 \pm 9.0^{\cdots *}$ \\
\hline Percentage fat mass (\%) & $41.8 \pm 6.3$ & $37.4 \pm 7.3^{x * *}$ \\
\hline Resting energy expenditure, measured (MJ/d) & $7.30 \pm 1.02$ & $6.65 \pm 0.90^{* * *}$ \\
\hline Resting energy expenditure, predicted (MJ/d) & $7.29 \pm 0.98$ & $6.92 \pm 0.91^{\cdots *}$ \\
\hline REEp / REEm & $1.00 \pm 0.08$ & $0.96 \pm 0.08^{* \prime}$ \\
\hline Physical activity (Mcounts/d) & $1.60 \pm 0.38$ & $1.56 \pm 0.39^{*}$ \\
\hline
\end{tabular}

BMI; Body Mass Index

$P<0.05$

$* P<0.01$

$\cdots P<0.001$

Table 7.2: Genotypic and allelic distributions per single nucleotide polymorphism

\begin{tabular}{|c|c|c|c|c|c|c|c|}
\hline Gene & SNP & $G$ & $F(N)$ & $F(\%)$ & Allele* & $F(\%)$ & HWE \\
\hline \multirow[t]{3}{*}{ FTO } & rs9936909 & AA & 25 & 16.9 & $A$ & 38.9 & 0.65 \\
\hline & & AT & 65 & 43.9 & $\mathrm{~T}$ & 61.1 & \\
\hline & & $\mathrm{TT}$ & 58 & 39.2 & & & \\
\hline \multirow[t]{3}{*}{ MC4R } & rs 17782313 & $\mathrm{CC}$ & 15 & 10.1 & C & 24.1 & 0.19 \\
\hline & & $\mathrm{CT}$ & 46 & 31.1 & $\mathrm{~T}$ & 75.9 & \\
\hline & & $\mathrm{TT}$ & 87 & 58.8 & & & \\
\hline \multirow[t]{3}{*}{ ADRB2 } & rs1042713 & GG & 56 & 37.8 & $G$ & 62.3 & 0.92 \\
\hline & & GA & 71 & 48.0 & A & 37.7 & \\
\hline & & AA & 21 & 14.2 & & & \\
\hline \multirow[t]{3}{*}{ PPARD } & rs2076168 & GG & 16 & 10.9 & G & 28.1 & 0.33 \\
\hline & & GT & 52 & 35.4 & $\mathrm{~T}$ & 71.9 & \\
\hline & & $\mathrm{TT}$ & 79 & 53.7 & & & \\
\hline \multirow[t]{3}{*}{ PPARGC1A } & rs8192678 & AA & 20 & 13.6 & A & 37.2 & 0.95 \\
\hline & & $A G$ & 70 & 47.6 & G & 62.8 & \\
\hline & & GG & 57 & 38.7 & & & \\
\hline \multirow[t]{3}{*}{ PPARG2 } & rs1801282 & Ala12Ala & 1 & 0.7 & Ala & 10.7 & 0.83 \\
\hline & (Pro12Ala) & Pro12Ala & 30 & 20.1 & Pro & 89.3 & \\
\hline & & Pro12Pro & 117 & 79.2 & & & \\
\hline
\end{tabular}

$\mathrm{G}$, genotype; F, frequency, both absolute (N) and relative (\%)

Risk/minor allele in bold

P-values obtained from the $\chi^{2}$-test of Hardy Weinberg equilibrium (HWE). 
related to a lower REEm/REEp after weight loss $(\mathrm{P}<0.05)$ (Figure 7.2c) with age, gender and baseline REEm/REEp as covariates.


genotypes and REE, physical activity as well as energy restriction induced adaptations have been found.
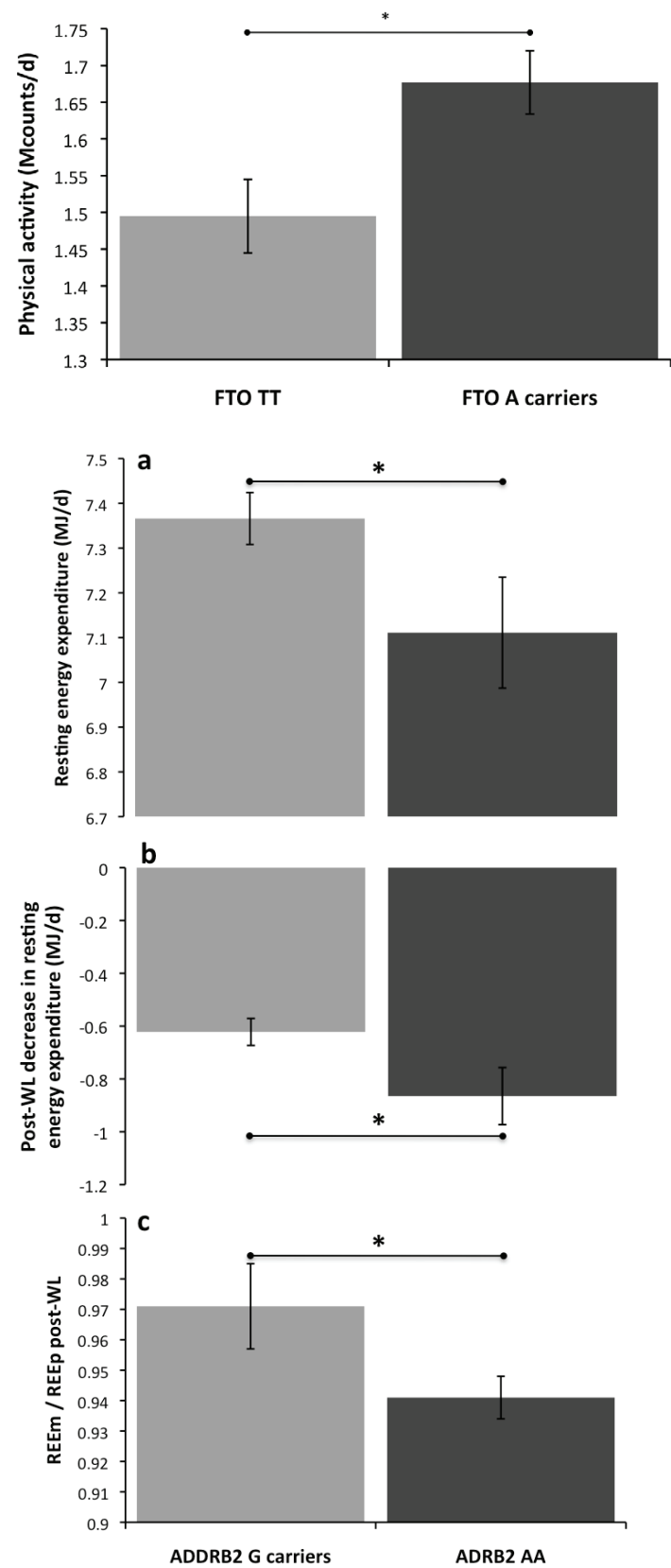

Figure 7.1 Physical activity (Mcounts/d) according to FTO rs9939609 polymorphism genotypes groups (TT wildtype genotype carriers vs. A variant allele carriers) adjusted for age, gender, fat mass and fat free mass.

* $P<0.01$

Values are meanststandard errors.

Figure $\mathbf{7 . 2}$ Baseline resting energy expenditure $(\mathrm{MJ} / \mathrm{d})(\mathbf{a})$, decrease in resting energy expenditure (MJ/d) after weight loss (b), measured resting energy expenditure (REEm) divided by the predicted resting energy expenditure (REEp) after weight loss (c) according to ADRB2 rs 1042713 polymorphism genotypes groups ( $G$ wildtype allele carriers vs. AA variant genotype carriers).

Adjusted for age, gender, fat mass and fat free mass (a), for age, gender, weight loss $(\mathrm{kg})$ and baseline REE (b) and age, gender, weight loss ( $\mathrm{kg}$ ) and baseline REEp/REEm (c).

${ }^{*} \mathrm{P}<0.05$

Values are means \pm standard errors. 


\section{Discussion}

The present study shows that obese men and women homozygous for the minor ADRB2 rs 1042713 allele tend to have lower resting energy expenditure and show a larger energy restriction induced decrease in resting energy expenditure. Subjects carrying the minor allele of FTOrs9936909 had higher physical activity at baseline.

Subjects, homozygous for the minor ADRB2 allele tend to have lower resting energy expenditure. Moreover, obese men and women homozygous for the minor ADRB2 allele show a greater adaptation in the resting energy expenditure induced by energy restriction. The disproportionate reduction in energy expenditure favors a positive energy balance during weight maintenance and may predispose to weight regain $(13,43)$. Several studies have suggested a link between the ADRB2 risk allele and the metabolic syndrome $(44,45)$, while Ruiz et al. showed higher weight loss in women carrying the common ADRB2 allele (46). ADRB2 is a member of the G-protein-coupled adrenergic receptor superfamily and participates in the peripheral regulation of energy expenditure (47). Expressed in subcutaneous adipose tissue, ADRB2 mobilizes lipids within human fat cells by stimulating lipolysis. Experimental studies have shown that the minor ADRB2 allele reduced the function of the $\beta 2$-receptor. The association between REE, adaptive thermogenesis and the altered function of the $\beta 2$ adrenergic receptor suggest that the reduced ability of mobilizing lipids within adipose tissue through lipolysis has a central role. This is in line with results from a previous study, showing that people with a reduced ability to increase $\beta$-oxidation of free fatty acids had more energy restriction induced thermogenesis, which in turn leads to a higher risk for weight regain (48).

Results showed no association between REE and FTO genotype variation. This is in line with previous results in adult humans (49-51), except for a study that did find lower REE in women carrying the minor allele of FTO (52).

Higher physical activity was found in subjects carrying the risk allele of the FTO polymorphism. This seems to be conflicting with results from previous studies showing an association of the FTO risk allele with higher body weight and BMI $(53,54)$ and additionally, between people with a higher BMI and less physical activity (55). However, it does suggest that higher BMI in people carrying the FTO risk allele is not caused by an inactive lifestyle. A metaanalysis of the results found in 218166 adults and 19268 children showed that the increased risk of obesity due to genetic variation in FTO can be attenuated by physical activity but did not find an association between FTO variation and the level of physical activity (56). It should be noted that this study was relatively superior in subject number. In contrast to our study, the majority of the studies included in this meta-analysis, used self-reported measures of physical activity instead of accelerometers that are a more objective measure. Additionally, subjects were categorized in only two categories, inactive people that accounted for 20 percent of the subjects and active people. Besides the relation between FTO and BMI, weight and energy expenditure, from literature, it is known that carriers of the FTO risk allele have an increased food intake of between 0.50 and $1.23 \mathrm{MJ} / \mathrm{d}$ compared to common FTO allele carriers, which 
is in line with the high expression of FTO in the hypothalamic site of brain tissue that controls food intake (57). Carrying the FTO risk allele could comprise a compensatory mechanism of physical activity and energy intake to match each other. This would explain the higher $\mathrm{BMI}$ that is seen in people carrying the FTO risk allele as the result of overcompensation of energy intake to increased physical activity, which is in line with the increased energy intake to compensate for exercise-induced increase in energy expenditure (58).

No significant associations between variations in MC4R, PPARY2, PPARGC1 $\alpha$, or PPAR $\delta$ genotypes and REE, physical activity as well as energy restriction induced adaptations have been found. For MC4R, this is in accordance with previous results showing no influence of the MC4R rs17782313 polymorphism on energy metabolism in obese women (52). As far as we are aware, studies determining the relation between PPAR 2 , PPARGC1 $\alpha$, or PPAR $\delta$ genotypes and REE, physical activity as well as energy restriction induced adaptations are very limited.

From these results we cannot exclude whether there were gene-environment interactions masking effects of a genetic variant. In addition six SNPs as measured in 148 subjects are low compared to other genetic studies. However, this is a consequence of the design of our study since accurate assessment of REE, physical activity and adaptations during short-term weight loss was a limiting factor. A recent study suggests that IRX3 is a functional long-range target of obesity-associated variants within FTO and represents a novel determinant of body mass and composition, however they don't dispute the idea emerging from animal studies that FTO is also a regulator of body mass and composition (59).

In conclusion, carrying the risk allele of FTO was associated with higher physical activity at baseline, which could be a compensatory mechanism for higher energy intake or vice versa. Subjects, homozygous for the minor ADRB2 allele tend to have lower resting energy expenditure and show a larger energy restriction induced decrease in resting energy expenditure in which a reduced stimulation of lipolysis in adipose tissue could play a central role.

\section{Acknowledgements}

K.R. Westerterp and S.P.M. Verhoef designed the study. S.G.J.A. Camps and S.P.M. Verhoef collected the data. S.G.J.A. Camps, S.P.M. Verhoef, and F.G. Bouwman analyzed the data. S.G.J.A. Camps, wrote the manuscript. K.R. Westerterp and E.M. Mariman contributed to the interpretation of the data and reviewed the manuscript. The study was executed under supervision of K.R. Westerterp. All authors read and approved the final manuscript. None of the authors had any conflict of interest. 


\section{References}

1. Catenacci VA, Hill JO, Wyatt HR. The obesity epidemic. Clin Chest Med 2009;30:415-44, vii.

2. Kraschnewski JL, Boan J, Esposito J, Sherwood NE, Lehman EB, Kephart DK, Sciamanna CN. Longterm weight loss maintenance in the United States. Int J Obes (Lond) 2010;34:1644-54.

3. Wing RR, Phelan S. Long-term weight loss maintenance. Am J Clin Nutr 2005;82:222S-225S.

4. Maclean PS, Bergouignan A, Cornier MA, Jackman MR. Biology's response to dieting: the impetus for weight regain. Am J Physiol Regul Integr Comp Physiol 2011;301:R581-600.

5. Mariman EC. Human biology of weight maintenance after weight loss. J Nutrigenet Nutrigenomics 2012;5:13-25.

6. Leibel RL, Rosenbaum M, Hirsch J. Changes in energy expenditure resulting from altered body weight. N Engl J Med 1995;332:621-8.

7. Doucet E, St-Pierre S, Almeras N, Despres JP, Bouchard C, Tremblay A. Evidence for the existence of adaptive thermogenesis during weight loss. Br J Nutr 2001;85:715-23.

8. Dulloo AG, Jacquet J. Adaptive reduction in basal metabolic rate in response to food deprivation in humans: a role for feedback signals from fat stores. Am J Clin Nutr 1998;68:599-606.

9. Johannsen DL, Knuth ND, Huizenga R, Rood JC, Ravussin E, Hall KD. Metabolic Slowing with Massive Weight Loss despite Preservation of Fat-Free Mass. J Clin Endocrinol Metab 2012;97.

10. Schwartz A, Doucet E. Relative changes in resting energy expenditure during weight loss: a systematic review. Obes Rev 2010;11:531-47.

11. Tremblay A, Chaput JP. Adaptive reduction in thermogenesis and resistance to lose fat in obese men. Br J Nutr 2009;102:488-92.

12. Weyer C, Walford RL, Harper IT, Milner M, MacCallum T, Tataranni PA, Ravussin E. Energy metabolism after 2 y of energy restriction: the biosphere 2 experiment. Am J Clin Nutr 2000;72:946-53.

13. Camps SG, Verhoef SP, Westerterp KR. Weight loss, weight maintenance, and adaptive thermogenesis. Am J Clin Nutr 2013;97:990-4.

14. Martin CK, Heilbronn LK, de Jonge L, DeLany JP, Volaufova J, Anton SD, Redman LM, Smith SR, Ravussin E. Effect of calorie restriction on resting metabolic rate and spontaneous physical activity. Obesity (Silver Spring) 2007;15:2964-73.

15. Camps SV, SPM; Westerterp KR. Weight loss induced reduction in physical activity recovers during weight maintenance. Am J Clin Nutr 2013.

16. de Groot LC, van Es AJ, van Raaij JM, Vogt JE, Hautvast JG. Adaptation of energy metabolism of overweight women to alternating and continuous low energy intake. Am J Clin Nutr 1989;50:131423.

17. Velthuis-te Wierik E, Westerterp K, van den Berg H. Impact of a moderately energy-restricted diet on energy metabolism and body composition in non-obese men. International journal of obesity and related metabolic disorders : journal of the International Association for the Study of Obesity 1995;19:318-324.

18. Redman LM, Heilbronn LK, Martin CK, de Jonge L, Williamson DA, Delany JP, Ravussin E. Metabolic and behavioral compensations in response to caloric restriction: implications for the maintenance of weight loss. PLoS One 2009;4:e4377.

19. Bonomi AG, Soenen S, Goris AH, Westerterp KR. Weight-Loss Induced Changes in Physical Activity and Activity Energy Expenditure in Overweight and Obese Subjects before and after Energy Restriction. PLoS One 2013;8:e59641. 
20. Loos RJ, Bouchard C. Obesity--is it a genetic disorder? J Intern Med 2003;254:401-25.

21. Li S, Zhao JH, Luan J, Luben RN, Rodwell SA, Khaw KT, Ong KK, Wareham NJ, Loos RJ. Cumulative effects and predictive value of common obesity-susceptibility variants identified by genome-wide association studies. Am J Clin Nutr 2010;91:184-90.

22. Leibel RL. Energy in, energy out, and the effects of obesity-related genes. N Engl J Med 2008;359:2603-4.

23. Day FR, Loos RJ. Developments in obesity genetics in the era of genome-wide association studies. J Nutrigenet Nutrigenomics 2011;4:222-38.

24. Loos RJ. Genetic determinants of common obesity and their value in prediction. Best Pract Res Clin Endocrinol Metab 2012;26:211-26.

25. Gielen M, Westerterp-Plantenga MS, Bouwman FG, Joosen AM, Vlietinck R, Derom C, Zeegers MP, Mariman EC, Westerterp KR. Heritability and genetic etiology of habitual physical activity: a twin study with objective measures. Genes Nutr 2014;9:415.

26. Wheeler E, Huang N, Bochukova EG, Keogh JM, Lindsay S, Garg S, Henning E, Blackburn H, Loos RJ, Wareham NJ, et al. Genome-wide SNP and CNV analysis identifies common and low-frequency variants associated with severe early-onset obesity. Nat Genet 2013;45:513-7.

27. Corella D, Ortega-Azorin C, Sorli JV, Covas MI, Carrasco P, Salas-Salvado J, Martinez-Gonzalez MA, Aros F, Lapetra J, Serra-Majem L, et al. Statistical and biological gene-lifestyle interactions of MC4R and FTO with diet and physical activity on obesity: new effects on alcohol consumption. PLoS One 2012;7:e52344.

28. Berglund ED, Liu T, Kong X, Sohn JW, Vong L, Deng Z, Lee CE, Lee S, Williams KW, Olson DP, et al. Melanocortin 4 receptors in autonomic neurons regulate thermogenesis and glycemia. Nat Neurosci 2014;17:911-3.

29. Beckers S, Zegers D, de Freitas F, Mertens IL, Van Gaal LF, Van Hul W. Association study of MC4R with complex obesity and replication of the rs17782313 association signal. Mol Genet Metab 2011;103:71-5.

30. Stefan N, Thamer C, Staiger H, Machicao F, Machann J, Schick F, Venter C, Niess A, Laakso M, Fritsche A, et al. Genetic variations in PPARD and PPARGC1A determine mitochondrial function and change in aerobic physical fitness and insulin sensitivity during lifestyle intervention. J Clin Endocrinol Metab 2007;92:1827-33.

31. Fernandes J. [Nutrition and health--recommendations of the Health Council of the Netherlands regarding energy, proteins, fats and carbohydrates]. Ned Tijdschr Geneeskd 2002;146:2226-9.

32. Ginde SR, Geliebter A, Rubiano F, Silva AM, Wang J, Heshka S, Heymsfield SB. Air displacement plethysmography: validation in overweight and obese subjects. Obes Res 2005;13:1232-7.

33. Dempster P, Aitkens S. A new air displacement method for the determination of human body composition. Med Sci Sports Exerc 1995;27:1692-7.

34. Westerterp KR, Wouters L, van Marken LichtenbeltWD. The Maastricht protocol for the measurement of body composition and energy expenditure with labeled water. Obes Res 1995;3 Suppl 1:49-57.

35. Adriaens MP, Schoffelen PF, Westerterp KR. Intra-individual variation of basal metabolic rate and the influence of daily habitual physical activity before testing. Br J Nutr 2003;90:419-23.

36. Schoffelen PF, Westerterp KR, Saris WH, Ten Hoor F. A dual-respiration chamber system with automated calibration. J Appl Physiol 1997;83:2064-72.

37. Brouwer E. On simple formulae for calculating the heat expenditure and the quantities of carbohydrate and fat oxidized in metabolism of men and animals, from gaseous exchange (Oxygen intake and carbonic acid output) and urine-N. Acta Physiol Pharmacol Neerl 1957;6:795-802. 
38. Westerterp KR, Donkers JH, Fredrix EW, Boekhoudt P. Energy intake, physical activity and body weight: a simulation model. Br J Nutr 1995;73:337-47.

39. Bonomi AG, Plasqui G, Goris AH, Westerterp KR. Estimation of free-living energy expenditure using a novel activity monitor designed to minimize obtrusiveness. Obesity (Silver Spring) 2010;18:184551.

40. Bonomi AG, Plasqui G, Goris AH, Westerterp KR. Improving assessment of daily energy expenditure by identifying types of physical activity with a single accelerometer. J Appl Physiol 2009;107:65561.

41. Leibel RL, Rosenbaum M, Hirsch J. Changes in Energy Expenditure Resulting from Altered Body Weight. N Engl J Med 1995;332:621-628.

42. den Hoed M, Westerterp-Plantenga MS, Bouwman FG, Mariman EC, Westerterp KR. Postprandial responses in hunger and satiety are associated with the rs9939609 single nucleotide polymorphism in FTO. Am J Clin Nutr 2009;90:1426-32.

43. Tremblay A, Royer MM, Chaput JP, Doucet E. Adaptive thermogenesis can make a difference in the ability of obese individuals to lose body weight. Int J Obes (Lond) 2013;37:759-64.

44. Dallongeville J, Helbecque N, Cottel D, Amouyel P, Meirhaeghe A. The Gly16-->Arg16 and GIn27-$>$ Glu27 polymorphisms of beta2-adrenergic receptor are associated with metabolic syndrome in men. J Clin Endocrinol Metab 2003;88:4862-6.

45. Park HS, Shin ES, Lee JE. Genotypes and haplotypes of beta2-adrenergic receptor and parameters of the metabolic syndrome in Korean adolescents. Metabolism 2008;57:1064-70.

46. Ruiz JR, Larrarte E, Margareto J, Ares R, Labayen I. Role of beta(2)-adrenergic receptor polymorphisms on body weight and body composition response to energy restriction in obese women: preliminary results. Obesity (Silver Spring) 2011;19:212-5.

47. Loktionov A. Common gene polymorphisms and nutrition: emerging links with pathogenesis of multifactorial chronic diseases (review). J Nutr Biochem 2003;14:426-51.

48. Camps SG, Verhoef SP, Roumans R, Bouwman FG, Mariman EC, Westerterp KR. Energy restriction induced changes in fatty acid and glucose metabolism of the adipose tissue relate to adaptations of body composition and energy expenditure in obese subjects. Obesity (Silver Spring) 2014; Submitted.

49. Berentzen T, Kring SI, Holst C, Zimmermann E, Jess T, Hansen T, Pedersen O, Toubro S, Astrup A, Sorensen TI. Lack of association of fatness-related FTO gene variants with energy expenditure or physical activity. J Clin Endocrinol Metab 2008;93:2904-8.

50. Speakman JR, Rance KA, Johnstone AM. Polymorphisms of the FTO gene are associated with variation in energy intake, but not energy expenditure. Obesity (Silver Spring) 2008;16:1961-5.

51. Do R, Bailey SD, Desbiens K, Belisle A, Montpetit A, Bouchard C, Perusse L, Vohl MC, Engert JC. Genetic variants of FTO influence adiposity, insulin sensitivity, leptin levels, and resting metabolic rate in the Quebec Family Study. Diabetes 2008;57:1147-50.

52. Arrizabalaga M, Larrarte E, Margareto J, Maldonado-Martin S, Barrenechea L, Labayen I. Preliminary findings on the influence of FTO rs9939609 and MC4R rs17782313 polymorphisms on resting energy expenditure, leptin and thyrotropin levels in obese non-morbid premenopausal women. J Physiol Biochem 2013;70:255-62.

53. Scuteri A, Sanna S, Chen WM, Uda M, Albai G, Strait J, Najjar S, Nagaraja R, Orru M, Usala G, et al. Genome-wide association scan shows genetic variants in the FTO gene are associated with obesity-related traits. PLoS Genet 2007;3:e115. 
54. Verhoef SP, Camps SG, Bouwman FG, Mariman EC, Westerterp KR. Genetic predisposition, dietary restraint and disinhibition in relation to short and long-term weight loss. Physiol Behav 2014;128:247-51.

55. Ekelund U, Aman J, Yngve A, Renman C, Westerterp K, Sjostrom M. Physical activity but not energy expenditure is reduced in obese adolescents: a case-control study. Am J Clin Nutr 2002;76:935-41.

56. Kilpelainen TO, Qi L, Brage S, Sharp SJ, Sonestedt E, Demerath E, Ahmad T, Mora S, Kaakinen M, Sandholt $\mathrm{CH}$, et al. Physical activity attenuates the influence of FTO variants on obesity risk: a meta-analysis of 218,166 adults and 19,268 children. PLoS Med 2011;8:e1001116.

57. Zhao X, Yang Y, Sun BF, Zhao YL, Yang YG. FTO and obesity: mechanisms of association. Curr Diab Rep 2014;14:486.

58. Stubbs RJ, Hughes DA, Johnstone AM, Horgan GW, King N, Blundell JE. A decrease in physical activity affects appetite, energy, and nutrient balance in lean men feeding ad libitum. Am J Clin Nutr 2004;79:62-9.

59. Smemo S, Tena JJ, Kim KH, Gamazon ER, Sakabe NJ, Gomez-Marin C, Aneas I, Credidio FL, Sobreira DR, Wasserman NF, et al. Obesity-associated variants within FTO form long-range functional connections with IRX3. Nature 2014;507:371-5. 

Chapter 8

General discussion 
Energy restriction induces adaptations in energy expenditure and physical activity. Moderate weight loss as induced by energy restriction lead to a disproportional reduction in resting energy expenditure, i.e. adaptive thermogenesis, and a decrease in physical activity. Adaptive thermogenesis was not only observed during energy restriction but was sustained up to 44 weeks of follow-up and was positively correlated to the amount of lost weight. However, physical activity returned to baseline levels when weight loss was maintained. During the weight loss phase, maintaining physical activity or minimizing the decrease in physical activity improved insulin sensitivity. During weight maintenance, improved insulin sensitivity was maintained better if physical activity returned to baseline or increased further. Physical activity and body mass index (BMI) were higher in carriers of the FTO risk allele, whereas homozygous carriers of the ADRB2 risk allele had a reduced resting energy expenditure and a larger energy restriction induced adaptive thermogenesis. The energy restriction induced decrease in physical activity was related to a decreased glycolytic capacity in adipose tissue. The energy restriction induced adaptive thermogenesis was related to a change in mitochondrial beta-oxidation in adipose tissue. Leptin analysis revealed a possible role of this hormone in the underlying mechanism explaining adaptive thermogensis and improved movement economy during weight loss.

\section{Energy restriction induced adaptations in energy expenditure}

Moderate weight loss induced a disproportional reduction in resting energy expenditure, which agrees with results that have been described before (1-5). Additionally, subjects with greater weight loss had more adaptive thermogenesis. Theoretically, adaptive thermogenesis in response to energy restriction reduces weight loss, however, subjects with the greatest adaptation had the greatest weight loss. This suggests that weight loss is primarily determined by the energy restriction itself and the compliance with the diet, while the amount of weight loss determines the degree of adaptive thermogenesis (6).

Moderate weight loss also induced a decrease in physical activity. Reducing physical activity can be seen as another biological mechanism to conserve energy storages. It was shown that physical activity spontaneously decreased during the diet, where total daily activity was measured with different techniques including measurement of total energy expenditure using doubly labeled water and measurement of body movement using accelerometry. There are many studies on energy restriction in combination with increasing physical activity via exercise to increase the energy deficit. However, Wu et al. showed in a meta-analysis that additional exercise will be compensated by a reduction of non-training activity (7).

Energy restriction leads to a decrease of physical activity, while overeating does not seem to lead to an increase in physical activity (8-13). Similarly, an exercise-induced increase in energy expenditure will lead to energy intake that compensates for the additional requirement, while a change from a physically active to a more sedentary lifestyle does 
not induce an equivalent reduction of energy intake (14). These interactions implicate that eating less instead of moving more is the way to reduce body weight, and the best method for weight maintenance is to prevent overeating.

During weight maintenance, there was no indication for a change in adaptive thermogenesis up to one year after moderate weight loss, extending the knowledge about sustained adaptive thermogenesis up to 6 years after severe weight loss or up to 7 weeks of follow-up after $10 \%$ of weight loss $(15,16)$. Moreover, the same correlation between the lost weight and adaptive thermogenesis that was observed after the diet was observed up to 44 weeks after weight loss. This indicates that when weight is still below the initial weight from before the diet, adaptive thermogenesis is sustained. At the same time, this indicates that, in case of unsuccessful maintenance of the lost weight and a return to the starting weight, adaptive thermogenesis is no longer observed. In contrast, the results revealed that after weight maintenance, physical activity returned to baseline levels when weight loss was maintained in line with previous literature. This should not be confused with lower activity induced energy expenditure (AEE) that comes along with a lower body weight after weight maintenance even at the same level of physical activity.

In relation to insulin sensitivity, results showed that avoiding or minimizing the decrease in physical activity during energy restriction had a beneficial effect on the improvement of insulin sensitivity. Moreover, improved insulin sensitivity was maintained better if physical activity returned to baseline or increased further during weight maintenance. These results seem contradictory to studies showing no effect on insulin sensitivity of the addition of aerobic or resistance training to an energy restricted diet (17-21). However, as described above, energy restriction leads to a decrease in physical activity $(22,23)$ and addition of exercise to an energy restricted diet is compensated by a reduction of non-training activity (7). To overcome compensation of additional exercise, one might track daily physical activity patterns with portable accelerometers (24), to avoid more sedentariness during weight loss.

Throughout evolution, conserving energy in case of starvation and dangerously low energy supplies was a meaningful survival mechanism $(25,26)$. However, energy conservation could be an important contributor to the low success of long-term weight loss maintenance in our modern world where diet and exercise are the most applied strategies to counteract the increasing prevalence of obesity and its comorbidities (27).

\section{Underlying pathways of adaptations in energy expenditure}

\section{Adipose tissue metabolism}

Energy restriction induced a decrease of AldoC in adipose tissue, indicating a reduced total glycolytic capacity to preserve blood glucose levels and preserve the glucose supply for glucose-dependent tissues such as the brain or red blood cells during energy restriction (28). Additionally, the decrease in AldoC was related to the relative decrease in AEE, which 
can be explained by the decreased total body glycolytic capacity resulting from energy deficiency. The preservation of glucose as an energy source for glucose-dependant tissues might be driven by a reduction in physical activity and muscle usage. Indeed, the correlation between the decreased AldoC and the decrease in fat free mass suggests that there may be an increased use of muscle protein as an energy source in case of physical activity when glucose availability is low.

The correlation between the change in HADHsc and adaptive thermogenesis after the 8-weeks VLED is described as less adaptive thermogenesis when there is more mitochondrial beta-oxidation of long-chain fatty acids in the adipose tissue. This implies that if up-regulation of the mitochondrial beta-oxidation is possible during the diet there is a smaller reduction in resting energy expenditure. Or the other way around, a larger adaptation in REE is the cause for lower up-regulation of HADHsc and delayed increase of the mitochondrial beta-oxidation in fat cells during energy restriction. Previously, Bouwman et al. showed a positive correlation between three enzymes of the beta-oxidation (HADHsc, Acetyl-CoA acetyltransferase and Acyl-CoA dehydrogenase) and plasma free fatty acids (29). This is in line with the idea that up-regulated beta-oxidation leads to less adaptive thermogenesis because of the adipose tissue's ability to increase free fatty acids in the circulation. Overall, the findings reveal a clear link between changes on a physiological level and changes of the molecular metabolism in fat cells. This shows the important role of adipose tissue in obese people. The molecular changes in adipose tissue as a result of a negative energy balance could be the underlying driver of adaptations in body composition and energy expenditure. The latter should be the subject of future research.

\section{Leptin}

The results showed that the decrease in leptin in response to energy restriction is related to adaptive thermogenesis. Previously, leptin had been shown to be correlated to the weight loss induced decrease of REE (30,31); our results specifically indicated a relation with adaptive thermogenesis, in line with Lecoultre et al. and Knuth et al. (32, 33). It has been shown that leptin concentrations are still decreased during weight maintenance proportional to fat mass (34), however our research did not supply data that could clarify if reduced leptin concentrations were correlated to adaptive thermogenesis during weight maintenance. Rosenbaum et al. showed that leptin administration during a weight-reduced state (weight maintenance) returned energy expenditure to pre-weight loss levels (16, 35).

Furthermore, the decrease in leptin is not correlated to the reduction in the amount of physical activity, however leptin is independently correlated to the increased movement economy. In accordance with our results, Doucet et al. described a relation between the changes in leptin concentration and the difference between the predicted and the measured fall in net exercise energy expenditure (36). This implies that leptin does not play a role in the reduction of the amount of physical activity but that it points towards an effect on increased movement economy during energy restriction. 
The combined results suggest a central role for leptin in the underlying mechanisms of metabolic adaptation, where a leptin associated decrease in sympathetic nervous activity seems an important mediator (37). That way, leptin could modulate sympathetic ouflow to target organs with roles in the triglycerides metabolism like the liver (production), adipose tissue (storage) and skeletal muscle (combustion to generate ATP), still the exact mechanism remains speculative $(38,39)$.

\section{Genetic predisposition}

Higher physical activity was found in subjects carrying the risk allele of the FTO polymorphism. This seems to be conflicting with results from previous studies showing an association of the FTO risk allele with higher body weight and BMI $(40,41)$ and additionally, between people with a higher BMI and less physical activity (42). However, it does suggest that higher BMI in people carrying the FTO risk allele is not caused by an inactive lifestyle. Besides the relation between FTO and BMI, weight and energy expenditure, it is known that carriers of the FTO risk allele have an increased food intake which is in line with the high expression of FTO in the hypothalamic site of brain tissue that controls food intake (43). Carrying the FTO risk allele could comprise a compensatory mechanism of physical activity and energy intake to match each other. This would explain the higher BMI that is seen in people carrying the FTO risk allele as the result of overcompensation of energy intake to increased physical activity, which is in line with the increased energy intake to compensate for exercise-induced increase in energy expenditure (14).

Results showed that subjects with the minor homozygous genotype of ADRB2 tend to have lower resting energy expenditure. Moreover, obese men and women, homozygous for the minor ADRB2 allele show a greater adaptive thermogenesis induced by energy restriction. Several studies have suggested a link between the ADRB2 risk allele and the metabolic syndrome $(44,45)$, while Ruiz et al. showed higher weight loss in women carrying the common ADRB2 allele (46). ADRB2 is a member of the G-protein-coupled adrenergic receptor superfamily and participates in the peripheral regulation of energy expenditure (47). Expressed in subcutaneous adipose tissue, ADRB2 mobilizes lipids within human fat cells by stimulating lipolysis. Experimental studies have shown that the minor ADRB2 allele reduced the function of the $\beta 2$-receptor. The association between REE, adaptive thermogenesis and the altered function of the $\beta 2$-adrenergic receptor suggests that the reduced ability to mobilize lipids within adipose tissue through lipolysis has a central role. This is in line with the results that showed that people with a reduced ability to increase $\beta$-oxidation of free fatty acids had more energy restriction induced adaptive thermogenesis. 


\section{Conclusions}

- Energy restriction induces sustained adaptive thermogenesis when weight loss is maintained.

- The larger the weight loss the larger the adaptive thermogenesis.

- Energy restriction induces a decrease in total daily physical activity.

- An energy restriction induced decrease in total daily physical activity is not sustained when energy intake meets again energy expenditure.

- Avoiding or minimizing a decrease in physical activity during energy restriction has a beneficial effect on the improvement of insulin sensitivity.

- Moremitochondrial beta-oxidation in adiposetissue is related to less adaptive thermogenesis after energy restriction.

- A greater decrease in glycolytic capacity in adipose tissue following energy restriction is related to a larger decrease in activity induced energy expenditure.

- The larger the weight loss induced decrease in circulating leptin concentration, the larger the adaptive thermogenesis.

- The larger the weight loss induced decrease in circulating leptin concentration, the larger the increase in movement economy.

- Subjects carrying the risk allele of the FTO polymorphism show higher physical activity.

- Subjects, homozygous for the minor ADRB2 allele show lower resting energy expenditure before energy restriction and more adaptive thermogenesis after energy restriction

\section{$\rightarrow$ FIGURE 8.1}

Figure 8.1. Energy restriction leads to adaptive thermogenesis. More mitochondrial beta-oxidation in adipose tissue is related to less adaptive thermogenesis after energy restriction. Additionally, more beta-oxidation is correlated to more plasma free fatty acids (29). The larger the weight loss induced decrease in circulating leptin concentration, the larger the adaptive thermogenesis. Subjects carrying the homozygous minor ADRB2 allele show more adaptive thermogenesis after energy restriction. Expressed in subcutaneous adipose tissue, ADRB2 mobilizes lipids within human fat cells by stimulating lipolysis. Leptin promotes lipolysis and energy expenditure; as a result lower circulating leptin concentration is related to less lipolysis (48). This could involve the beta-adrenergic receptor (ADRB2); leptin is considered to be able to stimulate catecholamine synthesis in the adrenal medulla; subsequently, catecholamines can bind to the to ADRB2 on adipocytes to stimulate lipolysis (49).

\section{Perspectives for future research}

Quantification of adaptations in energy expenditure following energy restriction is necessary to understand the impact on the success of weight loss maintenance. Future research could look into the quantification of adaptive thermogenesis during different amounts of energy restriction. It seems plausible that a smaller negative energy balance causes less pronounced adaptive thermogenesis. Therefore, it could be of use to quantify the energy gap that prevents 
or minimizes the development of adaptive thermogenesis. Additionally, establishing the time schedule of the development of adaptive thermogenesis could increase the success of weight loss and possibly minimize adaptations. It could be important to look deeper into the sustained adaptive thermogenesis even long after initial weight loss. With a lot of people being on constant weight loss and regain cycles it would be interesting to assess if multiple weight cycles could add up to more adaptive thermogenesis and cause more severe and permanent metabolic damage.

Unraveling underlying molecular pathways in adaptations in energy expenditure following energy restriction will be of great importance to understand why there is a low success of weight loss maintenance. It should give us the knowledge as well as therapeutic targets important to increase success against the growing obesogenic epidemic that causes a multitude of health problems. Possible mechanisms found in the adipocyte metabolism are just the starting point for understanding the role of adipocytes not only in energy storage, but especially their role in energy storage protection. In regard to adipocyte metabolism, future research should also investigate the possible relation between cellular stress and energy expenditure in response to weight loss (50). For the same reason, leptin can be a focal point for future research as it represents a central role regulating energy intake and energy expenditure. Leptin administration can reverse many adaptations caused by energy restriction $(16,35,51)$. In physique sports, periodic refeeding has become common during longer periods of energy restriction. The goal of periodic refeeding is to temporarily increase circulating leptin and stimulate energy expenditure $(52,53)$. More research is needed to determine if leptin administration or acute bouts of refeeding are an efficient strategy to decrease metabolic adaptations during energy restriction.

Effective methods to counteract decreased physical activity during energy restriction could be assessed as maintained physical activity levels are shown to be more beneficial with respect to insulin sensitivity. This probably causes difficulties since it is seen that increased exercise is compensated by more sedentariness after exercise.

Concerning the understanding of the genetic contribution to adaptations in energy expenditure as well as weight loss and weight maintenance, it is important to investigate gene-gene and gene-environment interactions. More loci already associated with obesity could be investigated in relation to adaptations in energy expenditure in longitudinal cohort studies to gain insight to bolster the network of interactions involved in the regulation of energy expenditure during weight loss. 


\section{References}

1. Leibel RL, Rosenbaum M, Hirsch J. Changes in energy expenditure resulting from altered body weight. N Engl J Med 1995;332:621-8.

2. Doucet E, St-Pierre S, Almeras N, Despres JP, Bouchard C, Tremblay A. Evidence for the existence of adaptive thermogenesis during weight loss. Br J Nutr 2001;85:715-23.

3. Martin CK, Heilbronn LK, de Jonge L, DeLany JP, Volaufova J, Anton SD, Redman LM, Smith SR, Ravussin E. Effect of calorie restriction on resting metabolic rate and spontaneous physical activity. Obesity (Silver Spring) 2007;15:2964-73.

4. Tremblay A, Chaput JP. Adaptive reduction in thermogenesis and resistance to lose fat in obese men. Br J Nutr 2009;102:488-92.

5. Johannsen DL, Knuth ND, Huizenga R, Rood JC, Ravussin E, Hall KD. Metabolic Slowing with Massive Weight Loss despite Preservation of Fat-Free Mass. J Clin Endocrinol Metab 2012;97.

6. Heymsfield SB, Harp JB, Reitman ML, Beetsch JW, Schoeller DA, Erondu N, Pietrobelli A. Why do obese patients not lose more weight when treated with low-calorie diets? A mechanistic perspective. Am J Clin Nutr 2007;85:346-54.

7. Wu T, Gao X, Chen M, van Dam R. Long-term effectiveness of diet-plus-exercise interventions vs, diet-only interventions for weight loss: a meta-analysis. Obesity reviews : an official journal of the International Association for the Study of Obesity 2009;10:313-323.

8. Joosen AM, Westerterp KR. Energy expenditure during overfeeding. Nutr Metab (Lond) 2006;3:25.

9. Westerterp KR. Physical activity, food intake, and body weight regulation: insights from doubly labeled water studies. Nutr Rev 2010;68:148-54.

10. Roberts SB, Young VR, Fuss P, Fiatarone MA, Richard B, Rasmussen H, Wagner D, Joseph L, Holehouse E, Evans WJ. Energy expenditure and subsequent nutrient intakes in overfed young men. Am J Physiol 1990;259:R461-9.

11. Diaz EO, Prentice AM, Goldberg GR, Murgatroyd PR, Coward WA. Metabolic response to experimental overfeeding in lean and overweight healthy volunteers. Am J Clin Nutr 1992;56:641-55.

12. Joosen AM, Bakker AH, Westerterp KR. Metabolic efficiency and energy expenditure during shortterm overfeeding. Physiol Behav 2005;85:593-7.

13. Siervo M, Fruhbeck G, Dixon A, Goldberg GR, Coward WA, Murgatroyd PR, Prentice AM, Jebb SA. Efficiency of autoregulatory homeostatic responses to imposed caloric excess in lean men. Am J Physiol Endocrinol Metab 2008;294:E416-24.

14. Stubbs RJ, Hughes DA, Johnstone AM, Horgan GW, King N, Blundell JE. A decrease in physical activity affects appetite, energy, and nutrient balance in lean men feeding ad libitum. Am J Clin Nutr 2004;79:62-9.

15. van Gemert WG, Westerterp KR, Greve JW, Soeters PB. Reduction of sleeping metabolic rate after vertical banded gastroplasty. Int J Obes Relat Metab Disord 1998;22:343-8.

16. Rosenbaum M, Goldsmith R, Bloomfield D, Magnano A, Weimer L, Heymsfield S, Gallagher D, Mayer L, Murphy E, Leibel RL. Low-dose leptin reverses skeletal muscle, autonomic, and neuroendocrine adaptations to maintenance of reduced weight. J Clin Invest 2005;115:3579-86.

17. Weinstock RS, Dai H, Wadden TA. Diet and exercise in the treatment of obesity: effects of 3 interventions on insulin resistance. Arch Intern Med 1998;158:2477-83. 
18. Trussardi Fayh AP, Lopes AL, Fernandes PR, Reischak-Oliveira A, Friedman R. Impact of weight loss with or without exercise on abdominal fat and insulin resistance in obese individuals: a randomised clinical trial. Br J Nutr 2013;110:486-92.

19. Snel M, Gastaldelli A, Ouwens DM, Hesselink MK, Schaart G, Buzzigoli E, Frolich M, Romijn JA, Pijl $\mathrm{H}$, Meinders AE, et al. Effects of adding exercise to a 16-week very low-calorie diet in obese, insulindependent type 2 diabetes mellitus patients. J Clin Endocrinol Metab 2012;97:2512-20.

20. Janssen I, Fortier A, Hudson R, Ross R. Effects of an energy-restrictive diet with or without exercise on abdominal fat, intermuscular fat, and metabolic risk factors in obese women. Diabetes Care 2002;25:431-8.

21. Fox AA, Thompson JL, Butterfield GE, Gylfadottir U, Moynihan S, Spiller G. Effects of diet and exercise on common cardiovascular disease risk factors in moderately obese older women. Am J Clin Nutr 1996;63:225-33.

22. Redman LM, Heilbronn LK, Martin CK, de Jonge L, Williamson DA, Delany JP, Ravussin E. Metabolic and behavioral compensations in response to caloric restriction: implications for the maintenance of weight loss. PLoS One 2009;4:e4377.

23. Camps SG, Verhoef SP, Westerterp KR. Weight loss-induced reduction in physical activity recovers during weight maintenance. Am J Clin Nutr 2013;98:917-23.

24. Bonomi AG, Plasqui G, Goris AH, Westerterp KR. Improving assessment of daily energy expenditure by identifying types of physical activity with a single accelerometer. J Appl Physiol 2009;107:65561.

25. Keys A. The residues of malnutrition and starvation. Science 1950;112:371-3.

26. Taylor HL, Keys A. Adaptation to caloric restriction. Science 1950;112:215-8.

27. Wing RR, Phelan S. Long-term weight loss maintenance. Am J Clin Nutr 2005;82:222S-225S.

28. Canto C, Jiang LQ, Deshmukh AS, Mataki C, Coste A, Lagouge M, Zierath JR, Auwerx J. Interdependence of AMPK and SIRT1 for metabolic adaptation to fasting and exercise in skeletal muscle. Cell Metab 2010;11:213-9.

29. Bouwman FG, Claessens M, van Baak MA, Noben JP, Wang P, Saris WH, Mariman EC. The physiologic effects of caloric restriction are reflected in the in vivo adipocyte-enriched proteome of overweight/ obese subjects. J Proteome Res 2009;8:5532-40.

30. Doucet E, St Pierre S, Almeras N, Mauriege P, Richard D, Tremblay A. Changes in energy expenditure and substrate oxidation resulting from weight loss in obese men and women: is there an important contribution of leptin? J Clin Endocrinol Metab 2000;85:1550-6.

31. Labayen I, Ortega FB, Ruiz JR, Lasa A, Simon E, Margareto J. Role of baseline leptin and ghrelin levels on body weight and fat mass changes after an energy-restricted diet intervention in obese women: effects on energy metabolism. J Clin Endocrinol Metab 2011;96:E996-1000.

32. Lecoultre V, Ravussin E, Redman LM. The fall in leptin concentration is a major determinant of the metabolic adaptation induced by caloric restriction independently of the changes in leptin circadian rhythms. J Clin Endocrinol Metab 2011;96:E1512-6.

33. Knuth ND, Johannsen DL, Tamboli RA, Marks-Shulman PA, Huizenga R, Chen KY, Abumrad NN, Ravussin E, Hall KD. Metabolic adaptation following massive weight loss is related to the degree of energy imbalance and changes in circulating leptin. Obesity (Silver Spring) 2014.

34. Rosenbaum M, Leibel RL. Adaptive thermogenesis in humans. Int J Obes (Lond) 2010;34 Suppl 1:S47-55. 
35. Rosenbaum M, Murphy EM, Heymsfield SB, Matthews DE, Leibel RL. Low dose leptin administration reverses effects of sustained weight-reduction on energy expenditure and circulating concentrations of thyroid hormones. J Clin Endocrinol Metab 2002;87:2391-4.

36. Doucet E, Imbeault P, St-Pierre S, Almeras N, Mauriege P, Despres JP, Bouchard C, Tremblay A. Greater than predicted decrease in energy expenditure during exercise after body weight loss in obese men. Clin Sci (Lond) 2003;105:89-95.

37. Arone LJ, Mackintosh R, Rosenbaum M, Leibel RL, Hirsch J. Autonomic nervous system activity in weight gain and weight loss. Am J Physiol 1995;269:R222-5.

38. Leibel RL. The role of leptin in the control of body weight. Nutr Rev 2002;60:S15-9; discussion S6884, 85-7.

39. Geerling JJ, Boon MR, Kooijman S, Parlevliet ET, Havekes LM, Romijn JA, Meurs IM, Rensen PC. Sympathetic nervous system control of triglyceride metabolism: novel concepts derived from recent studies. J Lipid Res 2013;55:180-9.

40. Scuteri A, Sanna S, Chen WM, Uda M, Albai G, Strait J, Najjar S, Nagaraja R, Orru M, Usala G, et al. Genome-wide association scan shows genetic variants in the FTO gene are associated with obesity-related traits. PLoS Genet 2007;3:e115.

41. Verhoef SP, Camps SG, Bouwman FG, Mariman EC, Westerterp KR. Genetic predisposition, dietary restraint and disinhibition in relation to short and long-term weight loss. Physiol Behav 2014;128:247-51.

42. Ekelund U, Aman J, Yngve A, Renman C, Westerterp K, Sjostrom M. Physical activity but not energy expenditure is reduced in obese adolescents: a case-control study. Am J Clin Nutr 2002;76:935-41.

43. Zhao X, Yang Y, Sun BF, Zhao YL, Yang YG. FTO and obesity: mechanisms of association. Curr Diab Rep 2014;14:486.

44. Dallongeville J, Helbecque N, Cottel D, Amouyel P, Meirhaeghe A. The Gly16-->Arg16 and GIn27-$>$ Glu27 polymorphisms of beta2-adrenergic receptor are associated with metabolic syndrome in men. J Clin Endocrinol Metab 2003;88:4862-6.

45. Park HS, Shin ES, Lee JE. Genotypes and haplotypes of beta2-adrenergic receptor and parameters of the metabolic syndrome in Korean adolescents. Metabolism 2008;57:1064-70.

46. Ruiz JR, Larrarte E, Margareto J, Ares R, Labayen I. Role of beta(2)-adrenergic receptor polymorphisms on body weight and body composition response to energy restriction in obese women: preliminary results. Obesity (Silver Spring) 2011;19:212-5.

47. Loktionov A. Common gene polymorphisms and nutrition: emerging links with pathogenesis of multifactorial chronic diseases (review). J Nutr Biochem 2003;14:426-51.

48. Altarejos JY, Montminy M. CREB and the CRTC co-activators: sensors for hormonal and metabolic signals. Nat Rev Mol Cell Biol 2011;12:141-51.

49. Shibuya I, Utsunomiya K, Toyohira Y, Ueno S, Tsutsui M, Cheah TB, Ueta Y, Izumi F, Yanagihara N. Regulation of catecholamine synthesis by leptin. Ann N Y Acad Sci 2002;971:522-7.

50. Mariman EC. Human biology of weight maintenance after weight loss. J Nutrigenet Nutrigenomics 2012;5:13-25.

51. Rosenbaum M, Sy M, Pavlovich K, Leibel RL, Hirsch J. Leptin reverses weight loss-induced changes in regional neural activity responses to visual food stimuli. J Clin Invest 2008;118:2583-91.

52. Trexler ET, Smith-Ryan AE, Norton LE. Metabolic adaptation to weight loss: implications for the athlete. J Int Soc Sports Nutr 2014;11:7. 
53. Dirlewanger M, di Vetta V, Guenat E, Battilana P, Seematter G, Schneiter P, Jequier E, Tappy L. Effects of short-term carbohydrate or fat overfeeding on energy expenditure and plasma leptin concentrations in healthy female subjects. Int J Obes Relat Metab Disord 2000;24:1413-8. 

Summary 
The increasing prevalence of obesity and its association with impaired insulin homeostasis are major health problems in our modern world; both are linked to the development of noncommunicable diseases as type 2 diabetes and cardiovascular diseases. Weight gain and obesity occur when energy intake exceeds energy expenditure; this positive energy balance results in the storage of excess energy as fat. The remedy to obesity is creating a negative energy balance for a longer period of time by dietary intervention and/or increased physical activity and although weight loss strategies target the intake as well as the expenditure side of the energy balance, the success of long-term weight loss maintenance is low. Thus, measures to improve the success of weight loss maintenance are warranted.

Weight loss as a result of energy restriction is counteracted by physiological adaptations that can promote a positive energy balance like adaptive thermogenesis, i.e. a disproportional reduction in resting energy expenditure beyond what can be predicted based on fat and fat free mass loss, and a decrease in physical activity. In origin, these adaptations were a meaningful survival mechanism to save energy in the face of starvation and dangerously low energy supplies, nowadays these adaptations increase the susceptibility for weight regain after intentional weight loss in overweight and obese subjects.

As an energy storing and releasing tissue and as an endocrine organ, adipose tissue could play an important role in functionally responding to disturbances in energy balance. Leptin is an adipocyte-derived hormone that is a critical mediator of energy balance. It functions as a satiety hormone in a negative feedback loop regulating energy intake and has been shown to be correlated to the weight loss induced decrease in resting energy expenditure. Individuals respond differently to environmental changes and weight gain risk factors and this inter-individual variation in the susceptibility to develop obesity is partly explained by genetics; currently the genetic contribution is estimated at $40-70 \%$.

Understanding how the body responds to energy restriction can lead to knowledge on, and improve the success of, weight loss strategies and can improve the long-term results. The first aim was to quantify adaptive thermogenesis and changes in physical activity before and after a very low energy diet, and during 1 year of follow-up. Additionally, weight loss and changes in physical activity were related to insulin sensitivity. The second aim was to examine adaptive changes in energy expenditure in relation to: 1) changes in glucose and fatty acid metabolism in fat cells, 2) plasma leptin levels and 3) single nucleotide polymorphisms previously associated with obesity, in order to unravel part of the underlying pathways of these adaptations.

More than 200 overweight and obese subjects followed a very low energy diet for 8 weeks, followed by 44 weeks of weight maintenance. First, they were characterized by six genetic variants with shown associations with obesity-related traits. Then, measurements took place before the diet and at 8, 20 and 52 weeks. Body composition was assessed using 3-compartment model based on body weight, total body water (deuterium dilution), and body volume (BodPod). Resting energy expenditure was measured with a ventilated hood 
and compared with predicted values based on measured body composition; adaptive thermogenesis was calculated as measured/predicted resting energy expenditure. Physical activity measures were physical activity level (PAL), doubly labeled water assessed total energy expenditure expressed as a multiple of measured resting energy expenditure, activity induced energy expenditure divided by body weight, and body movement measured with a triaxial accelerometer. Fasting plasma insulin, glucose and leptin were analyzed and protein levels of markers for adipocyte glucose and fatty acid metabolism were determined from adipose tissue biopsies.

Moderate weight loss, as a result of energy restriction, induced adaptive thermogenesis and subjects with greater weight loss showed more adaptive thermogenesis. During weight maintenance, there was no indication for a change in adaptive thermogenesis up to one year of follow-up. Moreover, the relation between weight loss and adaptive thermogenesis was unchanged during weight maintenance. Thus, in case of unsuccessful maintenance of the lost weight and a return to or beyond the starting weight, adaptive thermogenesis was no longer observed. Physical activity decreased during energy restriction. However, in contrast with adaptive thermogenesis, physical activity returned to baseline levels when the lost weight was maintained, which should not be confused with lower activity induced energy expenditure that comes along with a lower body weight after weight maintenance, even at the same level of physical activity. Avoiding or minimizing the decrease in physical activity during energy restriction improved insulin sensitivity in addition to the effect of weight loss. During weight maintenance, improved insulin sensitivity was maintained better when physical activity returned to baseline levels or higher.

During energy restriction, changes in energy expenditure were linked to changes in adipose tissue metabolism. Energy restriction induced a decrease in AldoC in adipose tissue, indicating a reduced glycolytic capacity, which helps to preserve blood glucose levels and preserve glucose supply for glucose-dependent tissues such as the brain or red blood cells during energy restriction. The decrease in AldoC was related to the decrease in activity induced energy expenditure, which could be explained by the decreased total body glycolytic capacity. Thus, preservation of glucose as an energy source for glucose-dependent tissues might be driven by a reduction in physical activity. The change in HADHsc was correlated with adaptive thermogenesis after the diet and implies that up-regulation of the mitochondrial beta-oxidation might reduce adaptive thermogenesis. This is supported by the positive correlation between increased beta-oxidation and free fatty acids in the circulation. Furthermore, the results showed that the decrease in leptin in response to energy restriction was related to adaptive thermogenesis and an increase in movement economy. The results suggest a central role for leptin in the underlying mechanism of metabolic adaptation, where a leptin associated decrease in sympathetic nervous activity seems an important mediator. Leptin possibly modulates sympathetic outflow to target organs with roles in triglyceride 
metabolism like the liver (production), adipose tissue (storage) and skeletal muscle (combustion to generate ATP).

Higher physical activity was observed in subjects carrying the risk allele of the FTO polymorphism, suggesting a higher BMI in people carrying the FTO risk allele is not caused by an inactive lifestyle. Carrying the FTO risk allele is known to be associated with increased food intake. Together, higher BMI in people carrying the FTO risk allele could be the result of overcompensation of energy intake to increased physical activity, in line with increased food intake to compensate for an exercise-induced increase in energy expenditure. Subjects homozygous for the ADRB2 risk allele had lower resting energy expenditure and showed greater adaptive thermogenesis following energy restriction. A reduced function of the $\beta 2-$ receptor as a result of the homozygous ADRB2 risk allele suggests that the reduced ability to mobilize lipids within adipose tissue through lipolysis has a role in adaptive thermogenesis. This is in line with the results that showed that people with a reduced ability to increase betaoxidation of free fatty acids had more energy restriction induced adaptive thermogenesis.

In conclusion, energy restriction leads to metabolic adaptations promoting a positive energy balance and increasing susceptibility for weight regain. The metabolic adaptations as described are linked to metabolism changes in fat cells, the adipocyte-derived satiety hormone leptin and obesity-related polymorphisms in FTO and ADRB2. This forms the basis for further research and may lead to additional or improved weight loss and weight maintenance interventions in overweight and obese subjects. 
Samenvatting 
De huidige samenleving kent een groeiend aantal mensen met overgewicht en obesitas, resulterend in gezondheidsproblemen zoals type 2 diabetes en hart- en vaatziekten. Overgewicht en obesitas ontstaan wanneer de inname van energie groter is dan het energiegebruik; waarbij de overtollige hoeveelheid energie wordt opgeslagen als vet. De meest voor de hand liggende oplossingen zijn een verlaging van de energie inname door minder te eten en een verhoging van het energiegebruik door meer lichaamsbeweging. Het bereikte gewichtsverlies en het behoud daarvan op de langere termijn is echter meestal teleurstellend.

Gewichtsverlies als gevolg van een negatieve energiebalans gaat gepaard met fysiologische aanpassingen die herstel van de energiebalans bevorderen. Voorbeelden zijn adaptieve thermogenese, dit is een daling van het rustmetabolisme die groter is dan verwacht op basis gewichtsverandering door verlies van vet- en vetvrije massa, en een vermindering van lichamelijke activiteit. Een adaptieve daling van het energiegebruik is een belangrijk overlevingsmechanisme in tijden van voedselschaarste. Anderzijds vergroot een adaptieve daling van het energiegebruik het risico op gewichtstoename na gewichtsverlies bij personen met overgewicht en obesitas.

Een factor die een mogelijke rol speelt bij de beschreven adaptaties als gevolg van veranderingen in de energiebalans is leptine. Leptine is een door de vetcellen geproduceerd hormoon. Afname van het lichaamsvet veroorzaakt een afname van de leptine productie. Voorheen is aangetoond dat daling van leptine gerelateerd is aan de daling van het rustmetabolisme na een dieet. De gevoeligheid om overgewicht en obesitas te ontwikkelen heeft gedeeltelijk te maken met genetische aanleg. Niet iedereen reageert hetzelfde op omgevingsveranderingen en risico's voor gewichtstoename. De genetische bijdrage wordt op dit moment geschat op 40-70\%.

Kennis over veranderingen in het energiegebruik als gevolg van een energie-beperkt dieet, kan leiden tot betere strategieën voor gewichtsverlies en gewichtsbehoud om zo het lange termijn succes hiervan te vergroten. Het eerste doel was om adaptieve thermogenese en de verandering in lichaamsbeweging voor en na een energie-beperkt dieet te kwantificeren en te volgen gedurende een jaar. De veranderingen in gewicht en lichaamsbeweging werden ook gekoppeld aan insulinegevoeligheid. Het tweede doel was om de veranderingen in het energiegebruik te onderzoeken in relatie tot: 1) veranderingen in het glucose en vetzuurmetabolisme in vetcellen, 2) de leptine concentratie in het bloed en 3) genetische varianten gekoppeld aan obesitas.

Meer dan 200 proefpersonen met een gewichtsindex hoger dan $28 \mathrm{~kg} / \mathrm{m}^{2} \mathrm{kregen} 8$ weken lang een energie-beperkt dieet en werden daarna nog 44 weken gevolgd. Zij werden allereerst gekarakteriseerd wat betreft genetische varianten gekoppeld aan obesitas. Vervolgens vonden metingen plaats vóór de start van het dieet en na 8, 20 en 52 weken. Lichaamssamenstelling werd bepaald met een 3-compartimenten model gebaseerd op gewicht, totaal lichaamswater (deuterium-verdunning) en lichaamsvolume (BodPod). Het 
rustmetabolisme werd gemeten met indirecte calorimetrie en vergeleken met voorspelde waardes gebaseerd op lichaamssamenstelling; adaptieve thermogenese werd berekend door vergelijking van gemeten rustmetabolisme met voorspeld rustmetabolisme. Parameters voor lichamelijke activiteit waren: "physical activity level" (PAL), het totaal energiegebruik gemeten met tweevoudig gemerkt water gedeeld door het rustmetabolisme; activiteit geïnduceerd energiegebruik; en lichaamsbeweging gemeten met een versnellingsopnemer. Daarnaast werden in bloedmonsters glucose, insuline en leptine bepaald en in vetbiopten markers voor het glucose en vetzuurmetabolisme.

Gewichtsverlies als gevolg van het energie-beperkte dieet leidde tot adaptieve thermogenese en personen met meer gewichtsverlies hadden meer adaptieve thermogenese. Bij behoud van gewichtsverlies veranderde de adaptieve thermogenese niet tijdens de 44 weken durende vervolgperiode. Het verband tussen gewichtsverlies en adaptieve thermogenese bleef hetzelfde als direct na het dieet. Dit betekent dat er na 1 jaar nog adaptieve thermogenese was bij een lager gewicht dan het uitgangsgewicht en dat de adaptieve thermogenese verdween bij terugkeer naar het uitgangsgewicht. De negatieve energiebalans door een energie-beperkt dieet resulteerde bovendien in een vermindering van lichamelijke activiteit. In tegenstelling tot het rustmetabolisme keerde het niveau van lichamelijke activiteit na het dieet terug naar het uitgangsniveau. Gewichtsverlies resulteerde in een verhoging van de insulinegevoeligheid, met name bij personen waarbij de lichamelijke activiteit minder afnam tijdens het dieet. De verhoogde insulinegevoeligheid werd tijdens de vervolgperiode beter behouden als de lichamelijke activiteit terugkeerde naar de oorspronkelijke waardes of hoger werd.

De bevindingen lieten een verband zien tussen metabole adaptaties op lichaamsniveau en veranderingen van het metabolisme in de vetcellen. Als gevolg van de negatieve energiebalans daalde het niveau van AldoC in het vetweefsel. Dit duidt op een daling van de glycolytische capaciteit (minder glucosegebruik) in het vetweefsel, die meehelpt om de glucosespiegel in het bloed op peil te houden en glucose-afhankelijke weefsels zoals de hersenen en rode bloedcellen van voldoende glucose te voorzien. Uit de data bleek verder dat de daling van AldoC gerelateerd was aan de relatieve daling van het activiteits-geïnduceerd energiegebruik. Dit kan betekenen dat de daling van het glucosegebruik in het vetweefsel een marker is voor een vergelijkbare daling in andere weefsels en daarmee van de daling van lichamelijke activiteit, waardoor de bloedglucosespiegel en de glucosevoorziening voor onder andere de hersenen op peil worden gehouden. Er werd ook een verband aangetoond tussen de verandering van HADHsc, een belangrijk enzym voor de vetzuur verbranding, en de adaptieve thermogenese; hoe hoger de capacteit van de vetzuur verbranding in het vetweefsel, des te lager was de adaptieve thermogenese. Ditsluit aan bij een eerder gevonden verband tussen een hogere vetzuur verbranding in vetcellen en een hogere concentratie aan vrije vetzuren in het bloed. Het idee hierbij is, dat de mate van vetzuur verbranding een marker is voor de mate waarin vetzuren uit de vetcellen worden vrijgemaakt voor eigen gebruik en 
als energiebron voor andere weefsels. Hoe meer energie er beschikbaar komt in de vorm van vrije vetzuren, des te minder hoeft het rustmetabolisme te dalen en des te geringer is de adaptieve thermogenese. De resultaten toonden tevens aan dat er een verband is tussen de daling van leptine, de adaptieve thermogenese en de gestegen bewegingsefficiëntie na het dieet. Hieruit blijkt dat leptine mogelijk een centrale rol vervult bij de metabole adaptaties; dit gebeurt dan waarschijnlijk via het sympathisch zenuwstelsel.

Uit de resultaten bleek dat dragers van het FTO risico allel een hogere lichamelijke activiteit vertoonden. Aangezien het FTO risico allel geassocieerd is met een hogere BMI lijkt dit tegenstrijdig maar het geeft in feite aan, dat de hogere BMI niet het gevolg is van een minder actieve levensstijl. Verder is bekend dat het dragen van het FTO risico allel geassocieerd is met een hogere voedselinname. Als zodanig kan de hogere BMI het gevolg zijn van overcompensatie van de energie-inname ten opzichte van de verhoogde lichamelijke activiteit. Homozygote dragers van het risico allel voor ADRB2, het gen voor de $\beta 2$-receptor die belangrijk is voor de signaal overdracht door het sympathische zenuwstelsel, hadden een lager rustmetabolisme; daarbovenop werd het homozygote ADRB2 risico allel geassocieerd met meer adaptieve thermogenese. Aangezien het risico allel zorgt voor een verminderde functie van de 32 -receptor passen de waarnemingen bij een verminderd vermogen om vetzuren uit vetweefsel vrij te maken. Dit past bij het bovenvermelde resultaat dat een geringer vermogen om de verbranding van vrije vetzuren te verhogen, een verband laat zien met een hogere adaptieve thermogenese.

Concluderend, een beperking van de energie-inname leidt tot adaptieve veranderingen in het energiegebruik die herstel van de energiebalans bevorderen en zo een effect op lichaamsgewicht verminderen of teniet doen. De metabole adaptaties zijn gerelateerd aan veranderingen van het metabolisme in vetcellen, de daling van het verzadigingshormoon leptine en aan obesitas gekoppelde genetische varianten van FTO en ADRB2. Dit vormt de basis voor verder onderzoek en kan leiden tot nieuwe of verbeterde strategieën voor gewichtsverlies en het behoud daarvan bij personen met overgewicht en obesitas. 
Valorization 
Overweight and obesity are defined as an excessive accumulation of body fat to the extent that it may impair health. Worldwide, obesity prevalence has doubled since 1980 and in 2008 more than 1.4 billion adults aged 20 years or older were overweight. More than 200 million men and nearly 300 million women of these overweight people were obese. Overweight and obesity are related to health problems such as type 2 diabetes, cardiovascular diseases and certain forms of cancer, which makes it one of the leading risks for global deaths. Each year, around 3.4 million adults die as a result of being overweight or obese. Currently, almost 50 million children under the age of 5 are overweight or obese and the rate of increase of childhood overweight and obesity has been more than 30\% higher in developing countries with emerging economies compared to that of developed countries. Childhood obesity is associated with a higher chance of obesity as well as an increased risk of related noncommunicable diseases later in life. The larger increase in developing countries has made overweight and obesity a clear worldwide problem that can no longer be considered as a typical Western disease. In addition to the health problems, overweight and obesity also have a considerable economic impact and increase healthcare costs. In the Netherlands where almost $50 \%$ of the adult population is overweight, it was responsible for an extra 2 billion euro on medical and social costs in 2010.

Weight gain and obesity occur when energy intake exceeds energy expenditure and the positive energy balance will result in the storage of excess energy as body fat. The prevalence of overweight and obesity coincided with technological developments like computers, cars, washing machines and television, contributing to a sedentary lifestyle, suggesting a causal link. However, doubly labeled water measurements showed that physical activity induced energy expenditure did not decrease between 1983 and 2005 while obesity rates doubled over the same period. The latter implies that an increased intake is responsible for the energy imbalance resulting in the gain of weight and subsequently obesity. It is supported by the fact that during the same period dietary habits changed, with increased portion sizes, changed meal composition and eating out, plus the fact that palatable, energy-dense foods became readily available. The change of our environment to an obesogenic risk factor cannot fully explain the development of obesity at an individual level, since there are still many individuals who manage to remain lean. In fact, the susceptibility to become obese also depends on behavioral, social, cultural, economic, metabolic, physiological and genetic factors.

There is a simple remedy to obesity, i.e. losing weight by creating a negative energy balance for a longer period of time. This can be realized by dietary intervention, increased physical activity, or pharmacological and/or surgical treatment. Although weight loss strategies target both sides of the energy balance, the success of long-term weight loss maintenance is low. Thus, measures to improve the success of weight loss maintenance are warranted. Understanding how the body responds to energy restriction can lead to important knowledge on, and improve the success of, weight loss strategies and can improve the long-term results. 
Therefore, energy expenditure components and physical activity were measured before and after weight loss and were followed up to one year of weight maintenance. The changes in energy expenditure and physical activity as a result of energy restriction were linked to: 1) changes in glucose and fatty acid metabolism in fat cells, 2) plasma leptin levels and 3) single nucleotide polymorphisms previously associated with obesity, in order to unravel part of the underlying pathways of these adaptations. In the next paragraphs, it is described how the key findings can be translated to society to have an impact that goes beyond science.

Adaptive thermogenesis, a disproportional reduction in resting energy expenditure, was observed and quantified during energy restriction and it was positively correlated to the amount of lost weight. Historically, it was important to preserve energy when energy supply was low; nowadays it is seen as undesirable during intentional weight loss since adaptive thermogenesis can reduce the negative energy gap. Quantification of adaptive thermogenesis can lead to more successful weight loss as it can be used for a better calculation of energy requirements during energy restriction. It is plausible that a smaller negative energy balance causes less pronounced adaptive thermogenesis. Therefore, a smaller negative energy gap should be preferred over faster weight loss. Especially, since it was shown that adaptive thermogenesis was sustained up to 44 weeks after the diet; after severe weight loss, adaptive thermogenesis has even been observed up to 6 years. After energy restriction, adaptive thermogenesis promotes a positive energy balance that can lead to weight regain. Since, the success of long-term weight loss maintenance is low, increased knowledge about impairing factors are important. The quantification of adaptive thermogenesis during weight maintenance can lead to more successful weight maintenance as it provides improved tools to calculate energy requirements after weight loss. As previously stated, a smaller negative energy balance during weight loss could be a method to minimize or avoid adaptive thermogenesis and consequently sustained adaptive thermogenesis. Additionally, adaptive thermogenesis long after weight loss raises concern about weight loss and weight regain cycles. It is not uncommon for people to regain weight after weight loss and then start energy restriction again before reaching the initial body weight. Under these conditions, adaptive thermogenesis could add up and may lead to permanently reduced resting energy expenditure.

Energy restriction reduces body movement and activity induced energy expenditure. The decrease in physical activity during weight loss decreases the negative energy balance and can slow down weight loss. Therefore, it should be encouraged to maintain the level of physical activity despite being in a negative energy balance. Additionally, the results showed that avoiding or minimizing the decrease in physical activity during weight loss has an extra beneficial effect on the improvement of insulin sensitivity. Improved insulin sensitivity will require smaller amounts of insulin to keep blood glucose levels stable. Low insulin sensitivity is associated with type 2 diabetes and the bodies' response to produce more insulin is 
associated with a variety of health problems like damage to blood vessels, high blood pressure, heart disease and heart failure. Monitoring physical activity during weight loss could be a way to avoid the unintentional decrease of physical activity. Therefore, accelerometry devices could be used; they are minimally obtrusive and just have to be carried along to have a measurement of physical activity. Consequently, it can affect the success of weight loss and improve insulin sensitivity.

Hormones and proteins involved in adipose tissue metabolism, revealed a link between changes on a physiological level and changes of the molecular metabolism in fat cells and these could be considered as a target for future research. In turn, this could lead to the development of drugs that could help avoid the adaptations in energy expenditure and improve the success of weight loss and weight loss maintenance. It was shown that the decrease in leptin was related to adaptive thermogenesis and increased movement economy. Together with previous results, it leads to the suggestion of a central role for leptin in the underlying mechanism of metabolic adaptations. In physique sports, periodic refeeding has become common during longer periods of energy restriction. The goal of periodic refeeding is to temporarily increase circulating leptin and stimulate energy expenditure. This strategy could be translated from sports to weight loss in general. Moreover, administration of leptin during energy restriction could be a future method to minimize or reverse metabolic adaptations. Additionally, results showed that metabolic adaptations were correlated to obesity-related polymorphisms. Genetic profiling could lead to individualized intervention and drug treatment programs with higher success rates of weight loss maintenance.

In general, the results can be translated to generate more successful weight loss and weight loss maintenance. However, with regard to overweight and obesity, prevention cannot go unmentioned. The results showed that there was a decrease in physical activity during energy restriction; previously, it has been shown that there seems to be no increase in physical activity induced by overeating. Similarly, an exercise-induced increase in energy expenditure will lead to increased energy intake to compensate the additional requirement, while a change from a physically active to a more sedentary lifestyle does not induce an equivalent reduction in energy intake. These interactions implicate that eating less instead of moving more is the way to reduce body weight, and that the best method for weight maintenance is to prevent overeating.

The results described in this thesis are written in original articles that have been published or submitted to scientific journals in the field of obesity, diabetes and nutrition. Moreover, the articles can be found online and are accessible to scientists who are interested in this topic. In addition, results have been presented on international conferences to colleagues inside and outside the specific field and have been discussed for possible explanations or innovative ways to look at certain associations or results. The present studies help to 
understand metabolic adaptations as a result of energy restriction and explore adipose tissue for possible pathways. 

Dankwoord 
Het dankwoord, de afsluiting van een periode met veel gezichten maar vooral een tijd om met voldoening en een brede lach op terug te kijken.

Allereerst wil ik mijn promotoren bedanken. Klaas, bedankt dat ik bij $u$ de mogelijkheid heb gekregen om te promoveren. Ik wil u bedanken voor het vertrouwen, de vrijheid en de begeleiding tijdens mijn promotietraject. Daadkrachtig heeft u mij gestuurd en wanneer nodig was u streng maar rechtvaardig zodat de tijd en grote lijn nooit uit het oog werden verloren. $U$ was altijd bereikbaar en ik heb veel van u kennis opgestoken. Met interesse heb ik geluisterd naar uw verhalen over uzelf, vogels en uw bijen en ik hoop van harte dat u nog lang van uw hobby's kunt genieten. Edwin, bedankt om de "moleculaire" vlam in mij weer aan te wakkeren. Van uw rust en kennis heb ik veel geleerd en door een open deur en een andere kijk op onze resultaten hebben we deze van meer diepgang kunnen voorzien.

Next, I would like to thank all the members of the reviewing committee, Prof. dr. L.P.A.J. Schrauwen, Dr. A. Bonomi, Prof. dr. A.H. Kersten, Prof. dr M.S. Westerterp-Plantenga and Prof. dr. M.P.A. Zeegers, for their time to review my thesis. Margriet, graag wil ik u ook bedanken uw hulp, leerzame uitjes en interesse tijdens mijn promoveren.

Dan wil ik graag de proefpersonen die deelgenomen hebben aan de studies -misschien wel de belangrijkste bijdragers aan dit proefschrift- bedanken. Daarnaast ook bedankt aan alle stagiaires voor hun hulp.

Eerder zei ik al dat het een tijd was om met een brede lach op terug te kijken en dat komt door de hele afdeling Humane Biologie. Met plezier kwam ik telkens naar het werk en dat komt door iedereen die er nu werkt of de afgelopen jaren heeft gewerkt, bedankt allemaal! Misschien is er de afgelopen jaren één en ander veranderd maar de mensen en daardoor de sfeer op de werkvloer zijn hetzelfde gebleven. Jos, jij bent hierin één van de stuwmotoren. Je zorgt -naast alle bloedanalyses, waarvoor dank!- voor de nodige ontspanning rond het werk en draagt bij aan een plek waar collega's vrienden worden! Antoine, je bent van alle markten thuis, serieus en flauwekul, onvergetelijk is de borrel met de poes... Dr. Freek, met jou samenwerken in het lab zou iedereen eens moeten doen, de perfecte dosis kennis, efficiëntie, zorgvuldigheid en humor; succes bij je aankomende promotie! De secretaresses Claudia, Desiree en Yolanda, altijd goedlachs maar belangrijker nog altijd hulpvaardig en vaak met een antwoord op een heel scala aan vragen. Loek, Paul, Laurens en Marc, de uitleg en technische hulp bij omnical metingen, alle computervragen, de vele analyses en de leuke anekdotes(!), zonder jullie had dit proefschrift er niet gelegen. Ik wil jullie allemaal extra bedanken!

Dan zijn er veel (oud)collega's en (oud)clustergenoten die ik wil bedanken voor de leuke tijd op zowel de universiteit als erbuiten bij onder andere de vele congressen, wetenschappelijke discussies, luchtige gesprekken, koffiepauzes, borrels, HB-weekenden, carnavals en 
kerstmarkten: Rick, Pilou, Sanne, Hanne, Guy, Giulio, Mieke, Eveline, Mathijs, Sofie, Mandy, Tanja, Nuria, Givan, Gill, Femke, Siti, Jurriaan, Alberto, Stijn, Blandine, Emanuel, Jasper, Bram, Jan, Dorien, Gabrielle, Dirk, Marlies, Rudi, Dennis, Roel, Mark, Emmani, Sophie, Simon, Erik, Maarten, Nadia, Max, Sabine, Dorien, Gijs, Cyril, Charlotte, Peter, Jean en Bernard. Velen ben ik als vrienden gaan zien en ik hoop dat ikjullie nog vaak zie en dat we een goed contact mogen houden. Ik wens jullie allemaal veel succes en geluk toe in de toekomst!

Pilou, je bent een echte vriendin geworden en nadat we huisgenoten werden is onze band enkel verbeterd. Samen boodschappen doen, spellen spelen, films kijken, Peter zoeken, Sherlock Holmesen, “tuinieren”, whisky's proeven en dan onze vaak ellenlange gesprekken en discussies over wetenschap, liefde, muziek, familie, films en nog veel meer. Nooit is mijn geklaag of gezeur jou te veel en ik wil je bedanken voor dit allemaal. Sanne, één van de eerste vragen die je me stelde was of we onderling Nederlands gingen praten of dat we het lekker bij het dialect zouden houden en natuurlijk is het 't plat geworden; toch ga ik het hier bij een voor iedereen begrijpbare taal houden. Het was prettig om met jou samen te werken en ik heb veel van je geleerd. Als kamergenoot was je net een zus voor me en vond ik het fijn dat ik met alles bij je terecht kon, dankjewel. Hanne, wat was ik trots dat ik paranimf bij jou mocht zijn. Ik bewonder je voor je harde werken en wil je bedanken voor de vele fijne gesprekken. Ik wens jou en Pieter heel veel plezier toe met jullie aankomende gezinnetje. Giulio, I liked working together, appreciated all your help and loved your "dry humor". Mieke, Duvel-maatje en danspartner, ik kijk nog steeds uit naar je lasagne. Eveline, ik heb veel bewondering voor jou, een roadrunner in zowel werk als sport. Mathijs, ik heb zo ongeveer al je puberjaren meegemaakt en dat maakte het voor mij speciaal om collega's en uiteindelijk zelfs nog even kamergenoten te zijn. Je komst als verse aio heeft de sfeer zeker een impuls gegeven. Dorien, wat mocht ik mezelf gelukkig prijzen met een "heel Holland bakt"-winnares in spe als buurvrouw op de gang maar ook op de rest van de afdeling heb je een positieve invloed. Guy, van jou als nog steeds jonge wetenschapper heb ik als jonge wetenschapper veel geleerd. Zowel op het werk als erbuiten kunnen we goed met elkaar opschieten en ik wil je erg bedanken voor de mogelijkheden die je mij geboden hebt. Het was een mooie zonnige herfstavond op het terras bij de Walkabout en onder het genot van een Guinness vroeg je mij of ik werken in Singapore zou zien zitten; ik zal het nooit vergeten. Via de Walkabout kom ik vanzelf bij Bram en Jasper, van nachten op de bank en songfestivalavonden tot waxinelichtjes en "risk", momenten om niet te vergeten. Echter doe ik jullie tekort als ik niet ook jullie serieuze kant belicht; carrières, het onderzoek, de wetenschap, ook daarin zijn jullie fijne gesprekspartners.

Rick, wat 5 jaar geleden rustig begon is inmiddels uitgegroeid tot een heel goede vriendschap! In die jaren hebben we tijdens congressen vele hotelkamers gedeeld en als bij de rest de energie al op was, gingen wij nog even door met het proeven van de lokale cultuur. Alhoewel we ook op het lab samengewerkt hebben, gebeurde de meeste samenwerking toch bij het 
koffieapparaat en op de borrel. Ontelbare wetenschappelijke discussies hebben we gevoerd bij de opkomende aroma's van verse koffie als we weer eens aankwamen als de koffie bijna niet helemaal op was of onder de klanken van Helene Fischer's "Atemlos". Waarschijnlijk zijn er collega's die ons nog nooit zonder elkaar hebben gezien en ik ben dan ook blij met jou als ervaren paranimf aan mijn zijde. We hebben veel gelachen maar ik heb toch zeker ook veel van jou geleerd! Ik kijk uit naar de vele dingen die we nog op de planning hebben staan en ik wens jou en Eveline veel geluk toe met de kleine Ricky die eraan komt.

Emanuel, een goede buur en een fijne vriend; altijd geïnteresseerd, een luisterend oor en bereid tot een goed gesprek. Met plezier heb ik geluisterd naar je aanstekelijke verhalen over vakanties, altijd geïllustreerd met prachtig geschoten foto's. Daardoor heb je me ook besmet met hetfotografievirus, al heb iknog veel oefenen voor de boeg. We hebben vaak gelachen om je mengeling van Duits en Nederlands of omdat een busreis Maastricht - Aken toch eigenlijk net te lang is. Inmiddels is je laatste jaar promoveren ook onderweg, wat ongetwijfeld gaat zorgen voor iets meer stress maar ik weet zeker dat je goed gaat "klaar kommen". Ik ben blij dat je me als paranimf bijstaat en weet zeker dat we ook met een grotere reisafstand goede vrienden zullen blijven.

Dan wil ik ook mijn vrienden bedanken die voor de broodnodige ontspanning hebben gezorgd buiten het werk om en zo ervoor zorgden dat er genoeg momenten waren om de gedachten te verzetten. Uiteraard horen hier de verenigingen Oranje Boys en Waardhof Boys bij waar het naast de sport zeker ook om de gezelligheid ging. Ik ben dankbaar voor de vele vrienden en vriendinnen die ik via school, studeren, sporten, uitgaan, bronken, carnavals en meer heb leren kennen. Janneke, je weet als geen ander dat niet alles van het promoveren altijd van een leien dak ging, maar telkens wist jij precies wat te zeggen. Ik ben blij dat we nog steeds vrienden zijn. De vaste kern uit Mesch wil ik meer dan extra bedanken: René, Jim, Dave, Mark, Philippe, Tim en Jordain. We hebben veel samen meegemaakt en ik vind het heel mooi dat we een hechte groep zijn en bijna allemaal al sinds de basisschool heel goede vrienden zijn! Jim, mijn beste vriend, we hebben al heel veel samen ondernomen maar nu ik dit schrijf, zijn we bezig aan ons grootste avontuur tot nu toe. Over alles kunnen we praten en met alles kan ik bij jou terecht, dankjewel!

René, zoals hierboven al te lezen ben ik blij met de ontspannende momenten die we samen hebben maar zeker ook met de serieuze gesprekken. Ik weet dat ik altijd op je kan rekenen en zou me geen betere broer kunnen wensen. Ik ben trots op wat je allemaal opgebouwd hebt en je niet aflatende harde werken is een groot voorbeeld voor me!

Tot slot, mam en pap (en de rest van de familie), ik wil jullie bedanken voor de mogelijkheden die jullie me gegeven hebben. Altijd waren jullie geïnteresseerd ook al kon ik soms niet alles 
in een begrijpelijke taal uitleggen. Mede door jullie onvoorwaardelijke liefde en steun heb ik dit punt kunnen bereiken, Ik ben jullie heel dankbaar!

Ik begon met een brede lach maar ik kan niet ontkennen dat er zich tijdens het schrijven van dit dankwoord af en toe een traan liet zien in een ooghoek. Nogmaals, allen bedankt! 



$$
\begin{array}{r}
\text { List of } \\
\text { publications }
\end{array}
$$




\section{Publications}

Camps SG, Verhoef SP, Westerterp KR. Weight loss, weight maintenance, and adaptive thermogenesis. Am J Clin Nutr. 2013 May;97(5):990-4. doi: 10.3945/ajcn.112.050310. Erratum in: Am J Clin Nutr. 2014 Nov;100(5):1405.

Verhoef SP, Camps SG, Bouwman FG, Mariman EC, Westerterp KR. Physiological response of adipocytes to weight loss and maintenance. PLoS One. 2013;8(3):e58011. doi: 10.1371/journal. pone.0058011.

Verhoef SP, Camps SG, Gonnissen HK, Westerterp KR, Westerterp-Plantenga MS. Concomitant changes in sleep duration and body weight and body composition during weight loss and 3-mo weight maintenance. Am J Clin Nutr. 2013 Jul;98(1):25-31. doi: 10.3945/ajcn.112.054650.

Camps SG, Verhoef SP, Westerterp KR. Weight loss induced reduction in physical activity recovers during weight maintenance. Am J Clin Nutr. 2013 Oct;98(4):917-23. doi: 10.3945/ ajcn.113.062935.

Verhoef SP, Camps SG, Bouwman FG, Mariman EC, Westerterp KR. Genetic predisposition, dietary restraint and disinhibition in relation to short and long-term weight loss. Physiol Behav. 2014 Apr 10;128:247-51. doi: 10.1016/j.physbeh.2014.02.004.

Valenti G, Camps SG, Verhoef SP, Bonomi AG, Westerterp KR. Validating measures of freeliving physical activity in overweight and obese subjects using an accelerometer. Int J Obes (Lond). 2014 Jul;38(7):1011-4. doi: 10.1038/ijo.2013.195.

Camps SG, Verhoef SP, Westerterp KR. Physical activity and weight loss are independent predictors of improved insulin sensitivity following energy restriction. Submitted for publication.

Camps SG, Verhoef SP, Roumans NJT, Bouwman FG, Mariman EC, Westerterp KR. Weight loss-induced changes in fatty acid and glucose metabolism relate to adaptation in body composition and energy expenditure. In press.

Camps SG, Verhoef SP, Westerterp KR. Leptin and energy restriction induced adaptations in energy expenditure. Submitted for publication.

Camps SG, Verhoef SP, Bouwman FG, Mariman EC, Westerterp KR. Genetic predisposition and energy restriction induced adaptations in resting energy expenditure and physical activity. Submitted for publication. 
Roumans NJ, Camps SG, Renes J, Bouwman FG, Westerterp KR, Mariman EC. The risk for weight regain after weight loss is related to weight loss-induced cellular stress in adipose tissue. Submitted for publication.

\section{Presentations}

Camps SG, Verhoef SP, Westerterp KR. Leptin and energy restriction induced adaptation in energy expenditure. Presented at Recent Advances and Controversies in Measuring Energy Meabolism 2014 in Tokyo, Japan. Poster presentation.

Camps SG, Verhoef SP, Westerterp KR.Maintaining physical activity during an energy-restricted diet is as beneficial for insulin sensitivity as weight loss. Presented at the International Congress on Obesity 2014 in Kuala Lumpur, Malaysia. Poster presentation.

Camps SG, Verhoef SP, Westerterp KR. Adaptive thermogenesis and leptin during weight loss and weight maintenance. Presented at the Dutch Endo-Neuro-Psycho Meeting 2013 in Lunteren, The Netherlands. Invited speaker.

Camps SG, Verhoef SP, Westerterp KR. Weight loss-induced reduction in physical activity recovers during weight maintenance. Presented at the European Congress on Obesity 2013 in Liverpool, Great Britain. Oral presentation.

Camps SG, Verhoef SP, Westerterp KR. Weight loss and adaptive thermogenesis. Presented at the Annual Nutrim symposium 2012 in Maastricht, the Netherlands. Poster presentation.

Camps SG, Verhoef SP, Westerterp KR. Weight loss and adaptive thermogenesis. Presented at the European Congress on Obesity 2012 in Lyon, France. Poster presentation.

Camps SG, Verhoef SP, Westerterp KR. Weight loss-induced disproportional Basal Metabolic Rate reduction is not sustained during weight maintenance? Presented at the European Congress on Obesity 2011 in Istanbul, Turkey. Oral presentation.

Camps SG, Verhoef SP, Westerterp KR. Weight loss-induced disproportional Basal Metabolic Rate reduction is not sustained during weight maintenance? Presented at the The Netherlands Association for the Study of Obesity (NASO) symposium 2011 in Zwolle, The Netherlands. Oral presentation. 



$$
\begin{array}{r}
\text { Curriculum } \\
\text { vitae }
\end{array}
$$


Stefan Camps was born on November $19^{\text {th }} 1985$ in Heerlen, the Netherlands. After he completed secondary school at the Provincial Secundaire School in Voeren (Belgium) in 2003 he started the study Molecular Life Sciences at Maastricht University for which he obtained his bachelor's degree in 2006. In 2009 he obtained his degree for the master Clinical Molecular Science at Maastricht University. During his master, he followed the pre-master Science and Innovation Management at Utrecht University.

In January 2010 he started his PhD research on energy restriction and energy expenditure at the department of Human Biology of the Faculty of Health, Medicine and Life Sciences at Maastricht University under supervision of Prof. dr Klaas Westerterp. The research performed during this period is described in this PhD-thesis entitled 'How humans economize, energy restriction and energy restriction'. During his PhD trajectory, Stefan presented several abstracts at national and international conferences. From June 2014 until October 2014, he worked as a co-investigator on a project on energy expenditure and cardiorespiratory fitness under supervision of Dr. Guy Plasqui. In April 2015, he starts as a research fellow in the group of Prof. dr. Jeyakumar Henry at the Clinical Nutrition Research Centre in Singapore. 


\section{Energy restriction}

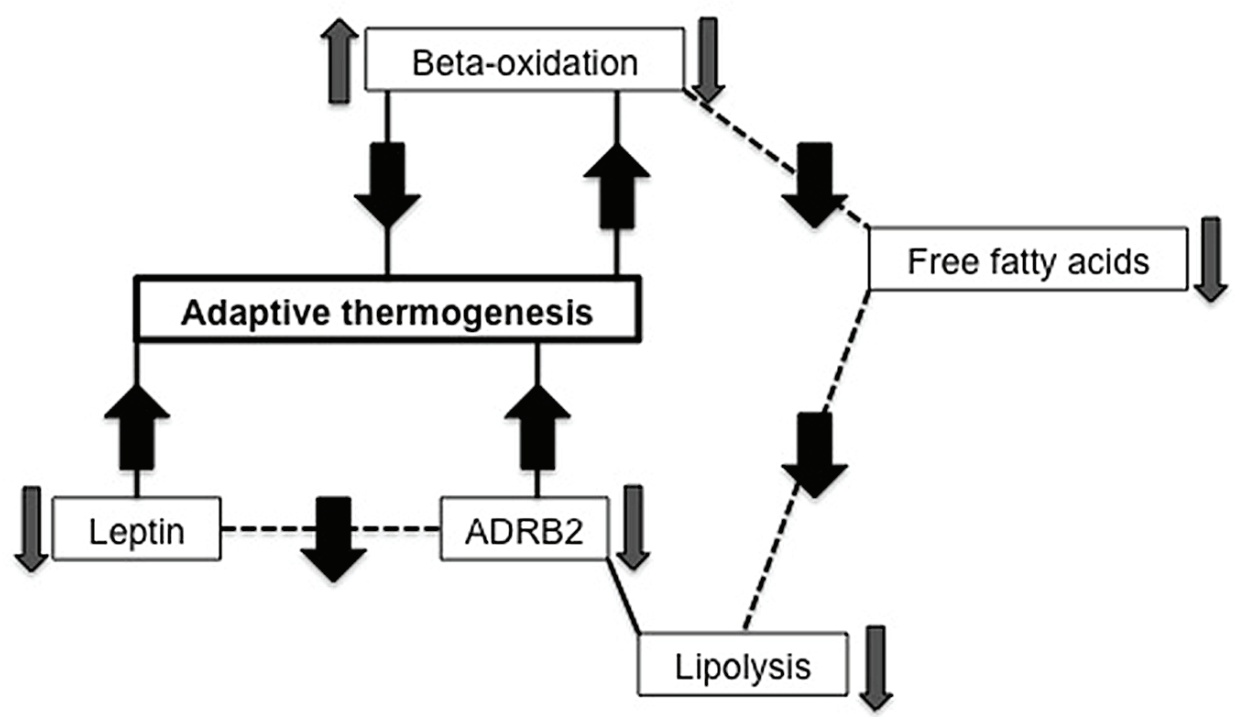

Figure 8.1. Energy restriction leads to adaptive thermogenesis. More mitochondrial beta-oxidation in adipose tissue is related to less adaptive thermogenesis after energy restriction. Additionally, more beta-oxidation is correlated to more plasma free fatty acids (29). The larger the weight loss induced decrease in circulating leptin concentration, the larger the adaptive thermogenesis. Subjects carrying the homozygous minor ADRB2 allele show more adaptive thermogenesis after energy restriction. Expressed in subcutaneous adipose tissue, ADRB2 mobilizes lipids within human fat cells by stimulating lipolysis. Leptin promotes lipolysis and energy expenditure; as a result lower circulating leptin concentration is related to less lipolysis (48). This could involve the beta-adrenergic receptor (ADRB2); leptin is considered to be able to stimulate catecholamine synthesis in the adrenal medulla; subsequently, catecholamines can bind to the to ADRB2 on adipocytes to stimulate lipolysis (49). 